\title{
Evolution of the skull shape in extinct and extant turtles
}

Evolução da forma do crânio em tartarugas extintas e viventes

Guilherme Hermanson Souza

Dissertação apresentada à Faculdade de Filosofia, Ciências e Letras de Ribeirão Preto da Universidade de São Paulo, como parte das exigências para obtenção do título de Mestre em Ciências, obtido no Programa de PósGraduação em Biologia Comparada

Ribeirão Preto - SP 


\section{Evolution of the skull shape in extinct and extant turtles}

Evolução da forma do crânio em tartarugas extintas e viventes

Guilherme Hermanson Souza

Dissertação apresentada à Faculdade de Filosofia, Ciências e Letras de Ribeirão Preto da Universidade de São Paulo, como parte das exigências para obtenção do título de Mestre em Ciências, obtido no Programa de PósGraduação em Biologia Comparada.

Orientador: Prof. Dr. Max Cardoso Langer

Ribeirão Preto - SP 
Autorizo a reprodução e divulgação total ou parcial deste trabalho, por qualquer meio convencional ou eletrônico, para fins de estudo e pesquisa, desde que citada a fonte. I authorise the reproduction and total or partial disclosure of this work, via any conventional or electronic medium, for aims of study and research, with the condition that the source is cited.

\section{FICHA CATALOGRÁFICA}

Hermanson, Guilherme

Evolution of the skull shape in extinct and extant turtles, 2021.

132 páginas.

Dissertação de Mestrado, apresentada à Faculdade de Filosofia, Ciências e Letras de Ribeirão Preto/USP - Área de concentração: Biologia Comparada.

Orientadora: Langer, Max Carodoso.

1. Ecomorphology. 2. Turtles. 3. Phylogenetic comparative methods.

4. Geometric morphometrics. 5. Computed tomography. 


\section{Acknowledgements}

Many were those I met during this whole journey, from when I began the conceptualisation of this work until its final steps. Therefore, I'd like to express my deepest gratitude to

Max Langer, my official supervisor. Thank you for everything you did for me. I have no doubts that every achievement in my short academic life so far has a lot of your input in it: your coherence, your extreme professionalism, and your plentiful support. Thank you for 'building' a magnificent space for us, in terms of physical space and providing a soulful environment above all, for doing research in such conditions become much more pleasant. Also, I wish everyone could see your honesty and your kindness as I know my friends from the Lab see, and I'm sure all students you supervise learn lot from you, as did I! I guess what I mostly want to tell you is that I could not have asked for a greater person to be my supervisor!

Gabriel Ferreira (Fumaça), my unofficial supervisor, mentor, and very dear friend. Thank you for guiding me since I was an undergrad, for all your professional and personal advices; I appreciate you so much for putting your trust in me. I probably don't say this enough, but I'm very lucky to have your friendship, and I can't express how much I admire you as a researcher and as a person! Thank you!

Roger Benson, my supervisor during both my internships in the UK, the second time mentoring me from distance unfortunately. Thanks for helping me improve coding skills, for sharing with me a little bit of your vast quantitative knowledge, and especially for teaching me different research perspectives. If I'm the researcher I am today, it's also because you kindly allowed me to see the world through your own lenses;

Serjoscha Evers, who I met during my first internship abroad and became a very close friend. Thank you for your extremely professional collaborations, for criticising me when I needed most, and for providing me with everything you could when I asked! I'm also very grateful to you for taking part in helping me directing my future steps, so many thanks!

Coordenação de Aperfeiçoamento de Pessoal de Nivel Superior (CAPES) for funding and supporting our Graduation Program, as well as funding the first three months of my research;

Fundação de Amparo à Pesquisa do Estado de São Paulo (FAPESP) for funding and supporting my research during most of time during my MSc studies both in Brazil (grant 2019/02086-6) and abroad (grant 2019/21787-5), assuring me the possibility to improve my professional and personal development;

Programa de Pós-Graduação em Biologia Comparada, for the full support during my time as a MSc student there;

Vera Cassia Cicilini de Lucca. I'm very much thankful to you for always making time when there was none to help us solve our slightest problems and questions. If for the Greeks, Atlas carries the world upon his shoulders, and in Hindu mythology Akupāra is the world-bearing turtle, for me you are the rock that keeps our graduation program standing still! 
Bete Dassie, for making FAPESP bureaucracies a bit less complicated to us, and for always elevating the elegance levels of our meetings, thanks! (we miss you a lot $:()$

all collection managers, online data repositories curators and department technicians that provided either assistance when scanning specimens or sharing data with me and with my collaborators in this project;

the cleaning staff of our building in Ribeirão Preto, thank you very much for keeping everything in order and always being so helpful, even when we fail to recognise all your effort;

the North Oxford Overseas Centre (NOOC) staff, in particular Daniel, Elita, Emma, and Kata, who gladly welcomed me in Oxford during my internship, and provided all the comfort and safety one can wish for during the uncertain times we underwent in 2020;

the few Oxford friends I could made at NOOC during my internship, especially Henrique and Lennart. You made the lockdown period much easier to endure, and I'll never forget how supportive and friendly you always were!

my friends from the Palaeontology Lab, to whom I certainly own my happiest and most joyful days during the week (and a few weekends) in Ribeirão Preto. I'd like to thank both former and current members: Ana Laura Paiva, Annie Hsiou, Wafa Alhalabi, Thiago Fachini, Julian Silva, João Kirmse, Julio Marsola, Mario Bronzati; forgive me if I missed anyone in here, there were quite many! Not to mention others that for different reasons were very important in a myriad of decisive situations for me: Francisco Neto, Gabriel Mestriner (a misunderstood genius), Fellipe Muniz, Gustavo Darlim (like a brother to me); special thanks go to Bruna Farina and Silvio Onary, for liking the same sort of sh*tposts I like, being so mentally questionable as I am, but also for your friendship and having such big hearts! You are undoubtedly the weirdest group of wonderful people per square meter an institution is lucky to have, and I love you all!

Dara, for being my dog, and all that represents in terms of unconditional love, as I'm sure anyone that has pets and care for them will understand;

Last, but definitely most importantly, I'd like to thank my parents, Claudia and Franco. If only could you know how lucky I am for having you by my side all the time. I'm at a loss for words to describe the importance that both of you have in my life, paving the way to being who I am. Be it with professional advice to pursuit my goals or with dimensionless loving you have given me every day of my existence. It's very cliché, but whenever I stumbled (and I did so countless times), you were always there to put me back on track. My never-ending 'thank you'!

I would like to dedicate this work to all those who sadly had to watch dear ones go during the unfortunate last months. 
[...] Most people are heartless about turtles because a turtle's heart will beat for hours after he has been cut up and butchered. But the old man thought, I have such a heart too and my feet and hands are like theirs. [...]

- Ernest Hemingway (The Old Man and the Sea) 


\section{Resumo}

Hermanson, G. Evolução da forma do crânio em tartarugas extintas e viventes. 2021. 132 p. Dissertação (Mestrado) - Faculdade de Filosofia, Ciências e Letras de Ribeirão Preto, Universidade de São Paulo, Ribeirão Preto, 2021.

A interação entre forma e função (ecomorfologia) é, de longa data, um tema de interesse no que diz respeito à evolução do crânio de vertebrados, tendo sido proposto que sua forma possui correlações com fatores como habitat ou dieta para diversos grupos. No presente trabalho, testa-se a hipótese de que diferentes aspectos ecológicos da história natural de tartarugas guardam relação com sua forma craniana e, a partir dos resultados para espécies viventes, infere-se a presença de tais aspectos em suas formas fósseis aparentadas. Para sua realização, empregou-se morfometria geométrica e métodos filogenéticos multivariados em uma base de dados de 93 modelos tridimensionais de crânios de tartaruga, obtidos com o auxílio de tomografia computadorizada. Encontrouse evidência que a morfologia do crânio de tartarugas viventes é estruturada por alometria, capacidade de retração do pescoço, hábitos marinhos, e um conjunto de características relacionadas à dieta, como o uso de alimentação por sucção, herbivoria e durofagia. Quando usadas para inferir aspectos ecológicos de espécies extintas, algumas predições corroboraram suposições prévias da literatura, como a presença de hábitos durófagos na tartaruga-estemática Eubaena e hábitos marinhos em linhagens extintas de queloniídeos, além de mostrar que membros de grupos marinhos fósseis exibiam características ecológicas convergentes às de algumas tartarugas-marinhas viventes. Por exemplo, a ausência de retração do pescoço, herbivoria em alguns pelomedusóideos litorâneos, e alimentação por sucção semelhante à da tartaruga-de-couro Dermochelys em grupos como bothremidídeos, angolaquelônios e provavelmente no protostegídeo Desmatochelys. De maneira geral, os resultados mostram que uma associação de fatores ecológicos múltiplos age em conjunto moldando o crânio de tartarugas, e fornecem mais evidência a respeito da influência da capacidade de retração do pescoço. Adicionalmente, infere-se características ecológicas para linhagens marinhas previamente não consideradas, ilustrando notáveis exemplos de convergência durante a adaptação a ecossistemas marinhos ao longo da história evolutiva de tartarugas. 


\begin{abstract}
Hermanson, G. Evolution of the skull shape in extinct and extant turtles. 2021. 132 p. Dissertation (Master) - Faculdade de Filosofia, Ciências e Letras de Ribeirão Preto, Universidade de São Paulo, Ribeirão Preto, 2021.
\end{abstract}

The interplay between form and function (ecomorphology) is a long-standing topic of interest concerning the evolution of the vertebrate skull, with shape being proposed to correlate with factors such as habitat or diet for several groups. Here, I test the hypothesis that different ecological aspects of turtles' natural history correlate to their skull shape and use the results of extant taxa to predict the presence of such aspects in their extinct relatives. To accomplish this, I employed geometric morphometrics and multivariate phylogenetic methods to a dataset comprising 93 three-dimensional models of turtle skulls obtained with computed tomography. I found evidence that the skull morphology of extant turtles is structured by allometry, neck retraction, marine habits, and a set of dietary traits including suction-feeding, herbivory and durophagy. When used to infer ecological traits in extinct species, some predictions corroborated previous literature assumptions, such as durophagy in the stem-turtle Eubaena, and marine habits in stemcheloniids. I showed that members of extinct marine groups convergently acquired ecological traits that are similar to those of some extant sea turtles. These include the absence of neck retraction, the presence of herbivory in some extinct nearshore pelomedusoids, and suction-feeding similar to the extant leatherback turtle Dermochelys coriacea among bothremydids, angolachelonians, and likely also in the protostegid Desmatochelys. Overall, my results show an association of multiple ecological factors act in parallel to shape the turtle skull and provide further evidence for the influence of neck retraction capability on it. In addition, I infer previously non-hypothesised features for extinct marine clades, illustrating remarkable instances of convergence during adaptation to marine ecosystems throughout the evolutionary history of turtles. 


\section{Summary}

Acknowledgements ..............................................................

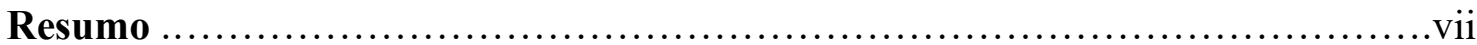

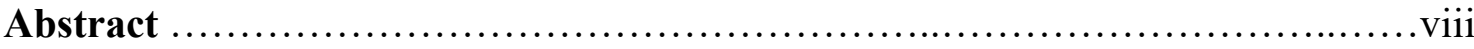

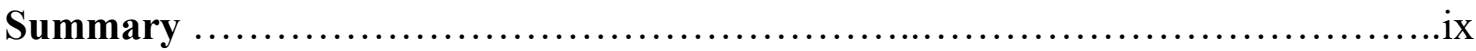

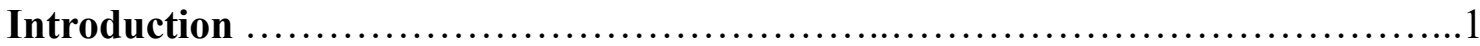

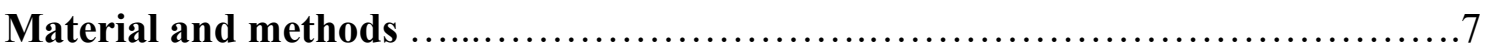

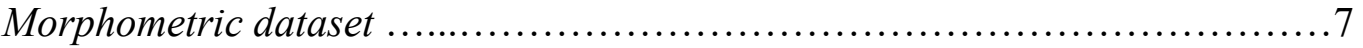

Habitat and dietary variables ............................................ 9

Geometric morphometric analyses .................................... 10

Ecomorphological hypotheses .........................................11

Results ......................................................................... 19

Skull shape variation among extant turtles ...................................19

Skull shape association with multivariate diet categories .....................21

Ecological predictors of skull shape in turtles ...............................25

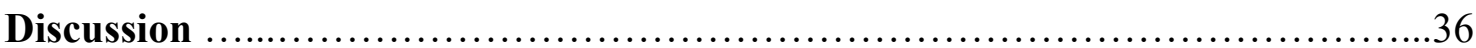

Form-function relationship in the skull of extant turtles ..........................36

Skull shape as a palaeoecological proxy ....................................42

Convergent ecomorphological scenarios in marine lineages .....................47

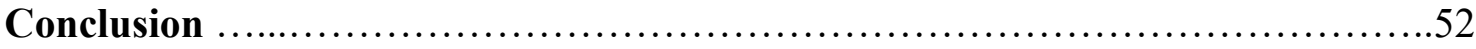

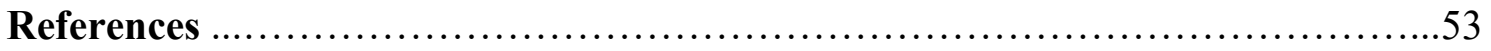

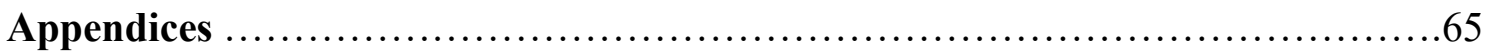

Appendix 1. Composite phylogenies used in the study .........................65

Appendix 2. Results of pFDA for extant and extinct turtles ......................66

Appendix 3. List of specimens and ecological traits ..........................71

Appendix 4. Landmarks description .................................... 82

Appendix 5. Description of binary ecological traits ..........................101

Appendix 6. List of D-PGLS regression models results ........................110

Appendix 7. Customised R functions ......................................118 


\section{Introduction}

Ecomorphology is the branch of biological sciences that aims to establish associations between morphological and ecological variation patterns, given these are considered to covary (Barr 2018). One of the most famous examples of ecomorphological studies regard Darwin's finches from Galapagos islands, in which it has been hypothesised that their beak shape correlates with the type of food they feed on (Grant \& Grant 2006; Herrel et al. 2010). In fact, the interplay between form and function has been a long-standing subject of interest concerning the evolution of feeding mechanisms among vertebrates (Lauder 1995; Ferry-Graham \& Lauder 2001; Feilich \& López-Fernández 2019; Corn et al. 2020), especially on aspects regarding different habitat characteristics, prey type, or both (e.g. Claude et al. 2004; Herrel et al. 2008; Segall et al. 2016; Olsen 2017; Lemell et al. 2019; Navalón et al. 2019). For instance, different authors have suggested the evolution of suction-feeding mechanisms in different aquatic vertebrate lineages as an efficient means of underwater prey capture (e.g. Bramble \& Wake 1985; Lauder 1985; Shaffer \& Lauder 1985; Lauder \& Prendergast 1992), since the synchrony of movements of head and hyolingual apparatus appear to be an effective way to cope with the higher density and viscosity in the aquatic medium (Heiss et al. 2018; Lemell et al. 2019). Furthermore, ecomorphological studies provide hypotheses of evolutionary processes such as convergence, allowing to corroborate connections between phenotypical traits and ecological shifts such as the evolution of similar skull shapes in phylogenetically distant lineages with the same diets, or comparable cranial morphologies among unrelated groups with similar habitats (e.g. Monteiro \& Nogueira 2011; Arbour et al. 2019; Gray et al. 2019; Ebel et al. 2020).

Evolutionary approaches to form-function association have profited from a manifold of tools developed for quantifying morphological variation, including geometric 
morphometrics (GMM). This method implies in the identification of homologous anatomical points across a set of specimens (landmarks) that are used to characterise the shape of a given object (Bookstein 1991; Rohlf \& Marcus 1993). Over the past decades, research on GMM has benefited from further improvement on data acquisition, especially with the improvement and increased availability of cutting-edge technology such as computed tomography (CT), which made possible the compilation of larger datasets (Adams et al. 2013). Yet, as the shape information of the studied objects became more complex (i.e. three-dimensional; 3D), the field of GMM has also seen increasingly more methods being developed to fulfil the needs of high-dimensional data handling, including its assembly (Gunz \& Mitteroecker 2013; Bardua et al. 2019; Goswami et al. 2019) and statistical procedures (Monteiro 1999; Rohlf \& Corti 2000; Adams \& Collyer 2018; 2019). The use of these statistical methods on high-dimensional 3D data has become widespread in the last few years, and different ecomorphological patterns are being unravelled for osteological and neuroanatomical aspects of the skull of several extinct and extant vertebrate lineages (e.g. Dumont et al. 2016; Marugán-Lobón et al. 2016; Benson et al. 2017; Cooney et al. 2017; Neenan et al. 2017; Felice et al. 2019; Godoy 2020).

In that regard, however, Testudines remain as an understudied group. Turtles possess a highly modified Bauplan in comparison to their modern reptilian relatives, including features like an anapsid skull, lack of teeth, expanded and flat ribs, and the shoulder girdle contained within the rib cage (Gaffney 1990; Bonin et al. 2006; Schoch \& Sues 2016; Lyson \& Bever 2020). The group accounts for less than $4 \%$ of extant diversity of reptiles (Pincheira-Donoso et al. 2013), but representatives are found in a great variety of habitats such as marine and continental, with multiple independent origins of freshwater, semi-aquatic and terrestrial forms in the latter (Bonin et al. 2006). These 
distinct evolutionary groups exhibit anatomical particularities that have already been hypothesised to correlate with general biotic factors such as habitat preference or diet (e.g. Claude et al. 2004; Joyce \& Gauthier 2004; Foth et al. 2017).

For instance, the postcranium of turtles (perhaps the most striking feature that characterises them among modern reptiles) has been the subject of many surveys. Regarding carapace geometry, Claude et al. (2003) used GMM to show morphological differences among testudinoid taxa with respect to habitat, e.g. overall more flattened shells in aquatic taxa in comparison to higher-domed carapaces in terrestrial forms. Benson et al. (2011) and Dziomber et al. (2020) also attempted to address this relation, using it as a basis for statistical predictions of ecological preferences in fossils, although some of their results of aquatic habits for some taxa go against other works (e.g. histological) that suggested terrestriality for stem-turtles (Scheyer \& Sander 2007). In addition, comparative ecomorphological studies of the turtle forelimb have established associations with locomotor styles. For instance, Joyce and Gauthier (2004) showed that 'swimming' chelonians (those equipped with flippers as modified limbs) like sea turtles (Chelonioidea) or the pig-nosed turtle (Carettochelys insculpta) have a greater manus-tohumerus ratio (i.e. longer fingers relative to the arm total length), in comparison to the opposite condition found in land-dwelling forms, which exhibit reduced phalanges and more developed humeri. In the same way, Dickson and Pierce (2019) examined extant turtle humeri across different lineages using four functional traits (strength, hydrodynamic efficiency, stride length, and mechanical advantage), and showed that for marine species, the first two traits are likely the most important in constraining the humeral shape, providing assistance on their 'subaqueous flying' locomotion, whereas semi-aquatic taxa, for instance, are equally characterised by all four traits, which is reasonable to assume considering they engage in different sorts of locomotion. Similarly, 
Depecker et al. (2006) presented close associations between shoulder girdle anatomy and movement specialisations, furthermore indicating intrinsic locomotor and hydrodynamic adaptations in the postcranial skeleton.

Accordingly, because of the diversity of habitats in which turtles are found, different functional constraints are expected to shape turtle skull morphology and are also hypothesized to covary with it (Lauder 1985; Richter et al. 2007; Lemell et al. 2019). Therefore, turtle cranial ecomorphology and the associated feeding apparatus likely involves important modifications that reflect selective pressures such as allometric effects, habitat preference, or prey type. For instance, Herrel et al. (2018) demonstrated that in the durophagous species Malaclemys terrapin (diamondback terrapin) larger individuals were able to bite relatively harder than smaller terrapins, and Pfaller et al. (2010) established a similar association for Sternotherus minor (loggerhead musk turtle), indicating larger heads in older individuals facilitate a durophagous diet in this species. Both these cases identify a similar increase in skull height correlating with higher bite forces, which had been previously addressed by Herrel et al. (2002) and Claude et al. (2004). Nevertheless, it has long been suggested for turtles that especially the morphology of the triturating surfaces of the palate (their primary food-grinding structure) would correlate to the type of food they eat, and therefore would be more prone to evolve similar morphologies in distantly related lineages (e.g. Claude et al. 2004). This happens to be the case for many herbivorous turtles, such as podocnemidids, testudinids, and geoemydids, that have finely serrated accessory ridges on their palates that facilitate shearing leafy material (Davenport et al. 1992), or aquatic turtles with mediolaterally broadened triturating surfaces, more apt to crushing shelled invertebrates, which is the case for a wide array of unrelated cryptodiran chelonians such as emydids, geoemydids, cheloniids, and trionychids (Dalrymple 1977; Lindeman 2000; Claude et al. 2004; 
Marshall et al. 2012), and possibly some extinct pleurodires (e.g. Gaffney et al. 2006; 2011; Ferreira et al. 2015).

Yet, other aspects of the turtle skull have also been proposed to correlate with the preferred type of food and/or feeding strategy, such as skull lengthening and flattening, and a more anterior positioning of the orbits, which would provide a binocular vision for turtles that usually prey on elusive animals such as fish or insect larvae (Pritchard 1984; Aerts et al. 2001; Herrel et al. 2002). This is the case for many aquatic turtles such as chelids, emydids, and trionychids, which evolved in many lineages a dorsoventrally lower skull (Darymple 1977; Pritchard 1984; 1993; Lemell et al. 2002) and very long necks (Dalrymple 1979; Aerts et al. 2001; Herrel et al. 2008). Indeed, some turtles rely on fast neck movements when thrusting at their prey, including cryptodires such as the snapping turtle (Chelydra serpentina) and the Indian narrow-headed softshell turtle (Chitra indica), and pleurodires such as the matamata (Chelus fimbriatus; Lauder \& Prendergast 1992; Lemell et al. 2002), but the functional feeding role of extremely long necks of some chelids (e.g. Hydromedusa and Chelodina spp.) during food capture has been questioned (Alcalde et al. 2010).

To date, a handful of studies have been conducted to assess patterns of cranial ecomorphology of turtles, mostly focusing on dietary ecology aspects such as prey type (e.g. Herrel et al. 2002; Ferreira et al. 2015; Foth et al. 2017), but also considering the feeding habitat (e.g. Claude et al. 2004). Except for the work of Claude et al. (2004), all of the abovementioned research was based on traditional geometric morphometric approaches (using 2D data) or linear measurements, and of these, only Ferreira et al. (2015) and Foth et al. (2017) included fossils in their analyses, and only the latter focused on Testudines as a whole. Additionally, only Herrel et al. (2002) took phylogeny into account in their analyses (but see Claude et al. 2004 for their inclusion of 'Clade' as an 
explanatory variable), which in evolutionary comparative studies is crucial to circumvent equivocal assumptions of ecomorphological associations driven by phylogenetic bias (Felsenstein 1985; Revell 2010; Motani \& Schmitz 2011).

With the relatively recent aid of CT-data, other aspects of chelonian skull ecomorphology have been explored, such as the association between the anatomy of sensory organs (e.g. brain endocast, labyrinth) and habitat preference (Lautenschlager et al. 2018; Evers et al. 2019b). In the last decade, 3D anatomical data for turtles has also allowed to identify correlation patterns between the cranial and postcranial structures under a phylogenetic context (Werneburg 2015; Werneburg et al. 2015; Werneburg \& Maier 2019). In fact, it has been suggested more often that the emarginations in the 'anapsid' skull of turtles are largely explained by the gradual acquisition of longer and more mobile necks (Werneburg 2012; Werneburg et al. 2015). However, in spite of these works showing co-evolutionary processes between more retractile necks and the emarginated skull of turtles, as well as the close relationship between the morphology of neck muscles and feeding biomechanics (Werneburg 2012; 2015; Ferreira \& Werneburg 2019; Ferreira et al. 2020), the link between chelonian skull geometry and neck retraction capacity was never analysed in a broader context that also included additional ecological factors.

Here, I investigate the influence of multiple ecological predictors on turtle skull shape by using 3D GMM on CT-scanning data. I test the hypotheses that size, food preference, feeding strategy, habitat, and neck retraction are associated to evolutionary changes in their skull shape. I aim to identify the main factors associated to the natural history of extant turtles that explain their cranial ecomorphology. These results will then form the basis for further probabilistic inference of ecological attributes that might have been present in closely related extinct lineages. In the end, I provide a quantitative method 
to characterise the palaeoecology of turtles, in which I statistically corroborate predictions of past qualitative studies, but also show evidence of cranial ecomorphological patterns previously unaccounted in the evolutionary history of the group.

\section{Material and methods}

\section{Morphometric dataset}

My study uses 3D skull models of 78 extant and 17 extinct turtles, which were generated from CT-scan images using manual segmentation tools in the software Avizo 9.0.0 (Visualization Sciences Group) and Mimics Research 21.0 (Materialise NV, Leuven, Belgium). This sample includes representatives of all 'family'-level groups of living turtles (sensu Turtle Taxonomy Working Group 2017), and taxa on the stem-lineage of Testudines (but see Joyce et al. 2016; Sterli et al. 2018; Evers et al. 2019a for competing hypotheses for the position of stem-taxa). These taxa explore a wide range of habitats and evolved distinct dietary preferences, ranging from fully terrestrial and herbivorous (e.g. tortoises) to aquatic faunivorous taxa (e.g. South American snake-necked turtles or softshell turtles; Bonin et al. 2006); see Appendix 3 for full table listing species and examined specimens.

I placed 75 single-point landmarks (type I and II; Bookstein 1991; MacLeod 2002) and 21 series of curve sliding semilandmarks (Gunz \& Mitteroecker 2013) in my 3D models (Fig. 1) using the software Avizo 9.0.0 (Appendix 4 contains descriptions and illustrations of my landmarks). Most of my single-point landmarks are type I landmarks, in which their homology is supported by the topological arrangement of the bones that describe such point (e.g. the triple joint between exoccipital, supraoccipital and opisthotic bones, present in all turtles; Gaffney 1979). Type II landmarks, on the other hand, were 
used for delimiting boundaries for an open curve of sliding semilandmarks, when specific bones present in that area of the skull might not be the same in all taxa; nevertheless, I considered points to represent fundamentally homologue structures in all turtles (e.g. the anteroventral emargination; Evers \& Benson 2019: Fig. S1.9). Many of my single-point landmarks have equivalents in previous studies that relied on a 2D geometric morphometric approach (e.g. Claude et al. 2004; Foth et al. 2017). I also placed landmarks in more internal regions of the turtle skull (e.g. descending process of the parietals and the otic trochlear process), as well as captured more thoroughly structures that could bear relationships to feeding habits of turtles, such as the outline of the labial ridges of the triturating surface and the mandibular condyles (Appendix 4). Finally, I followed the protocol described in Bardua et al. (2019) to include surface semilandmarks in my final dataset. I placed 202 surface semilandmarks on the triturating surfaces and 49 on the mandibular condyles to capture more densely the depth and potential fine anatomical structures (e.g. ridges and bumps).
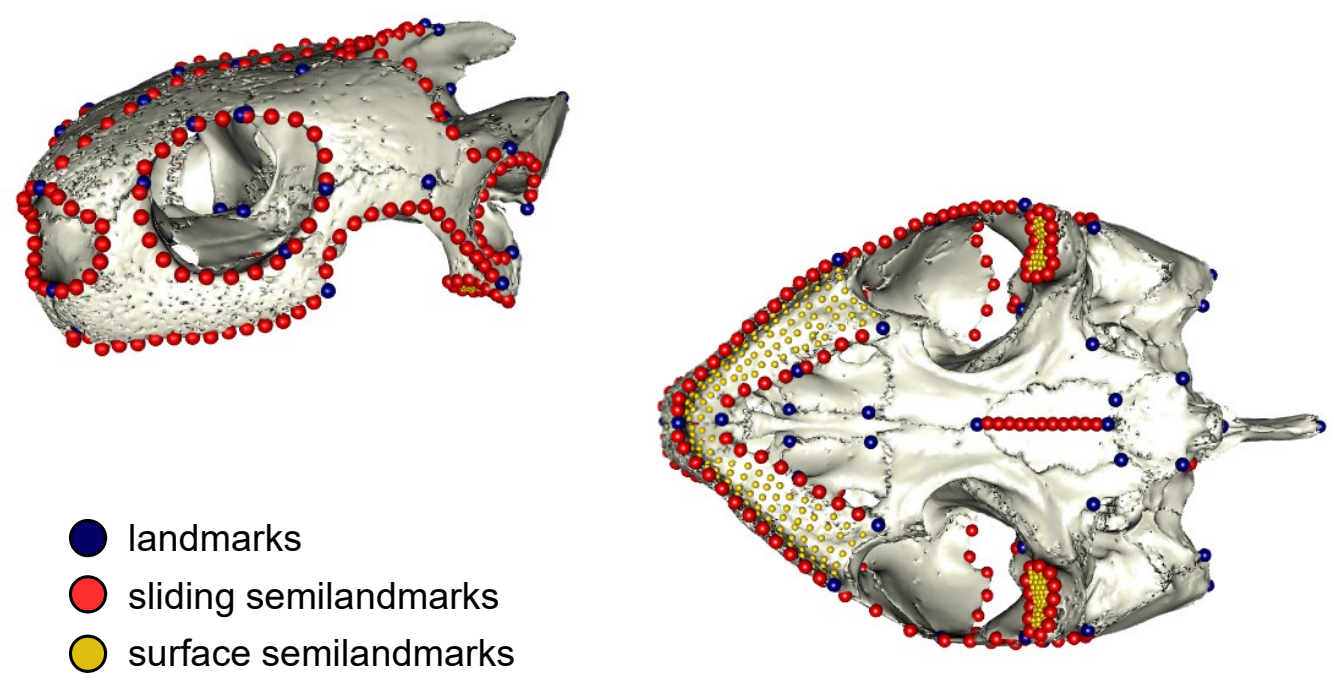

Figure 1. Landmark concept used in this study illustrated in a 3D rendering of the Mediterranean pond turtle (Mauremys leprosa NHMUK unnumbered) shown in oblique left lateral (left) and ventral (right) views. 


\section{Habitat and dietary variables}

Previous studies of turtle cranial ecomorphology assigned species to mutually exclusive dietary categories (e.g. Claude et al. 2004; Ferreira et al. 2015; Foth et al. 2017). This can be problematic (i) for not reflecting the actual complexity of turtle diets, and (ii) because categorisation of a given species might diverge between authors. For instance, Elseya dentata (northern Australian snapping turtle) and Peltocephalus dumerilianus (bigheaded Amazon river turtle) have both been classified as omnivorous or herbivorous (Pérez-Eman \& Paolillo 1997; Bonin et al. 2006; Eisemberg et al. 2017; Welsh et al. 2017). This occurs because many turtles possess a wide range of food preferences (Pritchard 1979), which is not accurately reflected by a binary categorisation. Apart from some notable exceptions (e.g. the herbivorous Dermatemys mawii and Galápagos tortoises, or predominantly carnivorous Chitra spp. and Chelus fimbriatus; Davenport et al. 1992; Lemell et al. 2002; Das \& Singh 2009; Blake et al. 2012), many turtles are opportunistic feeders and can also rely on resource seasonality (e.g. Souza 2004; Berry \& Iverson 2011; Platt et al. 2016; Bertolero \& Busack 2017; Welsh et al. 2017; Petrov et al. 2018).

To address these biases, I used a multivariate classification scheme (e.g. Wilman et al. 2014 [EltonTraits] for mammalian and avian ecology; Taylor \& Thomas 2014 for avian flight styles), in which I scored "absence" (0) or "presence" (1) for main food items according to natural history reviews of turtles (e.g. aquatic/terrestrial plants, molluscs, vertebrates; Appendix 5), which allowed me to attribute more than one category to the same species (rather than assigning exclusive classes such as 'omnivory' or 'carnivory'). My scheme also includes variables describing the presence of suction-feeding and whether a species feeds on land, water or both, which are expected to influence skull shape given the different physical properties of terrestrial and aquatic habitats (e.g. 
medium viscosity) and consequent skull kinetics (e.g. jaw opening) during feeding behaviour (Bramble \& Wake 1985; Lauder 1985; Claude et al. 2004; Natchev et al. 2015; Lemell et al. 2019). Yet, because previous studies suggested a relationship between the shape of the posterior region of the skull and neck movements (Werneburg 2015; Ferreira et al. 2020), I also included in my scheme the capacity of turtles to withdraw the head inside the shell (i.e. neck retraction). In the end, my set of traits comprised 20 traits related to different ecological aspects of turtles. My analyses have been constructed so that they can recognise and test the hypothesis that multiple factors affect skull shape, and my use of a multivariate classification scheme is central to that goal.

\section{Geometric morphometric analyses}

Geometric morphometric analyses were performed in R 4.0.2 (R Core Team 2020), using the packages 'geomorph' 3.2.1 (Adams et al. 2020) and 'Morpho' 2.8 (Schlager 2017). First, I performed a Generalised Procrustes Analysis (GPA; Rohlf \& Slice 1990) to remove the effects of size, position, and orientation of the skull from the original landmarks. Sliding semilandmarks were moved along their tangent vectors to minimise bending energy differences from the mean shape (Webster \& Sheets 2010; Gunz \& Mitteroecker 2013). The surface semilandmarks were placed on a template specimen (Bardua et al. 2019), i.e. the specimen with the closest shape to the estimated mean shape for a set of aligned coordinates from this first GPA, and then projected to the other specimens in an automated process. Then I ran a second and final GPA, combining all the landmarks, sliding semilandmarks, and surface semilandmarks. The resulting 3D coordinates (Procrustes coordinates) represent shape variation among the specimens. The centroid size values output from the GPA were used as proxy for skull size. Procrustes coordinates were then used to conduct a Principal Component Analysis (PCA) to visualise 
the principal component axes (PCs) of variation in turtle cranial geometry independent of ecomorphological hypotheses (see next section).

\section{Ecomorphological hypotheses}

\section{Correlation tests}

To verify the relationship between skull shape and my set of multiple ecological variables, I used ordinary and phylogenetic two-block partial least squares (PLS and pPLS, respectively), which allowed me to determine the structure of covariance between my two sets of data and the strength of a general association between cranial morphology and feeding (Rohlf \& Corti 2000; Adams \& Felice 2014). Because these analyses require continuous-valued input variables, the absence/presence scorings for my dietary categories were transformed to continuous-valued variables prior to analyses, using principal coordinates analysis (PCoA) for the Euclidean distance-matrix of the food scoring. PCoA was performed using the pcoa () function from the R package 'ape' 5.0 (Paradis \& Schliep 2019), and 2B-PLS analyses were performed using two.b.pls () (for ordinary) and phylo.integration() (for phylogenetic) functions of the $\mathrm{R}$ package 'geomorph' 3.2.1 (Adams et al. 2020). In addition, I used pPLS to determine the general association between the extent of both turtle skull emarginations (temporal and cheek), as they have been hypothesised to correlate with one another (Werneburg 2015).

\section{Phylogenetic regressions}

I also used phylogenetic Procrustes distance-based multivariate phylogenetic regression (D-PGLS; Adams 2014) to test the relationships between skull shape and selected ecological traits analysed as categorical variables (a full list of predictors and models is 
given in Appendix 6). Using species-specific data, my regression analyses were used to

test the relationships between skull shape and the following independent variables:

'Size': $\log _{10}$-transformed centroid size, output from the alignment of 3D landmark coordinates (GPA). This tests the hypothesis that shape changes in turtle skulls result from modification in size, i.e. allometry (e.g. Pfaller et al. 2010). Yet, after accounting for the individual effect of size (i.e. shape $\sim$ size), this predictor was always subsequently included as a covariate in more complex models, in order to define a strong relation with skull shape (see Appendix $6)$;

'Suction': presence of suction-feeding. This behaviour implies in modifications in the feeding apparatus that accommodate wider gapes and more powerful intraoral negative pressures (Van Damme \& Aerts 1997; Lemell et al. 2002). This variable tests the hypothesis that shape changes in turtle skulls result from adaptation to using this food-capturing strategy;

'Durophagous': presence of durophagy, identifying turtles that feed mostly on hard food (e.g. shelled invertebrates). Because triturating this sort of food requires a larger area of the jaw surfaces to crush it prior to ingestion (Claude et al. 2004), as well as more developed muscles involved in biting, this tests the hypothesis that skull changes in turtles are explained by the acquisition of a durophagous diet;

'Plant': presence of herbivory, identifying turtles that feed mostly on plant material (e.g. fruits, leaves, algae). Herbivory in extant reptiles is relatively rare, with changes in body size and teeth morphology recorded for lizards (Zimmerman \& Tracy 1989) and physiological adaptations in the digestive system recorded for some turtles (Bjorndal 1979; 1987). Additionally, many herbivorous chelonians exhibit finely serrated ridges in the palate (Pritchard 1979; Davenport et al. 1992), usually paralleling the inner border of the triturating surface. This predictor tests the hypothesis that skull shape changes in turtles result from the acquisition of a more herbivorous lifestyle;

'Meat': this identifies turtles that feed mostly on other animals. This tests the hypothesis that changes in turtle skull shape are associated with faunivory/scavenging, and is based on a previous assumption that 'in predatory and scavenging species the jaw surfaces may be exceedingly sharp' (Pritchard 1979, p. 35);

'Feeds in water': indicates the capacity to feed underwater. This tests the hypothesis that the capacity to feed in water is correlated with skull shape changes, in tandem with the different functional requirements for feeding in this medium (Lemell et al. 2019). This was shown to be the case for Testudinoidea i.e. tortoises, terrapins, Old World pond turtles (Claude et al. 2004). However, this is still to be tested for Testudines as a whole;

'Feeds on land': indicates the capacity of feeding on land. Previous studies have shown that terrestrialisation in turtles involved drastic changes in their Bauplan, including morphological changes in limb (Joyce \& Gauthier 2004), shell (Claude et al. 2003; Benson et al. 2011), and feeding apparatus (Richter et al. 2007; Natchev et al. 2010; 2015). Natchev et al. (2010) also noted the more vaulted palates of terrestrial turtles. These provide more space for larger tongues which are used in the first phase of food intake. This predictor tests the hypothesis that skull morphology in turtles can be explained by their role as terrestrial feeders;

'Marine': indicates marine habits. This predictor tests the hypothesis that aspects in turtle skull shape change in association with the presence of a marine lifestyle. Modern sea turtles 
(chelonioids) are the only living group of fully marine turtles, with a fossil record showing that morphological adaptations to this ecosystem appeared early in the evolution of the group (Evers et al. 2019). Yet, it is known that several other turtle lineages independently evolved adaptations to marine habits (e.g. Gaffney et al. 2006; Cadena \& Parham 2015; Ferreira et al. 2015). In this sense, this predictor tests whether, regardless of phylogeny, non-marine turtles could have 'marine'-like skulls;

'Neck retraction': capacity of neck retraction. Previous studies (Werneburg 2015; Ferreira et al. 2020) revealed associations between the architecture of the posterior region of the skull and neck motion. Therefore, besides ecological factors related to diet and habitat, I included this predictor to test the hypothesis that changes in the overall skull shape of turtles (not only the posterior part) correlate with their capacity of retracting the neck.

I evaluated the potential importance of individual variables first, by constructing models to test each of my predictors individually (e.g. skull shape associated to feeding in the water), retaining those that were significant. I then built more complex models, including combinations of multiple significant variables (e.g. skull shape $\sim$ skull centroid size + feeds in water). These analyses were performed using the procD.pgls ( ) function of the R package 'geomorph' 3.2.1 (Adams et al. 2020). Results of the D-PGLS regressions were evaluated according to Akaike Information Criterion scores (AIC; Akaike 1974). I then used the model . comparison ( ) function of the R package 'RRPP' 0.6.1 (Collyer \& Adams 2018; 2020) to determine the set of best models regarding cranial ecomorphology. However, it should be noted that it is still unclear how to evaluate which D-PGLS models are negligible or not. This is because the AIC weight calculation for such models appears to be very dependent on the dimensionality of the data (M. Collyer, pers. comm.). Additionally, there is no method that performs phylogenetic regression on highdimensional multivariate data such as $3 \mathrm{D}$ coordinates and simultaneously estimates phylogenetic signal of its residuals (Revell 2010; but see Clavel \& Morlon 2020 for potential solutions). Therefore, phylogenetic signal of the models residuals was estimated a posteriori for each model separately, with the phylosig() function of the R package 'phytools' (Revell 2012), using $\lambda$ as from Pagel (1999), which varies from 0 (independent 
observations in a given tree) to 1 (evolution following a Brownian motion model). Pagel's $\lambda$ was also used to estimate phylogenetic signal of Procrustes shape data.

Finally, I also used phylogenetic regression (pGLS; Grafen 1989) to test whether turtle skull size alone could be explained by my set of ecological predictors, in addition to body size (here I consider the maximum straight carapace line as a proxy for 'body size'). This tests if skull size is only determined by allometric effects (body size explaining turtle skull size variation; Bever 2008; 2009; Wilson \& Sánchez-Villagra 2011) or if turtle feeding ecology also have an effect on it (e.g. Pfaller et al. 2010). As with the D-PGLS models, I first retained individual significant predictors, and then included them in more complex combinations testing for independent effects. I used AIC for small samples (AICc; Burnham \& Anderson 2002) to evaluate the best combination of explanatory variables. To run the regressions, I used R packages 'nlme' 3.1-148 (Pinheiro et al. 2020) and 'ape' 5.0 (Paradis \& Schliep 2019). All of my phylogeny-based analyses for extant turtles use a topology derived from the most recent study regarding their phylogenetic relationships (Pereira et al. 2017), in which the tree was calibrated using a molecular clock approach (following Joyce et al. 2013) and branch lengths represent divergence time between lineages.

\section{Multivariate morphospace of regression scores}

For a graphical examination of the model results, I retrieved regression scores (as defined in Drake \& Klingenberg 2008) from the best model calculated from each predictor individually. Regression scores in a multivariate regression can be understood as the association between the shape variable (e.g. Procrustes 3D coordinates) and shape changes predicted (fitted) by the regression model coefficients, in which the shape data is projected "onto a line in the direction of the regression vector for each independent variable" (Drake \& Klingenberg 2008: p. 72). The regression scores from the D-PGLS 
analyses represent the shape axes that best distinguished between ecological categories while accounting for phylogenetic covariance. By retrieving these values separately for each independent factor, I can assess the relationship between different shape predictors in a multivariate ordination morphospace, similar to a PCA ordination plot, for instance. To calculate these, I used the customised function procD.scores () (Appendix 7).

\section{Assessment of shape changes in models}

To visualise shape deformation in a given model for a specific predictor, all the other variables were held constant except for that I was interested in. For instance, to visualise allometric changes, the remaining predictors were set to 0 ('absence') or 1 ('presence'), depending on the most common condition in my dataset. For the allometry effect ('skull size' variable), the first and third quartile of skull size values were used instead of minimum and maximum values, so outliers (e.g. the large skulls of some sea turtles) were avoided. For the remaining (binary) variables, the mean value of 'skull size' was used. This allowed me to graphically compare the deformation in a set of landmarks when a given variable was present or not, using the Euclidean distance between them (sum of squared differences between two points; Dryden \& Mardia 2016). These distances between the two constellations of points were normalized (i.e. values were set to range from 0 to 1), and coloured accordingly to represent these values.

\section{Fossil turtles}

\section{$\underline{\text { Regression scores }}$}

To infer ecological aspects for fossils, I chose a subset of landmarks that would allow the inclusion of most of the extinct taxa in subsequent analyses, because not all fossil specimens in my sample were completely preserved. This 'partial dataset' includes only skull aspects such as overall dimensions (length, width and height), as well as key features 
such as orbits and mandibular condyle position, and the outline and depth of the triturating surfaces (Appendix 4), all of which have been previously described as potential correlates to the feeding ecomorphology of turtles (e.g. Pritchard 1984; Herrel et al. 2002; Lemell et al. 2002; 2010). As with the 'full dataset', I applied the same pipeline methodology (model construction and evaluation, and getting regression scores) to this subset of landmarks.

The regression scores for the fossils were obtained in the same way as those for living turtles (see 'Multivariate morphospace of regression scores' section), using the customised function predict.procD.scores () (Appendix 7). This approach is useful to generate scores for specimens not included in the D-PGLS models for any given reason, e.g. fossil taxa for which I cannot be sure of their ecological attributes. These scores were then projected on the axes of the morphospace of regression scores I created to check how they fitted among extant taxa regarding each independent variable individually.

\section{Classification of fossils}

I used phylogenetic Flexible Discriminant Analysis (hereafter pFDA) to formally evaluate the posterior probability $\left(\mathrm{PP}_{\text {trait }}\right)$ that each fossil has a given ecology found to be predictive of turtle skull shape (i.e. discrete independent variables in the best model). I used the phylo.fda.pred() custom function from Motani and Schmitz (2011) to perform the pFDA on the regression scores. Despite accounting for phylogeny when retrieving such values by D-PGLS, the regression scores (as well as their residuals) are provided in the "original, phylogenetically dependent space" (Revell 2009, p. 3259). I understand that results (scores and residuals) obtained from D-PGLS analyses still contain phylogenetic information because residual calculation using the phyl.resid () function described in Revell (2009) yield the exact same values output from 
procD.pgls (). This means downstream analyses (e.g. discriminant analysis) should still employ methods that take phylogeny into account (e.g. pFDA) when treating the data.

Following Chapelle et al. (2020), I trained my discriminant function by iteratively resampling my dataset, and by using a 'leave-one-out' cross-validation method, running 100 replicates of pFDA. I randomly sampled an equal number of extant turtles from each category, so the prior probability of being classified to a given class would always be the same (see Motani \& Schmitz 2011 for further discussion on the implications assuming 'equal' or 'empirical' prior probabilities). In each round of $\mathrm{pFDA}$, considering $j$ as the number of extant species, I predicted the posterior probability of the presence of a trait $\left(\mathrm{PP}_{\text {trait }}\right)$ in the $j$-th taxon along with the extinct taxa as though it was also a fossil with unknown ecology. This allowed me to assess how accurately my pFDA could classify extant turtles. In the end, I extracted their mean $\mathrm{PP}_{\text {trait, }}$ and considered a $\mathrm{PP}_{\text {trait }} \leq 0.33$ to represent 'absence' of a trait, $0.33<\mathrm{PP}_{\text {trait }}<0.66$ to represent an 'equivocal' classification, and $\mathrm{PP}_{\text {trait }} \geq 0.66$ to represent 'presence'.

For this analysis, I used a calibrated topology (Fig. 2), in which relationships within extant groups (i.e. within 'families') follow Pereira et al. (2017), whereas the relationships between more inclusive clades (i.e. above the genus level) follow Evers et al. (2019a) consensus tree (B. Farina, unpublished data). In addition, because the position of angolachelonians in Evers et al. (2019a) as stem-pleurodires is only weakly supported, I also used a composite topology based on Sterli et al. (2018) consensus tree to account for this phylogenetic uncertainty, in which the abovementioned group is recovered in a more 'traditional' position as stem-Testudines. Unlike that used in the ecomorphology analyses, which included only extant taxa and was calibrated with a molecular clock (see 'Ecomorphological hypotheses' section), these trees were calibrated using a fossilised birth-death model (B. Farina, unpublished data). Both trees are presented in Appendix 1. 
Finally, to visualise these features throughout turtle evolutionary history, I plotted the resulting probabilities against my calibrated trees. For this visual representation, I used the plotBranchbyTrait () function of the R package 'phytools' (Revell 2012). This function uses continuous values from the edges, nodes, or tips of a phylogenetic tree as the input (e.g. $\mathrm{PP}_{\text {trait }}$ ) to estimate the conditions of the branches leading to such tips, colouring them according to the ancestral estimated value.

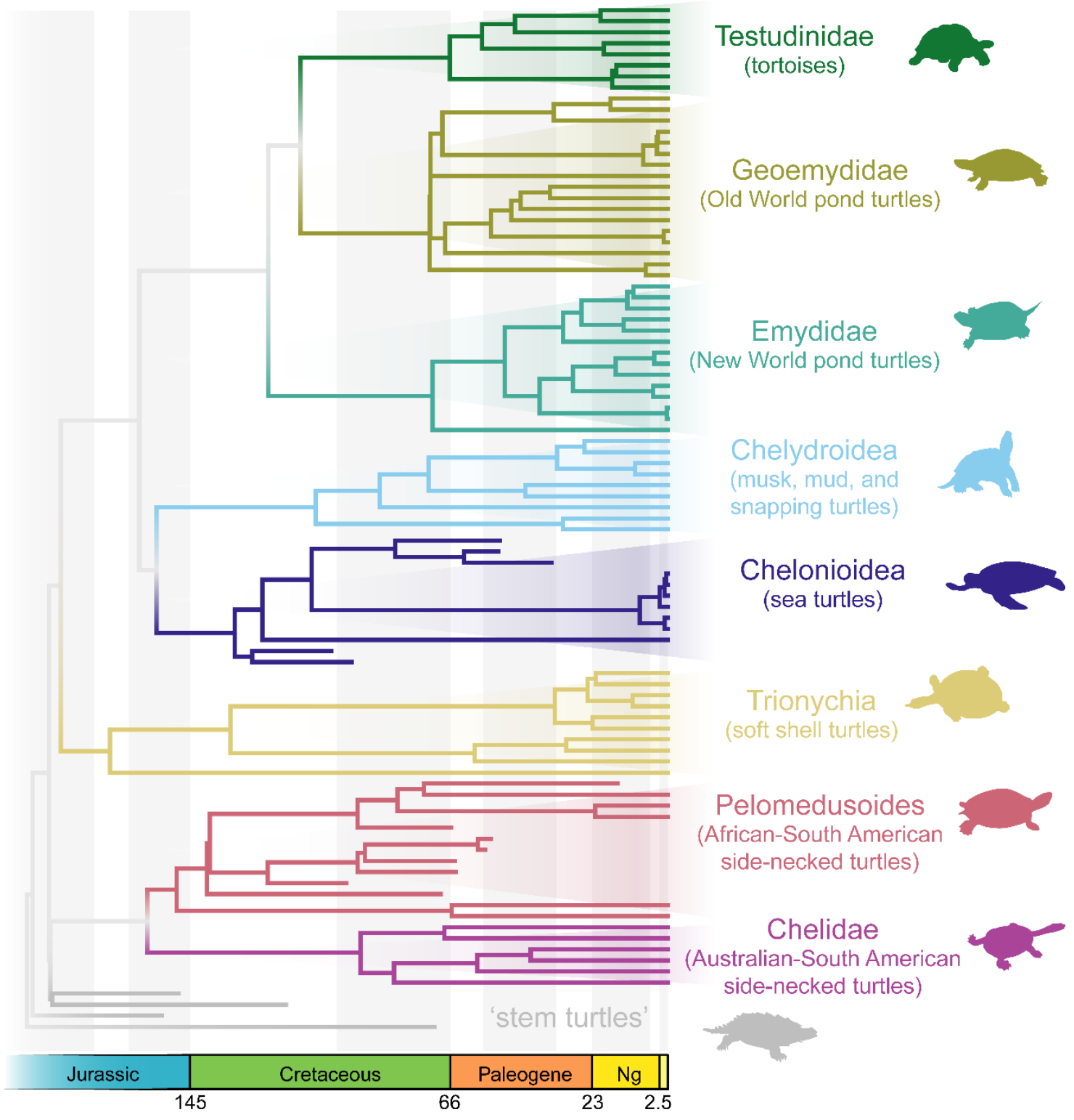

Figure 2. Phylogenetic hypothesis used in this study. Extant turtles relationships within 'families' follow Pereira et al. (2017) whereas more inclusive clades interrelationships follow Evers et al. (2019a). Silhouettes modified from Gaffney (1990). The full trees (with all species names) of both hypotheses I used are presented in Appendix 1. 


\section{Results}

\section{Skull shape variation among extant turtles}

The first three axes of my PCA explain $\sim 60 \%$ of shape variation among extant turtle skulls (Fig. 3). There is a partial separation of major turtle subclades along the first two axes (moreover, the estimated value of Pagels's $\lambda$ in my Procrustes coordinates $=0.87$ ). PC1 mostly describes the degree of the posterodorsal ("temporal") and anterolateral ("cheek") emarginations of the skull and the length of the supraoccipital crest, and explains $28.5 \%$ of total shape variation. Positive values of PC1 describe skulls that lack substantial temporal emargination, have shorter supraoccipital crests (such as those of chelonioids and most chelids and podocnemidids), are dorsoventrally higher, possess wider orbits, have a more developed cheek emargination, are anteroposteriorly shorter, and lack a pronounced otic trochlear process. Negative values of PC1 describe skulls that have very extensive temporal emargination and long supraoccipital crests, are anteroposteriorly longer and dorsoventrally lower, have a well-developed otic trochlear process, an upturned basisphenoid, and a less developed cheek emargination, such as trionychids and kinosternids.

Positive values of PC2 (20.8\% of variation) describe skulls that are more flattened dorsoventrally, have anterodorsally-oriented eyes, longer basisphenoids, a closed cavum tympani, greater cheek emargination, more posteriorly directed squamosals, as well as narrower and dorsoventrally lower triturating surfaces (e.g. long-necked chelids and trionychids). In addition, more positive values of PC2 describe taxa with rounder mandibular condyles, and flatter palates. More negative PC2 values describe taxa possessing high-domed skulls, laterally-placed orbits, shorter basisphenoids, mandibular condyles that are wider than long, and a less anteriorly developed descending process of the parietal (e.g. tortoises and sea turtles). PC2 negative values also describe skulls that 
have less developed cheek emarginations, a broader area for the triturating surfaces with more mediolaterally expanded maxillae and anteroposteriorly longer premaxillae, and a more vaulted palate.

A
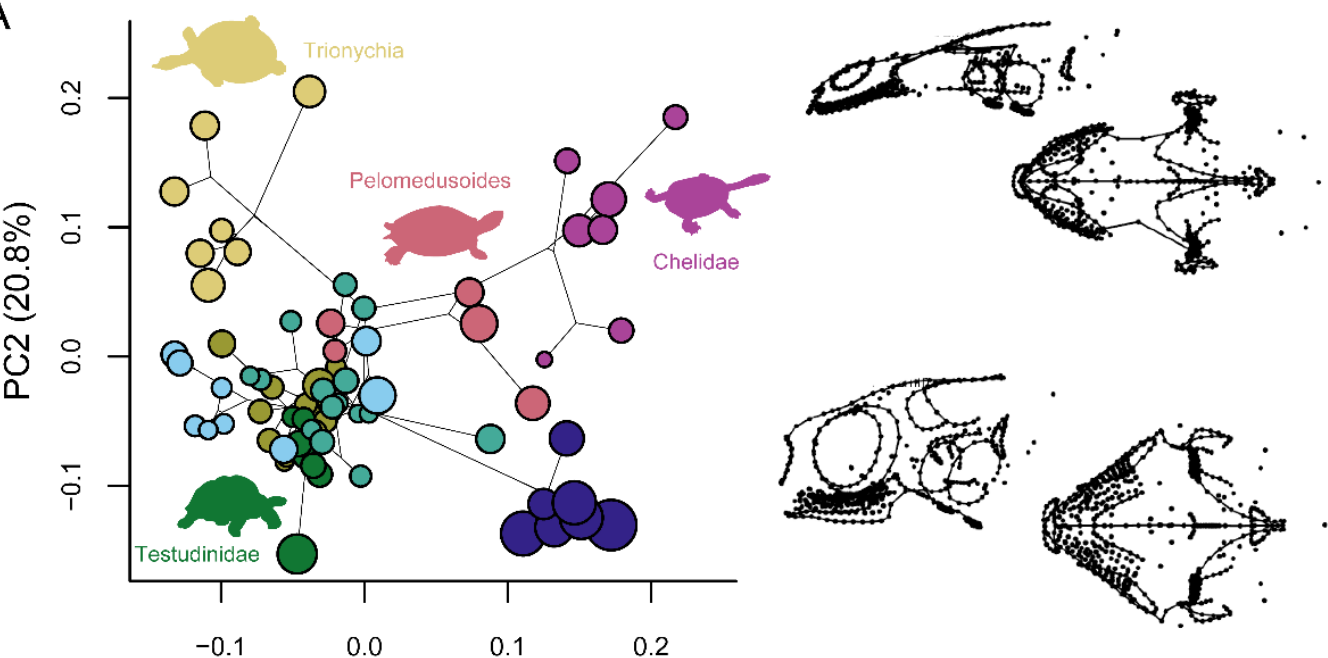

B
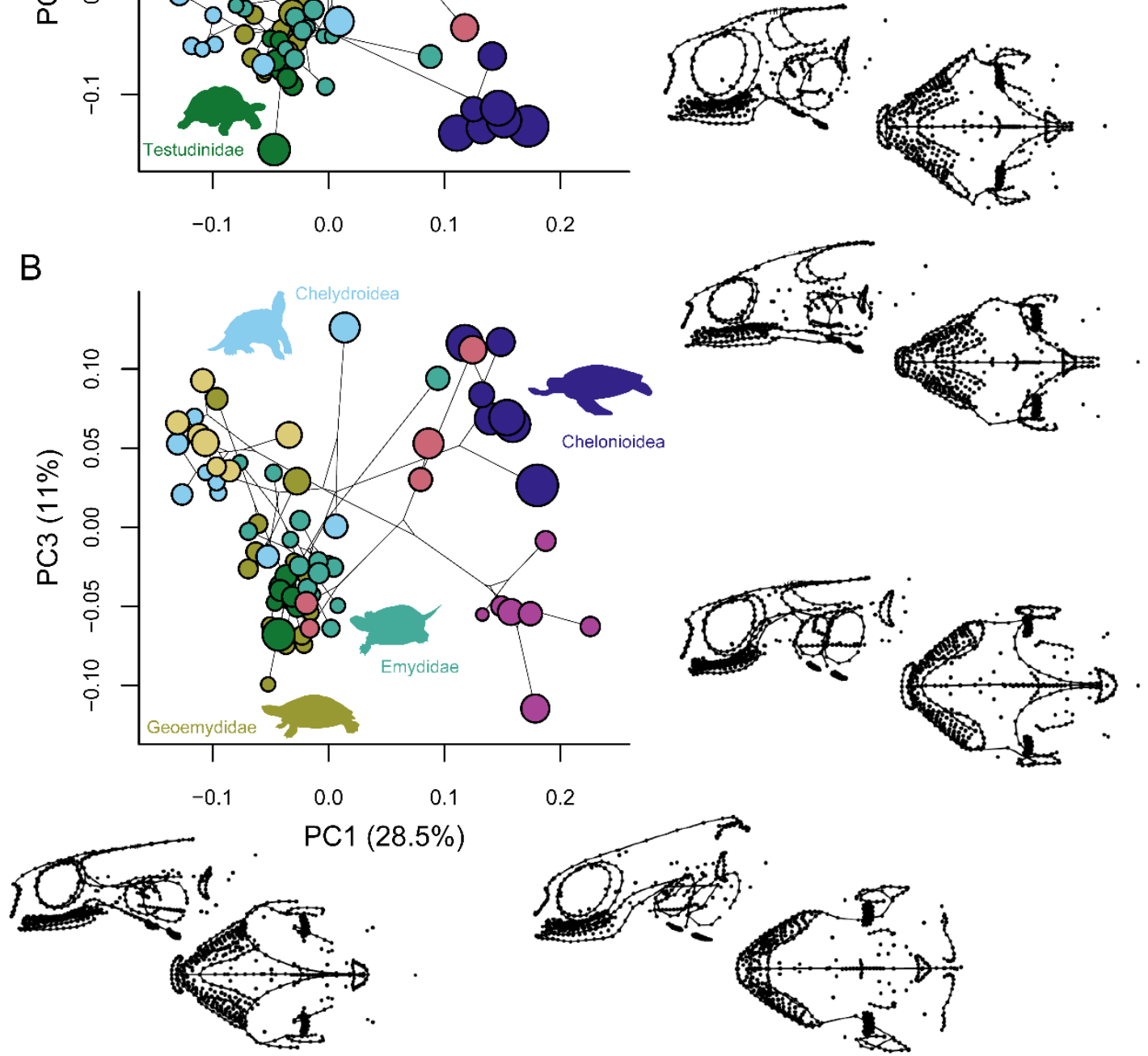

Figure 3. Skull shape variation among extant turtles. Morphospace of (A) first vs. second, and (B) first vs. third PC axes projected onto extant turtle's topology of Pereira et al. (2017). Landmark configurations on the side ( $\mathrm{A}$ and $\mathrm{B}$ ) and below $(\mathrm{C})$ the graphs correspond to the extreme values (minimum and maximum) of each axis in left lateral (left) and dorsal (right) views. Larger points indicate larger skull sizes. 
Regarding PC3 (11\% of variation), skulls with more positive values show an almost complete reduction of the cheek emargination, a broader covering of the skull roof, shorter basisphenoids, maxillae parallel to the skull horizontal axis, as well as wider and deeper triturating surfaces (e.g. chelonioids). In addition, at more positive values it is observed the displacement of the more anterior contact between palatines and maxillae to a more lateral position, preventing its invasion on the internal nares. These abovementioned features are more commonly observed in taxa that develop a secondary palate. Negative PC3 values describe taxa with skulls that have more posteriorly upturned maxillae, a more ventrally developed descending process of the parietal, more extended cheek and temporal emarginations, longer basisphenoids, and shorter squamosals, in which their posteriormost tip nearly coincides with the opisthotic contact, such as testudinids, some geoemydids and emydids.

\section{Skull shape association with multivariate diet categories}

My two-block partial least squares analyses (ordinary [PLS] and phylogenetic [pPLS]) show a significant and similar degree of association between turtle skull shapes and the principal coordinate values derived from my multivariate diet scheme. The association found by PLS has a coefficient of correlation (r-PLS) of 0.69 ( $p$-value $=$ $0.001)$, whereas the association found by pPLS has an r-PLS of 0.68 ( $p$-value $=0.007)$.

The first dimension of the PLS represents $56.6 \%$ of the variance explained by skull-diet association (Fig. 4a) and indicates a strong relation of skull shape with the first axis of my principal coordinate analysis (PCo1). PCo1 mostly separates taxa that do not feed in water and mostly feed on plant material from those with more faunivorous diets (Fig. 4a). Also, the lowest negative values describe taxa that mostly feed on land. More 
negative values of the X-scores (shape) in PLS first dimension describe taxa with skulls that are dorsoventrally higher, mediolaterally wider and anteroposteriorly shorter, possess lateralised orbits, wider external nares, shorter basisphenoids, as well as deeper and broader triturating surfaces (Fig. 5a). In contrast, more positive values describe skulls with a more dorsoventrally flattened and anteroposteriorly longer aspect, anterodorsallyoriented orbits, narrower triturating surfaces, with also more posteriorly developed squamosals and slightly more posteriorly placed mandibular condyles (Fig. 5a).

A

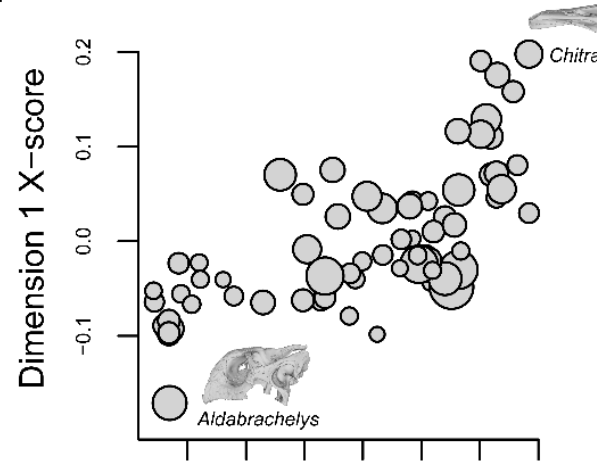

$\begin{array}{lllllll}-1.5 & -1.0 & -0.5 & 0.0 & 0.5 & 1.0 & 1.5\end{array}$

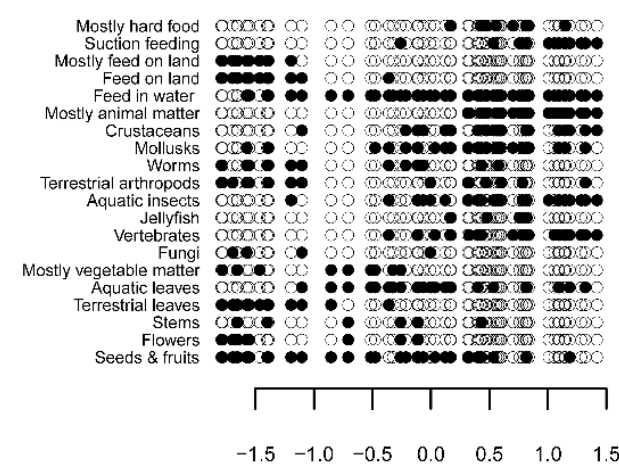

Dimension 1 Y-score
B

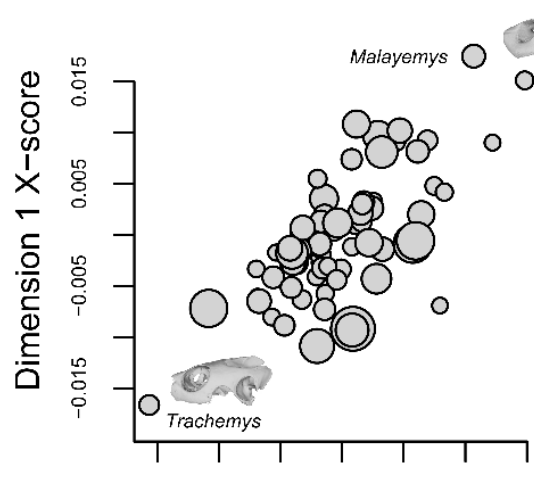

$\begin{array}{lllllll}-0.3 & -0.2 & -0.1 & 0.0 & 0.1 & 0.2 & 0.3\end{array}$

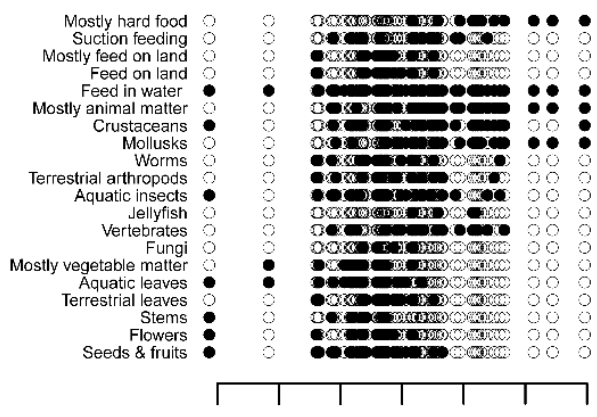

$\begin{array}{lllllll}-0.3 & -0.2 & -0.1 & 0.0 & 0.1 & 0.2 & 0.3\end{array}$

Dimension 1 Y-score

Figure 4. Dimension 1 of (A) ordinary and (B) phylogenetic 2B-PLS analyses, indicating the general association (top row) between skull shape (X-scores, 'shape axis') and multivariate feeding categories (Yscores, 'ecological axis'), and distribution (bottom row) of taxa scored as possessing each trait (black circles) along the Y-score axis. 
A
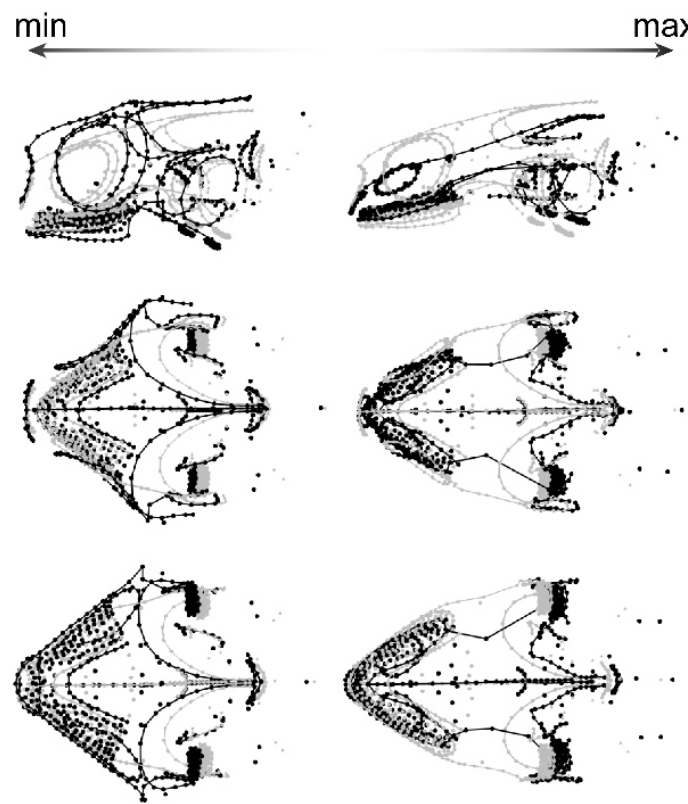

B
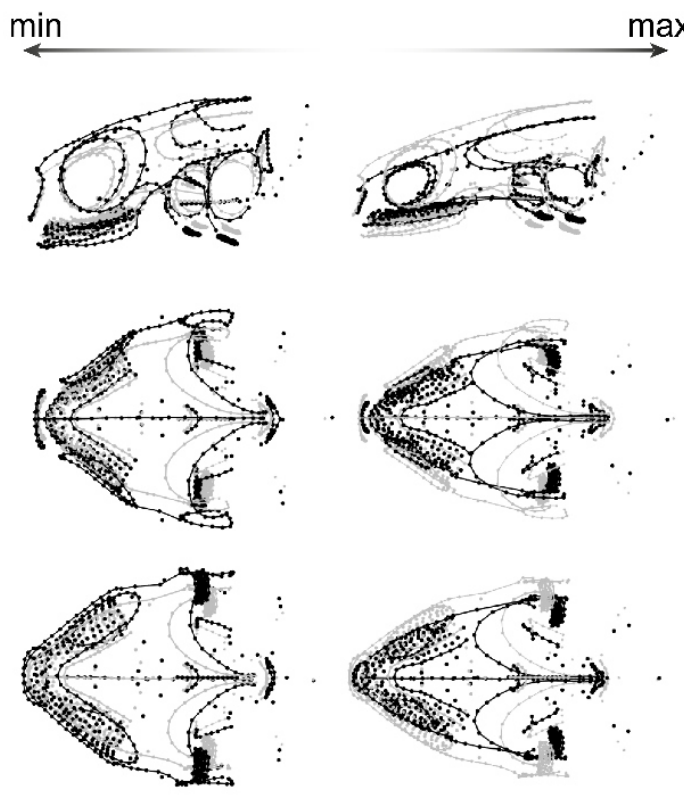

Figure 5. Landmark configuration of extreme values (black) from (A) ordinary, and (B) phylogenetic 2BPLS analyses, superimposed on the mean shape configuration (grey) of the GPA aligned coordinates. Shapes are shown in left lateral (top row), dorsal (middle row), and ventral (bottom row) views.

As for the pPLS, the first dimension represents $38 \%$ of the shape-diet association. Similar to the PLS, it is also correlated to PCo1. In pPLS, more negative X-scores describe taxa that feed mostly on plant material (Fig. 4b). Skulls with these values are dorsoventrally higher and mediolaterally wider, possess shorter squamosals, deeper maxillae, and broad triturating surfaces, a cavum tympani that is higher than long, wider external nares, as well as a less developed temporal emargination and a more developed cheek emargination, blunter otic trochlear processes and mandibular condyles more anteriorly placed (Fig. 5b). On the other hand, positive scores describe taxa that feed mostly on hard food (durophagous). Skull shapes with these values are dorsoventrally lower, have a more rounded cavum tympani, longer squamosals, shallower maxillae, broad triturating surfaces too (although with a lesser internal angle between the two halves, and anteroposteriorly longer premaxillae), in addition to less developed cheek 
emarginations but more extensive temporal ones, a more pronounced otic trochlear process and more posteriorly displaced mandibular condyles (Fig. 5b).

Lastly, my pPLS of turtle skull emarginations revealed a strong and significant association between them ( $\mathrm{r}$-PLS: $0.756 ; p$-value $=0.001)$. Skulls with positive X-scores correspond to a less dorsoventrally developed cheek emargination, whereas more negative X-scores are associated with a more dorsoventrally higher aspect of such structure (Fig. 6). Likewise, more positive Y-scores are associated with a decreased anteroposterior development of the temporal emargination (i.e. it is less extensive), and more negative $\mathrm{Y}$-scores correlate to more developed temporal emarginations.

A

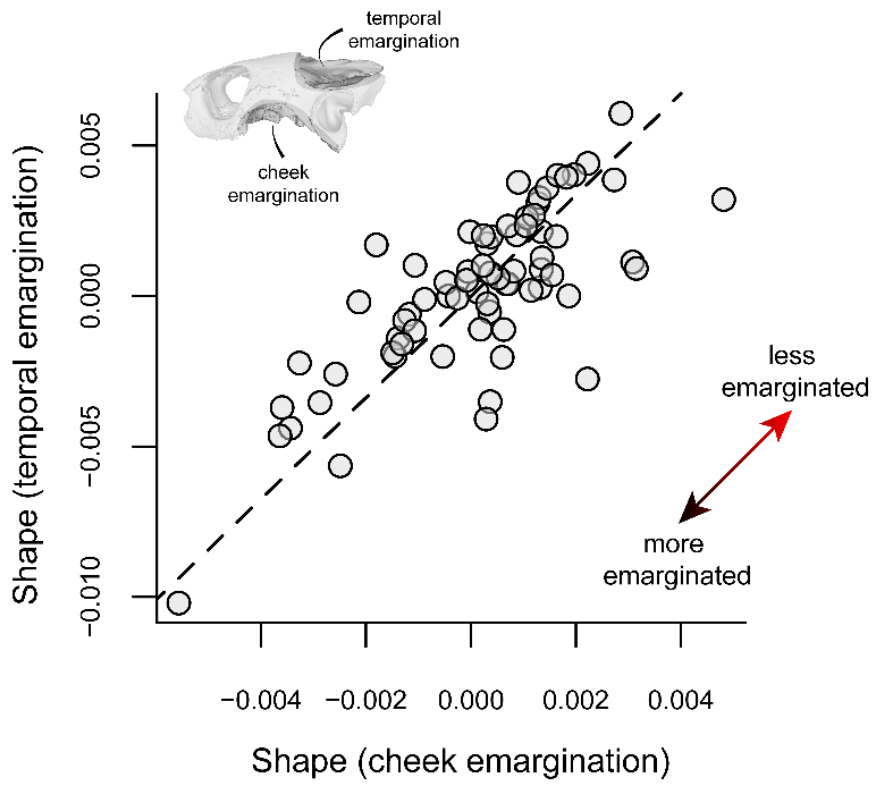

B

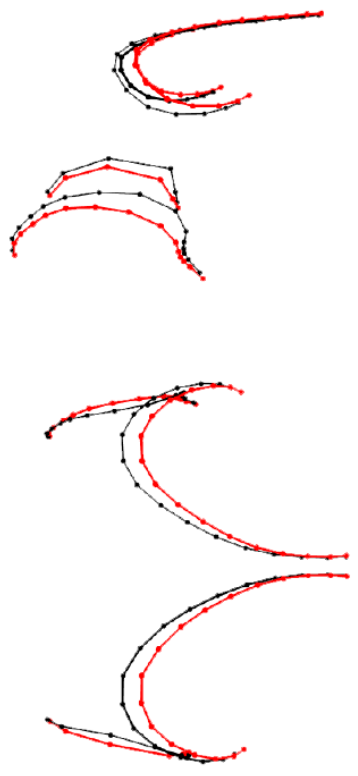

Figure 6. Correlation between emarginations of turtle skulls. (A) First dimension of p2B-PLS analysing the structure of association between the shape of the anterolateral (cheek) emargination (X axis) and the posterodorsal (temporal) emargination (Y axis). (B) Superimposition of landmark configurations for more positive (in red) and more negative (in black) scores, shown in left lateral (top) and dorsal (bottom) views. 


\section{Ecological predictors of skull shape in turtles}

\section{Full dataset}

My D-PGLS analyses indicate the best model (based on AIC scores) is one in which skull shape is predicted by allometry, use of suction-feeding for food capturing, eating hard food, and the capacity of neck retraction (AIC: $-16463.6 ; \mathrm{R}^{2}: 0.19$; see Table 1 for full disclosure of each predictor individual contribution to the model), indicating that apart from size, ecology explains up to $15 \%$ of shape variation in extant turtles skulls. Some of my other models also recover a significant effect of feeding in water; yet, when included together as explanatory variables in the same model (e.g. skull shape $\sim$ suction-feeding + feeds in water), both are statistically significant, indicating independent effects on skull shape (Table 1). Other, more complex models (i.e. with additional explanatory variables and hence greater determination coefficients) also show statistical significance and indicate that other factors could also be relevant in shaping the turtle skull as a whole. 'Feeding in water' was only significant when at least 'size' was included in the model (Appendix 6), indicating aquatic feeding explains turtle skull shape only when allometric effects are taken into account.

The multivariate morphospace of regression scores from my D-PGLS best model exhibit a clear separation between turtles incapable of neck retraction and those that use suction mechanisms for food capturing (Fig. 7a). The scores associated with the presence of suction also narrowly distinguishes turtles adapted to suction-feeding from those that are durophagous. In fact, the regression of shape on the presence of durophagy produce scores that indicate that some non-durophagous turtles can have 'durophagous'-like skulls (Fig. 7b). Also, skull size of extant turtles was found to be largely explained by the combination of their body size and their capacity of retracting necks (Figs. 7c, 8; Table 2). Body size and marine habits also explain skull size, but when neck retraction and 
marine lifestyle were included in the same model, the latter variable became nonsignificant. Moreover, I find the predicted shape for the absence of neck retraction (Fig.

7c) to be negatively correlated with the skull size of chelonians.

Table 1. Summary statistics of selected D-PGLS analyses of the full landmark dataset $(n=70)$ regarding ecomorphology of extant turtles' skull. $\triangle A I C$ : difference in AIC score between the best model and the model being compared; $R^{2}$ : coefficient of determination for each predictor; $\lambda$ : Pagel's lambda of regression residuals calculated a posteriori; $p$-value: numbers in bold denote significance level at $\alpha<0.05$.

\begin{tabular}{|c|c|c|c|c|c|}
\hline Model & AIC & $\Delta \mathrm{AIC}$ & $\mathbf{R}^{2}$ & $p$-value & $\lambda$ \\
\hline shape $\sim$ size + suction + durophagous + neck retraction & -16463.6 & 0 & & & 0.72 \\
\hline size & & & 0.046 & 0.001 & \\
\hline suction & & & 0.049 & 0.001 & \\
\hline durophagous & & & 0.049 & 0.001 & \\
\hline neck retraction & & & 0.050 & 0.001 & \\
\hline $\begin{array}{l}\text { shape } \sim \text { size }+ \text { feeds in water }+ \text { suction }+ \text { durophagous }+ \text { neck } \\
\text { retraction }\end{array}$ & -15878.9 & 584.8 & & & 0.76 \\
\hline size & & & 0.046 & 0.001 & \\
\hline feeds in water & & & 0.024 & 0.029 & \\
\hline suction & & & 0.048 & 0.001 & \\
\hline durophagous & & & 0.049 & 0.001 & \\
\hline neck retraction & & & 0.050 & 0.001 & \\
\hline $\begin{array}{l}\text { shape } \sim \text { size }+ \text { feeds in water }+ \text { suction }+ \text { durophagous }+ \text { plant }+ \\
\text { marine }+ \text { neck retraction }\end{array}$ & -15247.1 & 1216.6 & & & 0.75 \\
\hline size & & & 0.049 & 0.001 & \\
\hline feeds in water & & & 0.022 & 0.03 & \\
\hline suction & & & 0.041 & 0.002 & \\
\hline durophagous & & & 0.050 & 0.001 & \\
\hline plant & & & 0.022 & 0.01 & \\
\hline marine & & & 0.023 & 0.016 & \\
\hline neck retraction & & & 0.041 & 0.001 & \\
\hline
\end{tabular}

Table 2. Results of pGLS regressions ( $n=70$ ) of skull centroid size ('skull size') on selected explanatory variables. AICC: score of AIC for small samples; AICc weight: relative importance of the model; $R^{2}$ : coefficient of determination calculated for GLS models based on Ives (2019); $\lambda$ : phylogenetic signal (Pagel's lambda) estimated as part of the model fitting process; $p$-value: numbers in bold denote significance level at $\alpha<0.05$.

\begin{tabular}{|c|c|c|c|c|c|c|}
\hline Model & AICc & $\mathbf{R}^{2}$ & Coefficient & $p$-value & AICc weight & $\lambda$ \\
\hline skull size $\sim$ carapace size + neck retraction & -103.53 & 0.81 & & & 0.76 & 0.11 \\
\hline (Intercept) & & & 0.43 & 0.009 & & \\
\hline carapace size & & & 0.57 & $<0.001$ & & \\
\hline neck retraction & & & -0.21 & $<0.001$ & & \\
\hline $\begin{array}{l}\text { skull size } \sim \text { carapace size }+ \text { marine }+ \text { neck } \\
\text { retraction }\end{array}$ & -101.13 & 0.81 & & & 0.23 & 0.11 \\
\hline (Intercept) & & & 0.43 & 0.01 & & \\
\hline carapace size & & & 0.56 & $<0.001$ & & \\
\hline marine & & & 0.003 & 0.9637 & & \\
\hline
\end{tabular}




\begin{tabular}{|c|c|c|c|c|c|c|c|}
\hline \multirow{2}{*}{\multicolumn{2}{|c|}{ skull size $\sim$ carapace size + marine ${ }^{\text {neck retraction }}$}} & & & -0.21 & 0.002 & \multirow{4}{*}{0.00} & \multirow{5}{*}{0.14} \\
\hline & & -93.09 & 0.78 & & & & \\
\hline & (Intercept) & & & 0.19 & 0.233 & & \\
\hline & carapace size & & & 0.58 & $<0.001$ & & \\
\hline & marine & & & 0.19 & 0.003 & & \\
\hline
\end{tabular}

A

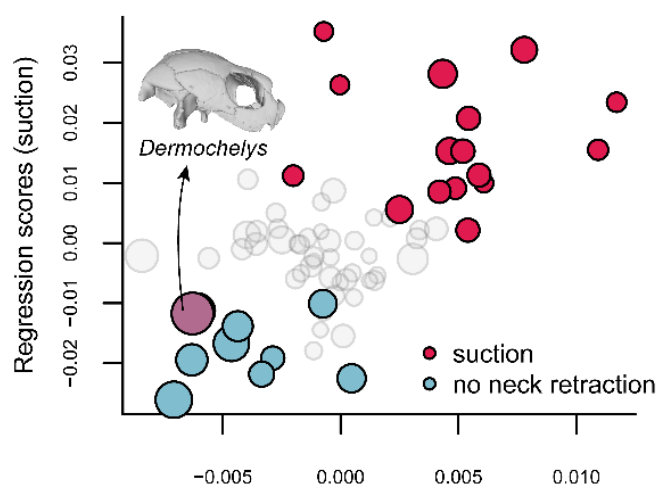

Regression scores (neck_retraction)

B

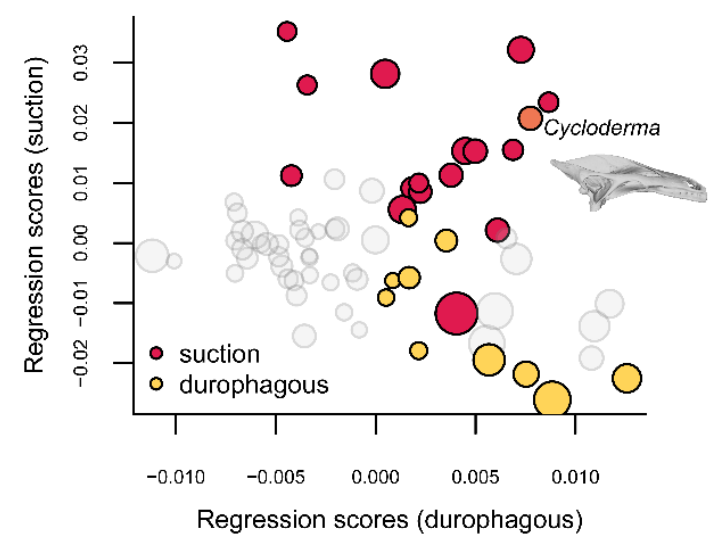

C

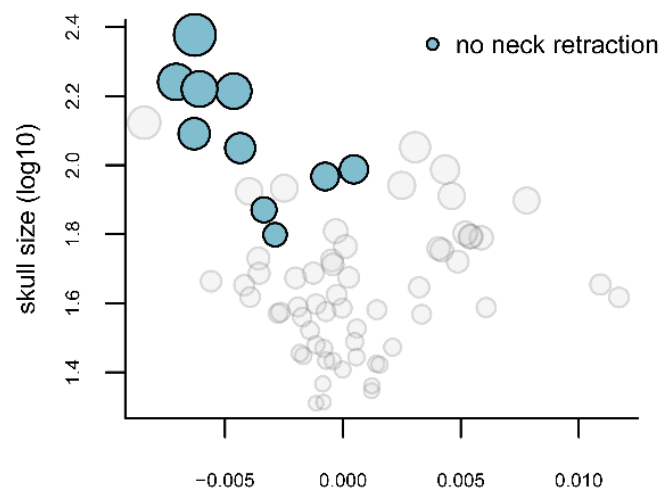

Regression scores (neck_retraction)

Figure 7. Ecological predictors of extant turtle skull shape. Regression scores for the presence of 'suctionfeeding' plotted against the regression scores of (A) presence of 'durophagy' and (B) neck retraction capacity. Dermochelys (in A) and Cycloderma (in B) are coloured differently for having both attributes highlighted in their respective plots. (C) Predicted shape scores of 'neck retraction' variable plotted against $\log _{10}$-transformed skull size. 

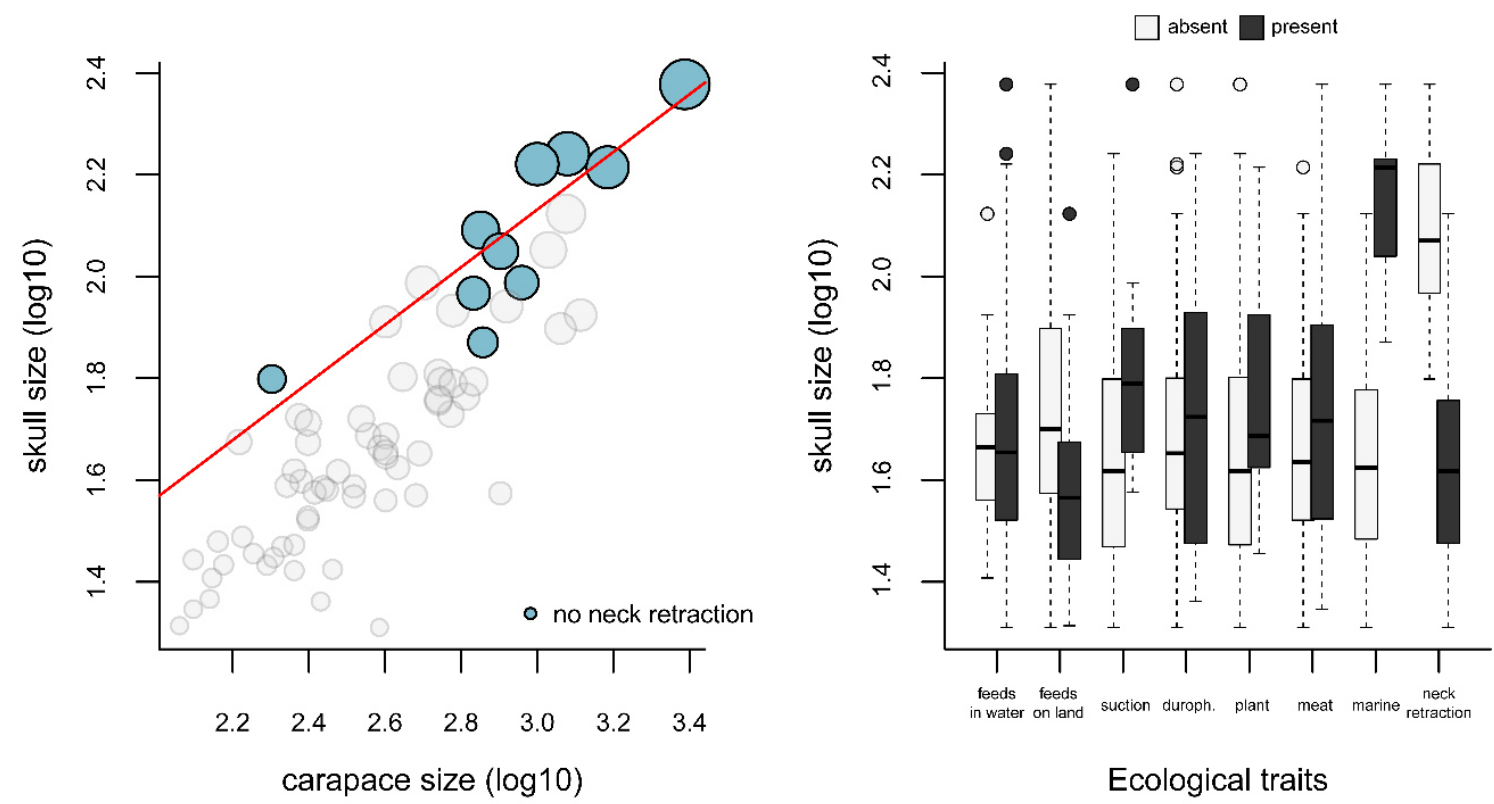

Figure 8. Predictors of turtle skull size. (A) Relationship between $\log _{10}$-transformed skull and carapace sizes (regression line in red illustrative of the 'carapace size' coefficient only); (B) Boxplots of skull size variation (Y-axis) included in each ecological category (X-axis).

As previously mentioned (see 'Ecomorphological hypotheses' section), multivariate statistics for high-dimensional data lack methods to evaluate the negligibility of such models. Therefore, results regarding shape deformation for individual predictors (i.e. the predicted response for each explanatory factor) are herein reported based on a slightly more complex model, which additionally includes the effect of aquatic feeding on skull shape (Table 1). Allometric effects on the turtle skull shape show larger skulls are shorter and wider, have shorter basisphenoids, mediolaterally broadened maxillae, and parietals extending a little more posteriorly, indicating a slightly greater skull roof cover (Fig. 9). Shape deformation between durophagous and non-durophagous taxa showed an increase in the width of the triturating surfaces, more developed posterodorsal emargination, less developed anterolateral emargination, and more posteriorly displaced mandibular condyles (Fig 9b). 
Regarding differences between taxa that are capable or not of full neck retraction within the shell, the greatest amount of deformation is found in the posterior part of the skull. Turtles unable to fully retract their heads possess an extensive covering of the skull roof, and virtually lack both the posterodorsal and anteroventral emarginations (Fig. 9c). Besides that, other posterior landmarks (e.g. foramen magnum and occipital condyle) are displaced more anteriorly, 'producing' a shorter skull. As for the capacity of feeding underwater (Fig. 9d), skull shape deformations for its 'presence' represent anteroposteriorly longer skulls, more posteriorly developed squamosals and opisthotics, a longer supraoccipital crest and a more flattened palate, as well as a decrease in skull height and relative size of orbits. Lastly, turtles that rely on a suction-feeding strategy have dorsoventrally lower skulls, more anterodorsally-oriented orbits, narrower triturating surfaces, longer parietals and basisphenoids, as well as more developed posterodorsal and anteroventral emarginations (Fig. 9e). 
A
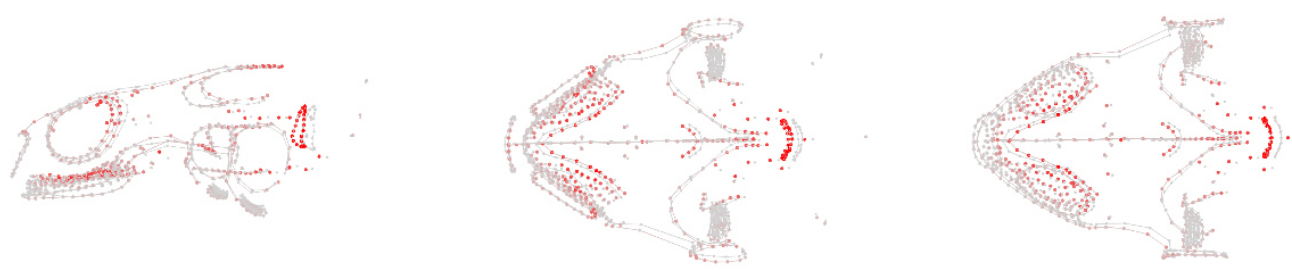

B
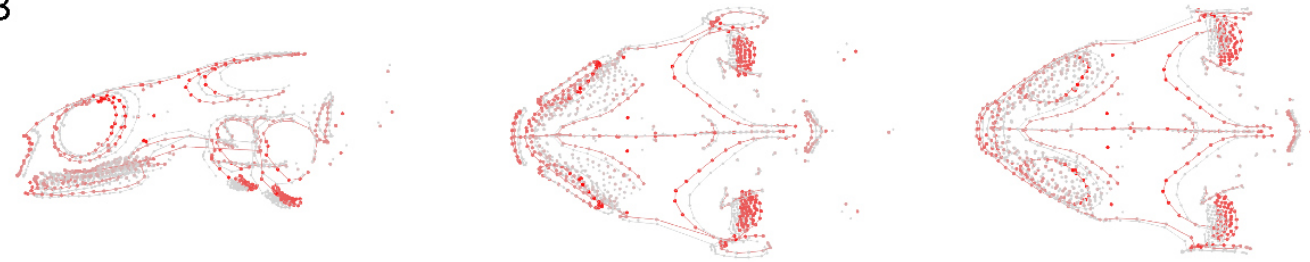

C
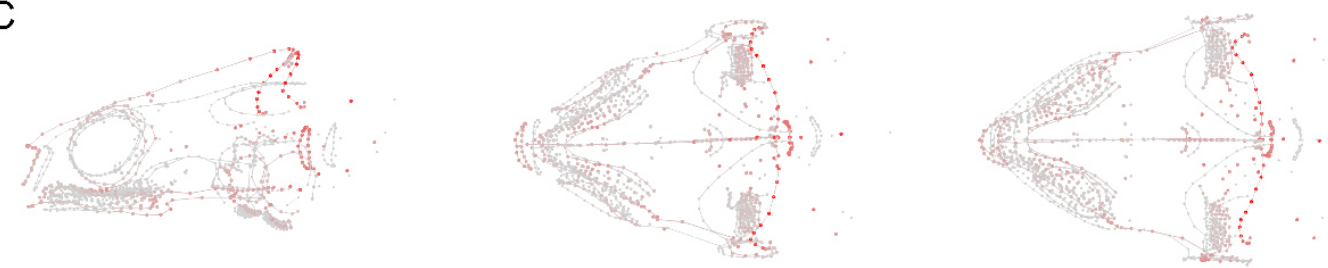

D
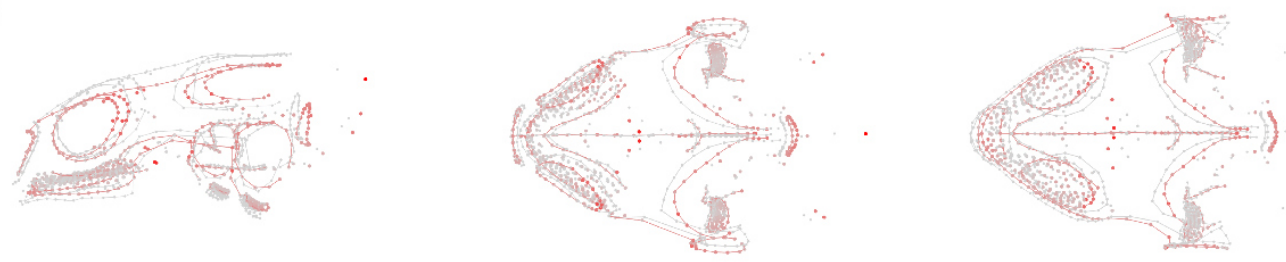

E
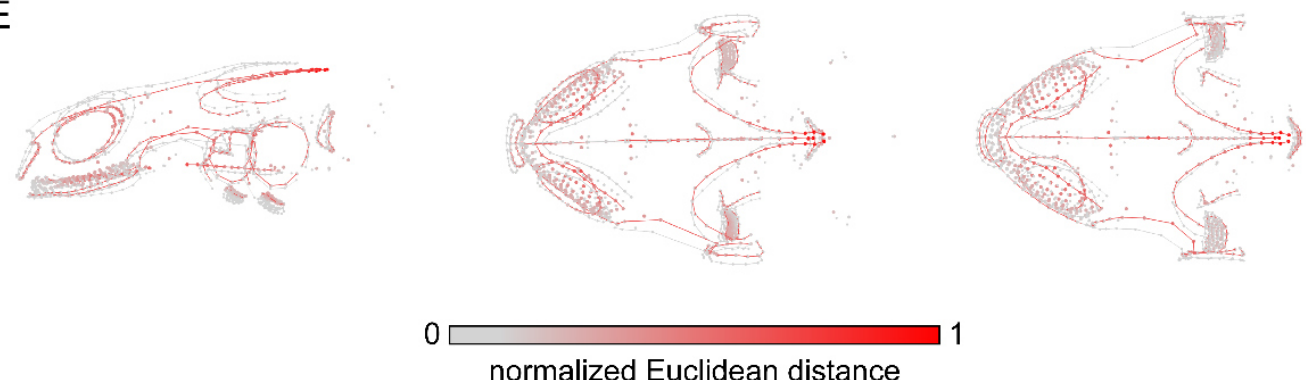

normalized Euclidean distance

Figure 9. Shape deformations of ecological predictors of the turtle skull. Landmark configurations describing the effects of (A) allometry and the presence of (B) durophagy, (C) neck retraction, (D) feeding in the water, and (E) use of suction feeding. Left, middle and right columns illustrate left lateral, dorsal and ventral views, respectively.

\section{Partial dataset}

The D-PGLS analyses of this dataset indicate the best model (Table 3), similar to the full landmark dataset, includes allometry, use of suction feeding, durophagy, and neck 
retraction capacity, as well as the presence of a marine lifestyle and whether a turtle feeds mostly on plant material ('herbivory' hereafter). Also, general trends can be observed in the predicted shape for the presence of a given ecological attribute in this model (Fig. 10).

Table 3. Summary statistics of the best D-PGLS model (according to AIC scores) of the partial landmark dataset $(n=76)$ regarding ecomorphology of extant turtles' skull. $R^{2}$ : coefficient of determination for each predictor; $\lambda$ : Pagel's lambda of regression residuals calculated a posteriori; $p$-value: numbers in bold denote significance level at $\alpha<0.05$.

\begin{tabular}{|c|c|c|c|c|}
\hline Model & AIC & $\mathbf{R}^{2}$ & p-value & $\lambda$ \\
\hline shape $\sim$ size + suction + durophagous + plant + marine + neck retraction & -9825.5 & & & 0.38 \\
\hline The size & & 0.046 & 0.001 & \\
\hline suction & & 0.042 & 0.001 & \\
\hline durophagous & & 0.052 & 0.001 & \\
\hline plant & & 0.034 & 0.001 & \\
\hline marine & & 0.024 & 0.014 & \\
\hline neck retraction & & 0.036 & 0.002 & \\
\hline
\end{tabular}

Shape deformations associated to allometry, the presence of suction or durophagy, and lack of neck retraction are similar to those described for the full dataset regression results (see previous 'Full dataset' section). The predicted shape for the presence of the 'marine' predictor describes skulls with increased overall height and orbit width (Fig. 10e), as well as being anteroposteriorly shorter, and having anteriorly displaced mandibular condyles. Regarding herbivory, the predicted shape describes anteroposteriorly longer and dorsoventrally higher skulls, with a slight increase in the width of orbits, as well as broadened triturating surfaces (Fig. 10d). Regarding my multivariate morphospace of shape scores, I identify an apparent negative correlation between the regression scores for the presence of suction and those for the presence of durophagy, herbivory and a marine lifestyle (Fig. 11a-c), suggesting that these traits are possibly mutually exclusive. For this partial set of landmarks, however, turtles with a retractile neck can have a 'non-retractile'-like skull shape (i.e. high-domed and anteroposteriorly short; Fig. 11d), quite opposite to what was found using the full set of landmarks (Fig. 7). 
A
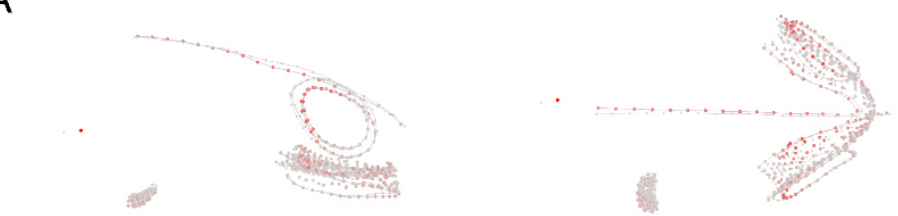

B

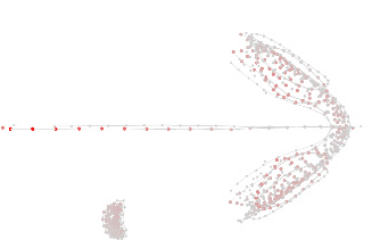

C
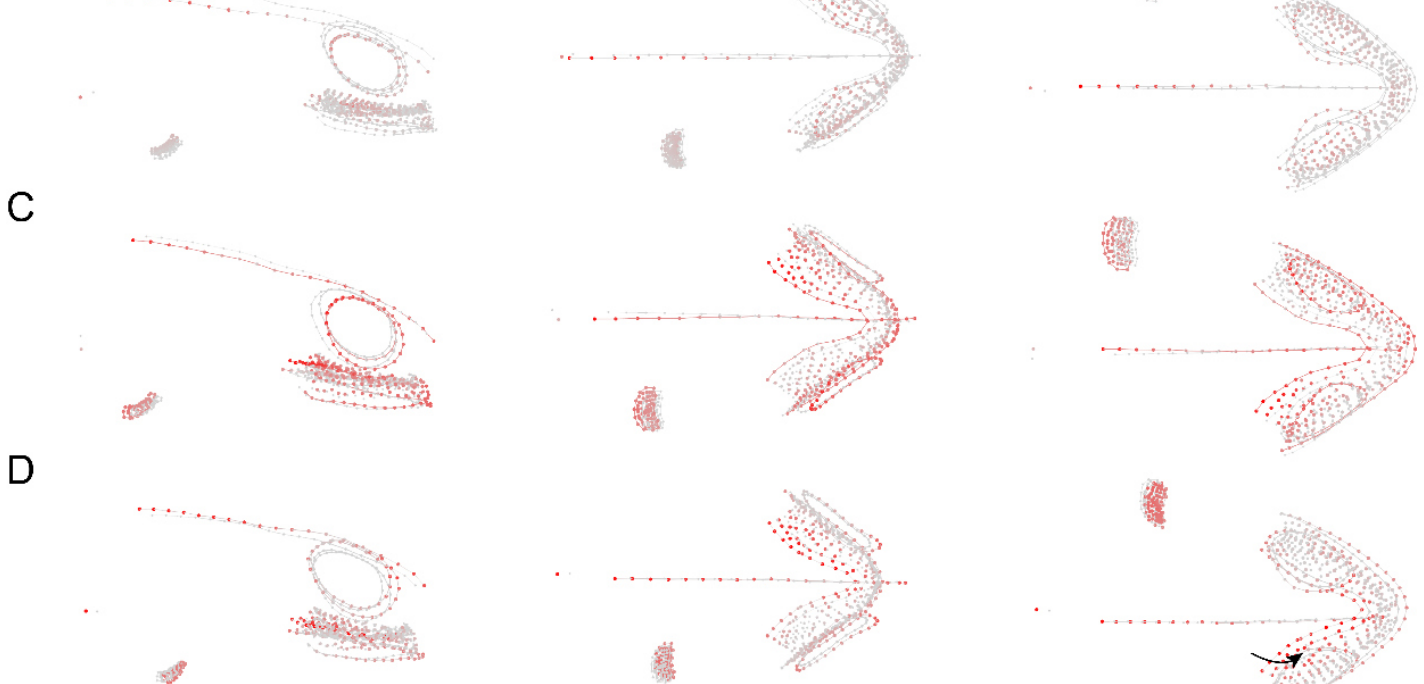

$E$
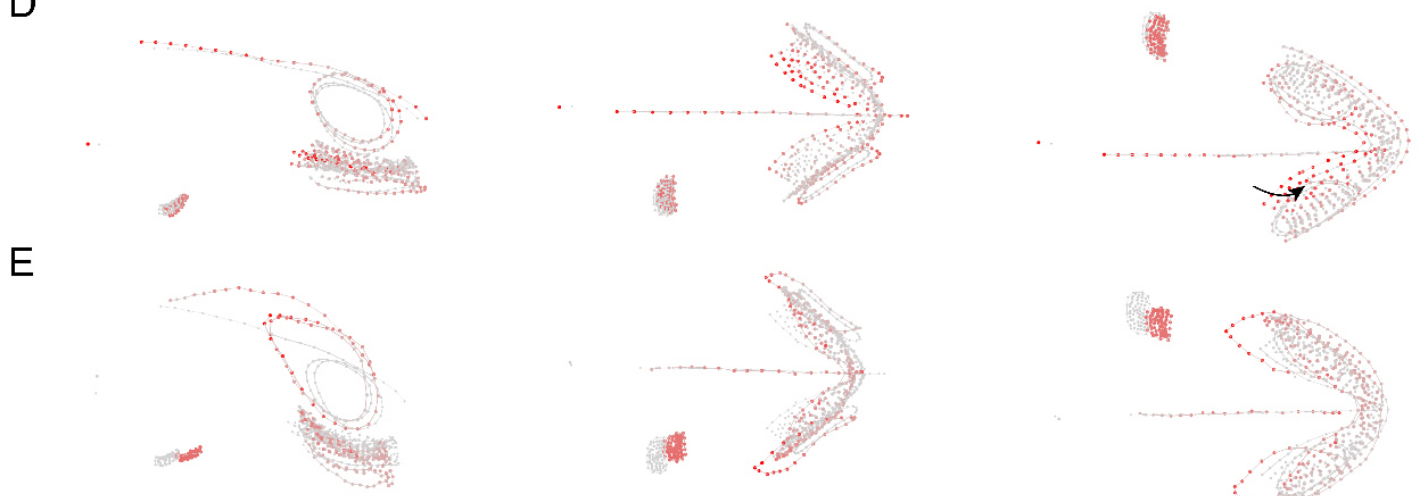

$\mathrm{F}$
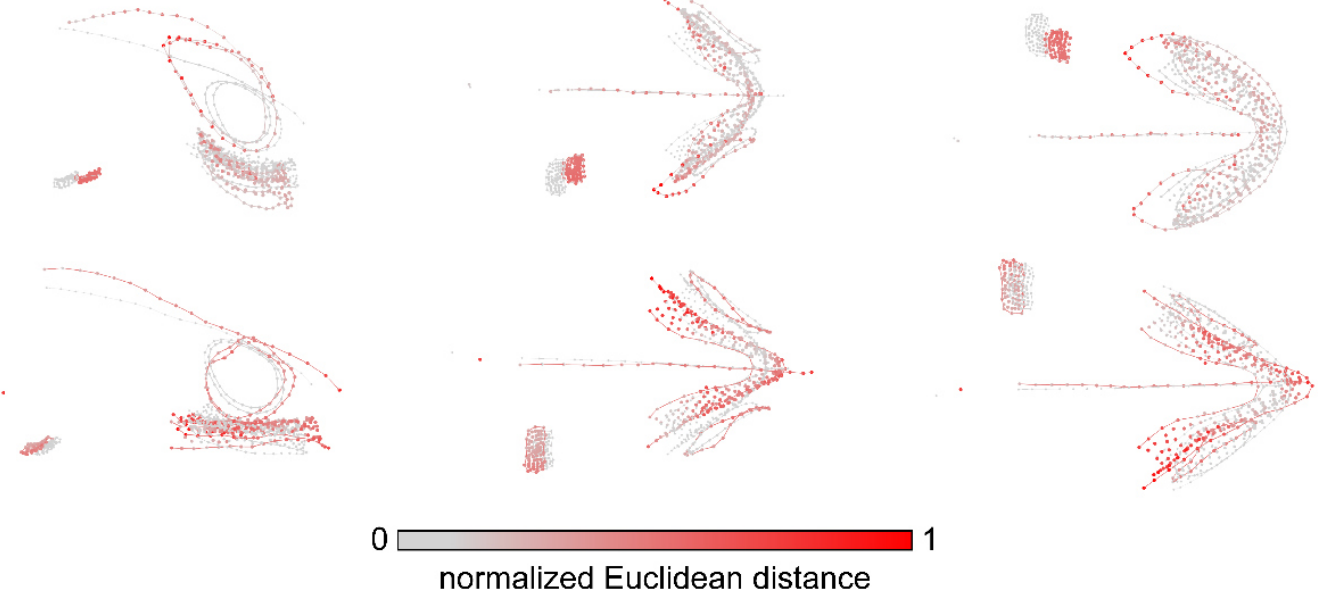

normalized Euclidean distance

Figure 10. Shape deformations regarding the influence of individual predictors of the best model on skull shape using the 'partial dataset' of landmarks. (A) allometry (B) presence of suction-feeding, (C) presence of durophagy, (D) presence of herbivory, (E) marine lifestyle, and (F) lack of neck retraction. Black arrow in (D) points to what could indicate the presence of an accessory ridge on the palate.

Concerning the scores calculated for extinct turtles, taxa with more dorsoventrally flattened skulls (e.g. Labrostochelys galkini and 'Madagascar turtle') have greater regression scores for the 'suction' predictor in contrast to smaller values for the other predictors (Fig. 11). On the other hand, fossil turtles exhibiting dorsoventrally higher 
skulls (e.g. protostegids, stem-cheloniids, some bothremydids) presented the opposite result, with greater scores for the 'marine' predictor and lesser for 'suction' (Fig. 11c). Similar to the 'marine' predictor, these turtle scores were also greater for the 'neck retraction' variable than for the 'suction' one (Fig. 11d). Concerning the 'durophagy' and 'herbivory' predictors, since both shape deformations exhibit comparable broadening of the palate, I found greater regression scores of these predictors for many extinct turtles with a more mediolaterally developed triturating surface (e.g. Eubaena cephalica, stemcheloniids, and Bairdemys hartsteini), which plots these taxa in a region of the morphospace more 'populated' by durophagous/herbivorous taxa (Fig. 11a-b).

\section{$\underline{\text { Discrimination of extant turtles' categories }}$}

The misidentification rate in my pFDA on each ecological predictor varied from $1 \%$ ('marine') to $18 \%$ ('herbivory'; results for the topology based on Sterli et al. (2018) are given in Appendix 2). In pFDA results for the presence of 'suction', 92\% of extant turtles were correctly classified (Appendix 2). Turtles scored as 'presence' for this trait (i.e. $\left.\mathrm{PP}_{\text {suction }}<0.66\right)$ but misclassified include Chrysemys picta (0.39), Phrynops geoffroanus (0.63) and Dermochelys coriacea (0.004), whereas those scored as 'absent' but misclassified were Chelydra serpentina (0.92), Peltocephalus dumerilianus $(=0.72)$ and Podocnemis expansa (0.85). Results for the presence of 'durophagy' had $90 \%$ of accurate classifications. Turtles scored as 'presence' for this trait, but misclassified were Lepidochelys olivacea $\left(\mathrm{PP}_{\text {durophagous }}=0.48\right)$ and Cycloderma frenatum (0.16), and those scored as 'absent' but misclassified were Batagur baska (0.83), Chelonia mydas (0.74), Macrochelys temminckii (0.92), Claudius angustatus (0.83) and Sternotherus odoratus (0.74).

The results of my pFDA for the presence of 'herbivory' had $82 \%$ correct classifications. Turtles misclassified as 'absent' were Cyclemys dentata $\left(\mathrm{PP}_{\text {plant }}=0.25\right)$, 
Hieremys annandalii (0.59), Notochelys platynota (0.49), Malacochersus tornieri (0.58), Testudo marginata (0.65), Gopherus polyphemus (0.64), Podocnemis expansa (0.62), P. unifilis (0.20), and Elseya dentata (0.36); those of which the $\mathrm{PP}_{\text {plant }}$ indicate 'presence' but were originally classified as 'absent' include Melanochelys trijuga (0.79), Siebenrockiella crassicollis (0.69), Dermochelys coriacea (0.76), Natator depressus (0.75) and Cyclanorbis senegalensis (0.76). Regarding the posterior probabilities for the 'marine' ( $\left.\mathrm{PP}_{\text {marine}}\right)$ and 'neck retraction' $\left(\mathrm{PP}_{\text {neck }}\right)$ predictors, only Peltocephalus dumerilianus was misclassified as a marine turtle $\left(\mathrm{PP}_{\text {marine }}=0.665\right)$, and only Notochelys platynota $\left(\mathrm{PP}_{\text {neck }}=0.35\right)$ and Glyptemys insculpta $\left(\mathrm{PP}_{\text {neck }}=0.52\right)$ were wrongly assigned as 'absent' for the capacity of neck retraction.

\section{Ecological attributes of fossil turtles}

Extinct turtles show different patterns for the presence of ecological attributes (Table 4). 'Stem' taxa such as Annemys sp. IVPPV 18106 (hereafter Annemys sp.) and Sandownia harrisi are predicted to present 'suction' but Jurassichelon oleronensis and Eubaena cephalica are not. Only E. cephalica in my sample is predicted to present durophagy. None of them are inferred to exhibit 'herbivory' or a marine habit, and all, according to my predictions, might have been able to fully retract their necks. Suction feeding is predicted to have evolved multiple times in turtles, including pan-pelomedusoids ('Madagascar turtle'), bothremydids (Labrostochelys galkini) and stem-podocnemidids (Lapparentemys vilavilensis). Extinct pelomedusoids considered nearshore marine such as Phosphatochelys tedfordi, Ummulisani rutgersensis and Bairdemys hartsteini were predicted to present 'herbivory'. Apart from L. vilavilensis and P. tedfordi predicted as 'equivocal', all remaining fossil side-necked turtles were capable of neck retraction like their extant relatives. 
Table 4. Mean posterior probabilities (PP) calculated in pFDA analyses (using Evers et al. 2019a topology) for the presence of each ecological trait in fossil turtles. Traits correspond to predictors from the best DPGLS model using the partial landmark dataset. $\mathrm{PP}_{\text {trait }}>0.66$ indicate 'presence', $\mathrm{PP}_{\text {trait }}<0.33$ indicate 'absence', and $0.66<\mathrm{PP}_{\text {trait }}>0.33$ indicate 'equivocal'. \# = number correspondent to regression plots. Clade abbreviations: 'Angol.' (Angolachelonia), 'Bothr.' (Bothremydidae), 'Chelon.' (Chelonioidea), 'Pelom.' (Pan-Pelomedusoides), 'Podoc.' (Podocnemididae) and 'stem' ('stem'-turtles).

\begin{tabular}{|c|c|c|c|c|c|c|c|}
\hline Taxon & Clade & $\#$ & suction & durophagous & plant & marine & $\begin{array}{c}\text { neck } \\
\text { retraction }\end{array}$ \\
\hline Annemys sp. & stem & 1 & 0.76 & 0.01 & 0.01 & 0.00 & 1 \\
\hline Araiochelys hirayamai & Bothr. & 2 & 0.53 & 0.03 & 0.45 & 0.02 & 0.98 \\
\hline Argillochelys antiqua & Chelon. & 3 & 0.00 & 0.99 & 0.46 & 0.73 & 0.48 \\
\hline Bairdemys hartsteini & Podoc. & 4 & 0.14 & 0.56 & 0.84 & 0.18 & 0.82 \\
\hline Desmatochelys lowii & Chelon. & 5 & 0.37 & 0.08 & 0.06 & 0.45 & 0.19 \\
\hline Eochelone brabantica & Chelon. & 6 & 0.42 & 0.53 & 0.45 & 0.78 & 0.03 \\
\hline Eubaena cephalica & stem & 7 & 0.05 & 0.91 & 0.01 & 0.04 & 0.95 \\
\hline Galianemys emringeri & Bothr. & 8 & 0.11 & 0.43 & 0.22 & 0.01 & 1 \\
\hline $\begin{array}{l}\text { Jurassichelon } \\
\text { oleronensis }\end{array}$ & Angol. & 9 & 0.17 & 0.00 & 0.00 & 0.01 & 1 \\
\hline Labrostochelys galkini & Bothr. & 10 & 0.96 & 0.00 & 0.22 & 0.00 & 1 \\
\hline $\begin{array}{l}\text { Lapparentemys } \\
\text { vilavilensis }\end{array}$ & Podoc. & 11 & 0.92 & 0.10 & 0.44 & 0.17 & 0.64 \\
\hline 'Madagascar turtle' & Pelomed. & 12 & 0.95 & 0.00 & 0.46 & 0.01 & 1 \\
\hline $\begin{array}{l}\text { Phosphatochelys } \\
\text { tedfordi }\end{array}$ & Bothr. & 13 & 0.03 & 0.04 & 0.78 & 0.30 & 0.53 \\
\hline Puppigerus camperi & Chelon. & 14 & 0.01 & 0.98 & 0.94 & 0.82 & 0.28 \\
\hline $\begin{array}{l}\text { Rhinochelys } \\
\text { cantabrigiensis }\end{array}$ & Chelon. & 15 & 0.00 & 0.94 & 0.03 & 0.58 & 0.61 \\
\hline Sandownia harrisi & Angol. & 16 & 0.88 & 0.39 & 0.53 & 0.01 & 1 \\
\hline Ummulisani rutgersensis & Bothr. & 17 & 0.07 & 0.00 & 0.79 & 0.13 & 0.94 \\
\hline
\end{tabular}

The pFDA for extinct chelonioids (stem-cheloniids and protostegids) did not predict the capacity for neck retraction in this clade. Results show a mixed signal of 'absence' for some taxa (Desmatochelys lowii, Eochelone brabantica and Puppigerus camperi), but also 'equivocal' for others (Rhinochelys cantabrigiensis and Argillochelys antiqua). I find evidence of presence for marine habits akin to that of modern sea turtles in stem-cheloniids, and to a lesser degree in protostegids. With respect to feeding aspects of fossil chelonioids, $D$. lowii was predicted as likely having suction-feeding, and $R$. cantabrigiensis as 'present' for durophagy. In stem-cheloniids, A. antiqua was predicted as durophagous and 'equivocal' for 'herbivory', whereas E. brabantica had 'equivocal' predictions for all ecological factors concerning diet, and P. camperi was predicted 'presence' for both 'durophagy' and 'herbivory'. 
A

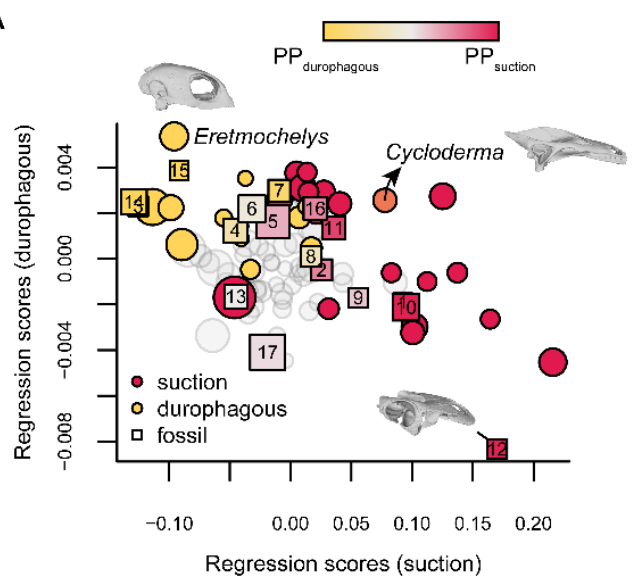

C

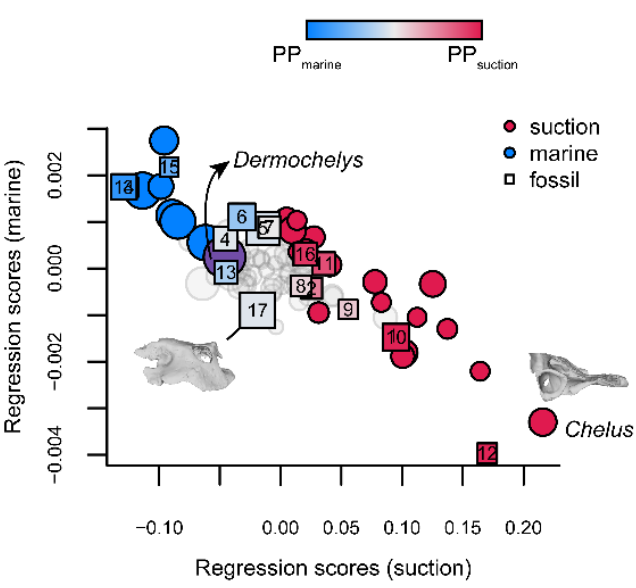

B

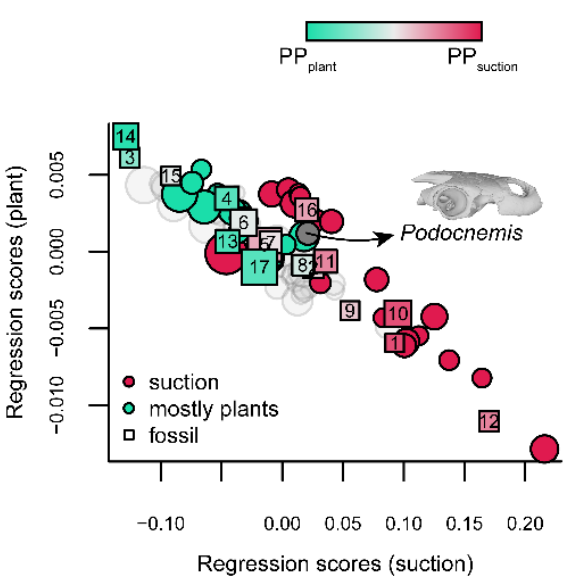

D

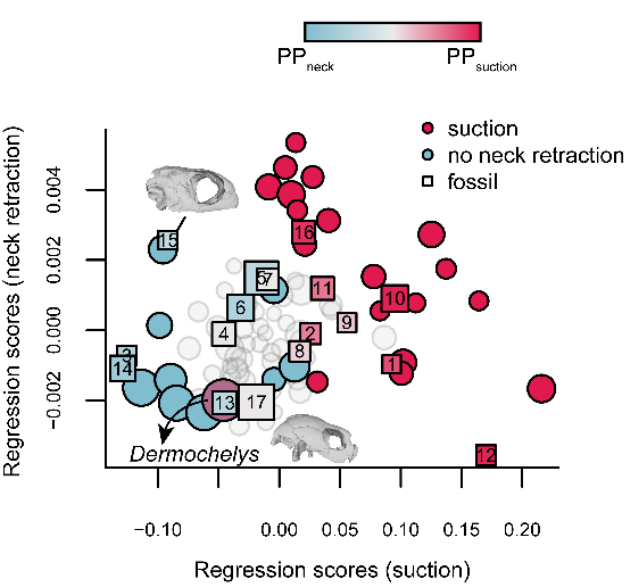

Figure 11. Ecological predictors of extant turtles' skull shape. Regression scores for the presence of 'suction-feeding' plotted against the regression scores of presences for (A) 'durophagy', (B) 'herbivory', (C) 'marine lifestyle', and absence of (D) 'neck retraction' capacity. Colour scale bars above plots represent calculated PP for fossil taxa only. Extant taxa are coloured according to presence/absence. Cycloderma (in A), Podocnemis unifilis (in B) and Dermochelys (in C and D) are coloured differently for being scored 'presence' for both attributes highlighted in the plots.

\section{Discussion}

\section{Form-function relationship in the skull of extant turtles}

My results show that aspects of the skull shape of extant turtles are best explained by multiple traits of their natural history, such as allometry, capacity of neck retraction, preference for hard food, and use of a suction mechanism (Table 1; Fig. 7), and that these relationships contain a moderate-to-strong phylogenetic signal (Pagel's $\lambda$ of 0.72 ). One of the most classical ecomorphological patterns of turtle skull suggested in literature 
concerns the environment where turtles feed (land/water), with several modifications described for the feeding apparatus including palate shape, tongue development, and hyoid stiffness (Bramble \& Wake 1985; Lauder 1985). In that regard, the significant results for the association between shape and 'feeding in water' (Appendix 6) are consistent with evolutionary changes associated with the capacity of feeding in the aquatic medium, a feature likely acquired during their transition from land to water in the Jurassic (Joyce \& Gauthier 2004). On the other hand, the lack of statistical significance in the model that included 'feeding on land' points to a strong phylogenetic structure in this relationship, considering most chelonians capable of terrestrial feeding belong to the same evolutionary lineage (Testudinidae), and suggesting this ecological aspect is likely ancestral to the group (Pritchard 1979; Bonin et al. 2006; Natchev et al. 2015). Yet, because 'feeding on land' or 'feeding in water' were not statistically significant when included in the same model (Appendix 6), I understand that both variables share similar information (Grafen \& Hails 2002), i.e. most turtles scored 'presence' for 'feeding on land' were also scored as not having 'feeding in water' and vice-versa. However, this could also result from a sample size effect, as few of the taxa in my sample were scored 'presence' for both these ecological categories (e.g. Cuora amboinensis and Glyptemys spp.).

The inverse relation between the shape scores for the presence of 'suction' and for the absence of 'neck retraction' (Fig. 7) suggests that turtles that cannot retract their necks (apart from Dermochelys coriacea) would be very unlikely to rely on a suction-feeding mechanism. In fact, it has been previously suggested that, at least for cryptodires, the evolution of their vertical neck retraction allowed a forward projection of the head when preying underwater (Anquetin et al. 2017b). Indeed, many of the turtles in my analyses that use suction-feeding do engage in a fast strike towards their prey (e.g. Chelus 
fimbriatus, Chelodina oblonga, Chitra indica; Van Damme \& Aerts 1997; Lemell et al. 2002). The negative correlation between skull size and the shape scores regarding the absence of 'neck retraction' suggests an allometric effect on the presence of this trait (Fig. 7c), which is corroborated by the results of my pGLS models explaining skull size among turtles (Fig. 8; Table 2). Taxa incapable of neck withdrawing have proportionally larger, as well as an anteroposteriorly shorter and dorsoventrally higher skulls, in addition to proportionally shorter basisphenoids, and very reduced posterodorsal and anteroventral emarginations. This could be potentially biased by marine turtles, most of which are larger than other taxa in my sample, although other macrocephalic turtles (e.g. Platysternon and Peltocephalus) possess some of the abovementioned features too. This corroborates previous findings that the posterior regions of the turtle skull are associated to neck mobility (Werneburg 2015; Ferreira et al. 2020).

Werneburg (2015) also pointed out to a significant correlation between the extent of both skull emarginations. Herein I corroborate his findings showing these aspects of the turtle skull are strongly associated, at least in taxa with non-retractile necks. Yet, despite showing the shape of both emarginations strongly correlate with one another among turtles in general (see 'Results' section; Fig. 6), this correlation does not concern the actual full extension of each emargination, given that the most extreme morphotypes of each case (e.g. Dermochelys coriacea with an extensively covered skull and Terrapene spp. with highly emarginated skulls; Gaffney 1979) are not contemplated in the extreme points of the variation axes. Moreover, I find evidence for effects of neck retraction capability on shape aspects other than the extent of emarginations, like greater height and smaller skull length (Fig. 9). These findings are consistent with previous assumptions that turtles with larger heads (macrocephalic) have less mobile necks, in contrast to those that rely on cervical movements for food capture (Van Damme \& Aerts 1997; Aerts et al. 
2001; Lemell et al. 2002). Instead, their larger and higher-domed skulls enhance the areas for the attachment of jaw closure muscles, allowing them to achieve stronger bites, a strategy that is opposite to 'suction' (Herrel et al. 2002; Nishizawa et al. 2010; Jones et al. 2012). Yet, this nearly complete coverage of the skull roof could also provide more protection to the head in taxa with incompletely retractile necks (Werneburg et al. 2015), possibly affording greater protection against predators (a hypothesis yet to be tested).

Effects of durophagy on skull shape of extant turtles include proportionally larger heads and an increase in the extent of the posterodorsal emargination. This emargination, besides being related to neck retraction capabilities, also accommodates mandibular adductor muscles. In this case, a larger head coupled with a more developed temporal emargination would provide more area and volumetric space for these muscles enabling higher bite forces (Herrel et al. 2002; but see Ferreira et al. 2020), and ultimately favouring a diet based on more heavily-armoured animals such as clams, mussels, or large crustaceans. Yet, it should be noticed that muscle architecture might also be an important factor controlling bite force (Herrel et al. 2002). In addition, Claude et al. (2004) showed that durophagous testudinoids possess wider palates, the same relationship found by Ferreira et al. (2015) for marine durophagous turtles. This independent broadening of the triturating surfaces shows that turtles, throughout their evolutionary history, evolved similar 'solutions' to deal with hard food, irrespective of the habitat where they feed.

I found evidence for dissociated effects of feeding in the water and using suction mechanisms on turtle skull shape (Table 1). This supports the conclusions of Lauder and Prendergast (1992), who had previously analysed the feeding kinematics of Chelydra serpentina and its 'negligible' use of suction-feeding, and that has also been demonstrated later for other aquatic turtles (e.g. Bels et al. 1998; Natchev et al. 2011; Kummer et al. 2017). The modifications in the skull shape of aquatic feeders are nevertheless consistent 
with the findings of Claude et al. (2004) especially concerning palate flattening, overall height decrease, and the extension of the posterior region of the skull (e.g. lengthening of supraoccipital and squamosals; Fig. 9d). That latter region accommodates mandibular depressor muscles, which are crucial during jaw opening (Schumacher 1973; Claude et al. 2004; Iordansky 2010). However, evolving suction-feeding seems to involve the reorganisation of a skull already adapted for aquatic feeding, over which I find practically no changes in features of the posterior region. For instance, no additional lengthening of squamosals and opisthotics is perceived on my warped shape for the presence of this trait (Fig. 9e). Instead, I find a slightly extra anterior development of the temporal emargination as well as anteroposteriorly longer parietals, coupled with a decreased skull height and narrower snouts.

In fact, all the abovementioned changes fit adaptations found in most turtles that use a quick strike of the head and wide gapes when hunting (Lemell et al. 2002). This is favoured by more flattened skulls, which diminish the water drag (Lemell et al. 2019) and more enlarged areas for the origin sites of abductor muscles that enable a more powerful oral depression and oesophageal expansion (Claude et al. 2004; Lemell et al. 2010). Other related features that are consistent with previous studies about morphological adaptations to suction-feeding include a lower-vaulted palate that lodges a less developed tongue (Lauder \& Prendergast 1992; Lemell et al. 2002) and mediolaterally narrower triturating surfaces that correspond to poorer biting performances (Herrel et al. 2002; Claude et al. 2004). Moreover, I find significant results for the joint presence of 'suction-feeding' and 'carnivory' in one of my models (Appendix 6), traits that are also significant when included alone, demonstrating their independent effects on skull shape. In a way, this goes against previous interpretations that this strategy is tightly linked to feeding on elusive prey (e.g. Pritchard 1984; Foth et al. 2017), suggesting instead it could have been exapted 
by other, non-strictly carnivorous turtles (e.g. Rhodin et al. 1981a; Lemell et al. 2000). Otherwise, all turtles that exhibit suction-feeding would have been scored as 'presence' with respect to feeding mostly on other animals. Furthermore, additional to these selected ecological traits present in my D-PGLS best model, the significant result of the phylogenetic PLS suggests the presence of a moderate co-evolutionary relationship between generalised aspects of diet and skull shape along the phylogenetic history of turtles (Fig. 4b).

\section{Morphofunctional aspects of the turtle skull}

My partial set of landmarks describing more morphofunctional aspects of turtle skulls is best explained by multiple factors that include allometry, lack of neck retraction, marine habits, and dietary predictors such as suction-feeding, durophagy and herbivory (Table 3). I was unable to detect significant results for the effect of 'feeding in water' or 'feeding on land' on shape. In fact, the predicted shape for the presence of this effect in the 'full dataset' shows that many morphological changes are associated to structures that were not contemplated in the 'partial dataset' (e.g. lengthening of squamosal and supraoccipital bones, or palate flattening; see 'Results: full dataset' section). My results using this morphofuncional set of cranial landmarks show that, for instance, the capability of neck retraction is not only correlated to the extent of the posterodorsal emargination, but also to a relative shorter and higher skull is correlated to the lack of that trait.

It is noteworthy that in the relationship between the predicted shape scores for marine habits (skulls with increased height and decreased length) and 'suction' (more flattened and longer skulls), Dermochelys coriacea appears as an intermediate point, having the most negative value for both traits (Fig. 11c). This species represents the only living dermochelyid taxon, and some of its skeletal features are considered to resemble general embryonic stages of turtles (Rhodin et al. 1981b), whereas some cranial aspects 
are similar to those of stem-chelonioids (e.g. the lack of a secondary palate; Matzke 2009). Also, Nishizawa et al. (2010) suggested greater importance of suction-feeding for younger green turtles (Chelonia mydas) in comparison to adults, and revealed ontogenetic modifications in skull shape coupled with the progressive decrease in the use of this foodcapturing mechanism. In this sense, the retention of suction in adults D. coriacea could be interpreted as another paedomorphic trait of this species, but further studies may shed light on this issue.

The effects of 'durophagy' and 'herbivory' on skull shape show some similarities, like the mediolateral expansion of the triturating surfaces, present in turtles that have these dietary preferences, although in herbivorous taxa these surfaces are usually less expanded and accompanied by serrated accessory ridges (Pritchard 1979; Foth et al. 2017). Those effects differ in that the predicted shape for 'herbivory' shows increase in both skull length and height, in contrast to proportionally shorter skulls for 'durophagy' (when compared to herbivores). Yet, I failed to predict the appearance of fine accessory ridges on the palate of the 'herbivorous' shape (Fig. 10), which might reflect a methodological problem related to the density of surface landmarks placed on the palate. There is a slight modification in the palate of the predicted shape for 'herbivory' though, involving an elevation of the maxillae close to the anterior border of the triturating surface (Fig. 10d), a region where part of these ridges is indeed located.

\section{Skull shape as a palaeoecological proxy}

My findings show that I can predict with relative confidence the actual ecological attributes of living turtles based on a subset of cranial landmarks that mostly reflect morphofunctional aspects of the skull (Appendix 2). However, some misclassifications 
in my pFDA results indicate predictions should be made with caution. For instance, the relatively flat skulls of Chelydra serpentina and Podocnemis expansa were predicted as 'presence' for the use of suction-feeding. Indeed, the skull shape of C. serpentina is considered well-adapted for its ambush predatory strategy (Lauder \& Prendergast 1992), which is also a strategy used by turtles actually scored 'presence' for this trait (e.g. Chelus fimbriatus; Lemell et al. 2002). On the other hand, the skull of P. expansa, although not a suction-feeder, is very similar to $P$. unifilis, which uses a specialised suction-feeding mechanism to feed on particles on the water surface (Belkin \& Gans 1968; Rhodin et al. 1981a). However, Lauder and Prendergast (1992) showed a negligible effect of suction for $C$. serpetina, and field observations of $P$. expansa did not record the same suction behaviour observed for $P$. unifilis (Rhodin et al. 1981a). Therefore, I recommend caution when using morphological features of extant taxa to interpret ecological aspects of fossils.

The pFDA results for fossils corroborate some previous qualitative inferences based on data of extant species. For instance, a durophagous diet was predicted for the stem-turtle Eubaena cephalica (Table 4), which is consistent with previous assumptions of molluscivory for this taxon, based on its expanded triturating surfaces (Joyce \& Lyson 2015). On the other hand, I did not find unequivocal evidence for the presence of such preference for other broad-jawed taxa inferred to have similar specialisation, such as Galianemys emringeri and Sandownia harrisi (Gaffney et al. 2006; Evers \& Joyce 2020). Of course, this does not mean the palate shape of these turtles did not enable them to crush harder food items, especially considering the up to $18 \%$ misclassified taxa. Nevertheless, it is important to stress that many living species also have broader triturating surfaces and are not durophagous, like the kinosternid Sternotherus odoratus (common musk turtle). Unlike S. minor (a closely related durophagous species), it has more omnivorous tendencies (Mahmoud 1968; Ernst 1986), although exhibiting a similar mediolaterally 
expanded palate (Bever 2009). This could otherwise reflect historical influence (i.e. phylogeny) on palate shape (Sasaki et al. 2006) or the capability instead of a specialization for feeding on hard prey.

I find evidence of herbivory in nearshore marine pelomedusoids, namely Bairdemys hartsteini, Phosphatochelys tedfordi and Ummulisani rutgersensis. Foth et al. (2017) were the first authors to predict herbivorous diets for the latter two taxa, although that result was interpreted as 'counterintuitive' at the time (Foth et al. 2017, p. 319), for such inference had never come up in literature before. My findings are in accordance to theirs, and therefore provide further support for an earlier and convergent evolution of this trait in those pelomedusoids, paralleled by extant podocnemidids (Eisemberg et al. 2017). Yet, this is the first prediction of herbivory for stereogenyine podocnemidids (a group that includes all extinct nearshore podocnemidids; Gaffney et al. 2011; Ferreira et al. 2015). The presence of this dietary preference in Bairdemys, a lineage that likely mostly comprises durophages (Ferreira et al. 2015), could reflect niche partitioning like that seen in modern sea turtles in the past analogue of that group (e.g. Parham \& Pyenson 2010).

I also found evidence that corroborates marine habits for stem-cheloniids akin to that of modern sea turtles (Table 4). This is in accordance with their predicted lifestyle as inferred from other aspects of their skeletal morphology like pectoral girdle and forelimbs (e.g. Evers et al. 2019a), as well as from the depositional environment of their fossil localities (e.g. Brinkman et al. 2006). This was not the case, however, for the pFDA results of marine habits in protostegids. Both protostegids (Desmatochelys lowii and Rhinochelys cantabrigiensis) were predicted as only likely having this trait (Table 4), although studies on chelonioid anatomy argue that postcranial skeletal adaptations to this lifestyle appeared early in the group evolution (Raselli 2018; Evers et al. 2019a). It is 
important to notice that my sample of stem-cheloniids is comprised only of more crownwardly nested Cenozoic taxa, the skulls of which resemble those of recent forms. In this sense, although accounting for phylogenetic bias by using pFDA, I still recover a strong phylogenetic inertia scenario for the evolution of marine habits in the chelonioid lineage. Likewise, I was not able to predict other turtles as adapted to marine ecosystems, namely angolachelonians and fossil pleurodires, which have been previously inferred as 'marine' or at least 'nearshore marine' based on isotopic signature (Anquetin et al. 2017a), limb morphology (Weems \& Knight 2013), or even fossilised eggshells (Winkler \& Sánchez-Villagra 2006). Indeed, skull shape aspects of these turtles deviate in greater or lesser degree from the predicted 'marine' shape (Fig. 10e), which might explain their low posterior probability of exhibiting this trait (Table 4) and be an indicative that such predicted shape for marine habits instead represents a 'Chelonioidea-like' skull shape.

My predictions for the presence of 'suction' in some turtles are consistent with previous inferences for species with very flattened skulls, e.g. Labrostochelys galkini. Based on its skull shape, Gaffney et al. (2006) suggested L. galkini fed similarly to some modern trionychids that seize their prey using a rapid strike of the head coupled with a wide gape, e.g. Chitra indica (Das \& Singh 2009). In both cases, the skulls have low profile, anteriorly placed orbits, and a narrower anterior angle of the snout, which according to Pritchard (1984) represent a suit of adaptations to this feeding mode. On the other hand, other predictions for the presence of 'suction-feeding' were unexpected. These include the predictions for Sandownia harrisi and Lapparentemys vilavilensis (Table 4). Foth et al. (2017) recovered L. vilavilensis as a 'gape and suction feeder' based on the ventral aspect of the skull, but with divergent classifications for the other views (lateral and dorsal). Despite finding this trait in stem-podocnemidids, it is important to stress the great similarity between the skulls of $L$. vilavilensis and the extant 
podocnemidine taxa in my sample (Podocnemis expansa and P. unifilis), for both of which the $\mathrm{PP}_{\text {suction }}$ pointed to the presence of such trait (Appendix 2). Yet, only Po. unifilis has been recorded as adopting such feeding strategy (Rhodin et al. 1981a).

The prediction of 'suction-feeding' for $S$. harrisi had never been proposed before, but cranial aspects such as a wide skull, coupled with small orbits placed very anteriorly, match some of those in the predicted shape for 'suction' (Fig. 10b). Its orbits size and position, as well as its broader palate could explain its similar regression scores for 'suction' to those of trionychids (Fig. 11a-d), some of which also exhibit these features (Dalrymple 1977; Brinkman et al. 1993; Pritchard 1993). Lastly, the presence of 'suction' in the xinjiangchelyid Annemys sp. is consistent with the aquatic palaeoecology inferred for these turtles (Rabi et al. 2014). This indicates that the evolution of a feeding strategy very common to aquatic turtles (Lauder 1985; Lauder \& Prendergast 1992; Claude et al. 2004) took place relatively early in the occupation of freshwater habitats by the group during the Jurassic (Joyce \& Gauthier 2004).

The high classification accuracy rate (97.3\%) for living species regarding an important feature of turtle natural history such as neck retraction capacity (Werneburg 2015; Anquetin et al. 2017b) provides a strong basis for further inference of this trait in fossils. My predictions for extinct chelonioids indicate that those in my sample were at least likely incapable of retracting their necks (Table 4). Taxa with large skulls, e.g. Desmatochelys lowii, Eochelone brabantica and Puppigerus camperi, were classified as unable to retract their necks like modern sea turtles, whereas species with smaller skulls such as Rhinochelys cantabrigiensis and Argillochelys antiqua were considered as probably unable of fully withdrawing their necks, emphasising my results of a negative allometric effect on the presence of this trait (Fig. 7c; Table 2). It should be noticed that other morphological aspects of modern sea turtles such as dorsoventral depression of the 
carapace (also seen in Platysternon megacephalum) and the stout cervical vertebrae are also related to this feature (Pritchard 1979). Because of this, different past authors based their assumptions of neck retraction capacity for extinct taxa (e.g. Zangerl 1953; Gaffney 1975; Sterli \& de la Fuente 2011).

Moreover, the observed general morphological trends towards the lack of neck retraction allows me to extrapolate this condition to some fossils not contemplated in my sample, both stem- (e.g. Kallokibotion bajazidi) and crown- (e.g. Nanhsiungchelys wuchingensis, Dacquemys paleomorpha) taxa, based on their overall cranial shape (Gaffney et al. 2002; Tong \& Li 2019; Martín-Jiménez et al. 2020). My pFDA predictions of neck retraction to be present in more crownward stem-turtles (e.g. Eubaena cephalica, Annemys sp.) are consistent with the hypothesis that increased neck mobility occurred early in the evolutionary history of turtles (Werneburg et al. 2015), and not only later during the Cretaceous period (contra Gaffney 1975), with reversals in unrelated modern groups (Ferreira et al. 2020).

\section{Convergent ecomorphological scenarios in marine lineages}

Independent lineages of turtles have colonised marine ecosystems multiple times along their evolutionary history (Gaffney et al. 2006; Rabi et al. 2012; Ferreira et al. 2015; Raselli 2018; Evers \& Benson 2019; Gentry et al. 2019). Although the most noticeable skeletal specialisation to a marine lifestyle comprises the full modification of limbs into flippers as seen in chelonioids (Evers et al. 2019a), some modifications in the skull have also been proposed to evolve along this habitat shift (Hirayama 1998; Ferreira et al. 2015). The invasion of these ecosystems likely provided the opportunity to occupy vacant niches left by other marine lineages and access to different sorts of resources (e.g. Stubbs \& 
Benton 2016; Reeves et al. 2020), which could have been important triggers of morphological innovation.

For instance, the great similarity between the shape regression scores of the protostegid Rhinochelys cantabrigiensis and the spongivorous (Meylan 1988) cheloniid Eretmochelys imbricata suggests the acquisition of a comparable durophagous specialisation early in sea turtle evolution. Both have a somewhat anteroposteriorly elongated palate, although $R$. cantabrigiensis only exhibits an incipient development of the secondary palate. The likely presence of suction-feeding in the large pelagic protostegid Desmatochelys lowii hints at another convergence between this taxon and the extant giant suction-feeder Dermochelys coriacea (Bels et al. 1998). Considering protostegids as sister-group to crown-Chelonioidea (as in Evers et al. 2019a), suctionfeeding would be ancestral to all chelonioids, being maintained in the pan-Dermochelys lineage and subsequently lost in pan-cheloniids. Indeed, the skull morphology of Toxochelys sp. (sister-taxon to all chelonioids; Evers et al. 2019a) does present some putative morphological adaptations indicative of suction-feeding (e.g. flat skull, anterodorsal orbits and a narrow palate; Matzke 2009). Alternatively, if protostegids were placed along the stem lineage of dermochelyids (e.g. Raselli 2018; Evers \& Benson 2019), this would require suction-feeding to have evolved only once in chelonioids as a possible 'pan-dermochelyid' trait, in any case providing further support for the presence of such feeding mode to other large protostegids such as Ocepechelon bouyai (Bardet et al. 2013).

I corroborate the interpretations of Parham and Pyenson (2010) of iterative evolution of feeding strategies among pan-cheloniids, but reinforce the difficulty of assigning detailed dietary preferences to extinct members of the group based on modern analogues. This difficulty becomes more apparent when looking at the similar predicted 
probabilities for both 'durophagy' and 'herbivory' seen in taxa like Puppigerus camperi and Eochelone brabantica compared to a mixed signal of predictions for extant taxa such as the herbivorous Chelonia mydas (predicted as durophagous) and the faunivorous Natator depressus (predicted as herbivorous; Appendix 2). According to Parham and Pyenson (2010), both $P$. camperi and E. brabantica would not fit the two main ecomorphs they identified for sea turtles ('crushing', as in the hyper-durophages such as carettine cheloniids; and 'shearing', as in the herbivorous C. mydas), and therefore this ambiguous signal for the extinct taxa could indicate the lack of a more specialised feeding apparatus. On the other hand, I find unequivocal evidence for durophagy in Argillochelys antiqua, suggesting the evolution of niche partitioning within the Argillochelys lineage, since $A$. cuneiceps (which was not included in my analyses) was hypothesised as having a 'shearing' ecomorph (Parham \& Pyenson 2010).

Additionally, according to my results, suction-feeding in marine turtles (restricted to $D$. coriacea among living species) evolved at least twice in unrelated non-chelonioid lineages in the past, once in angolachelonians (Sandownia harrisi) and at least one time in bothremydids (Fig. 12). This food-capturing mechanism in the bothremydid Labrostochelys galkini (and likely in Araiochelys hirayamai) extends its presence to another pleurodiran clade, being previously reported for podocnemidids (Belkin \& Gans 1968; Rhodin et al. 1981a), pelomedusids (Lemell et al. 2000), and chelids (Lemell et al. 2002). The likely probability of durophagy in S. harrisi (Table 4), coupled with its suction-feeding mechanism suggests an extinct nearshore marine analogue to the extant macrocephalic Dogania subplana, a durophagous trionychid which also possesses a wide skull, a broadened palate, and dorsally oriented orbits (Pritchard 1993; 2001). In the end, I provide the first statistical evidence of suction-feeders among fossil marine reptiles, which has already been discarded for other extinct lineages with pelagic lifestyle such as 
ichthyosaurs based on cranial and hyoid correlates of suction-feeding (Motani et al. 2013;

2015), but inferred for benthic taxa such as some sauropterygian groups based on overall skull morphology (Rieppel 2002).

A

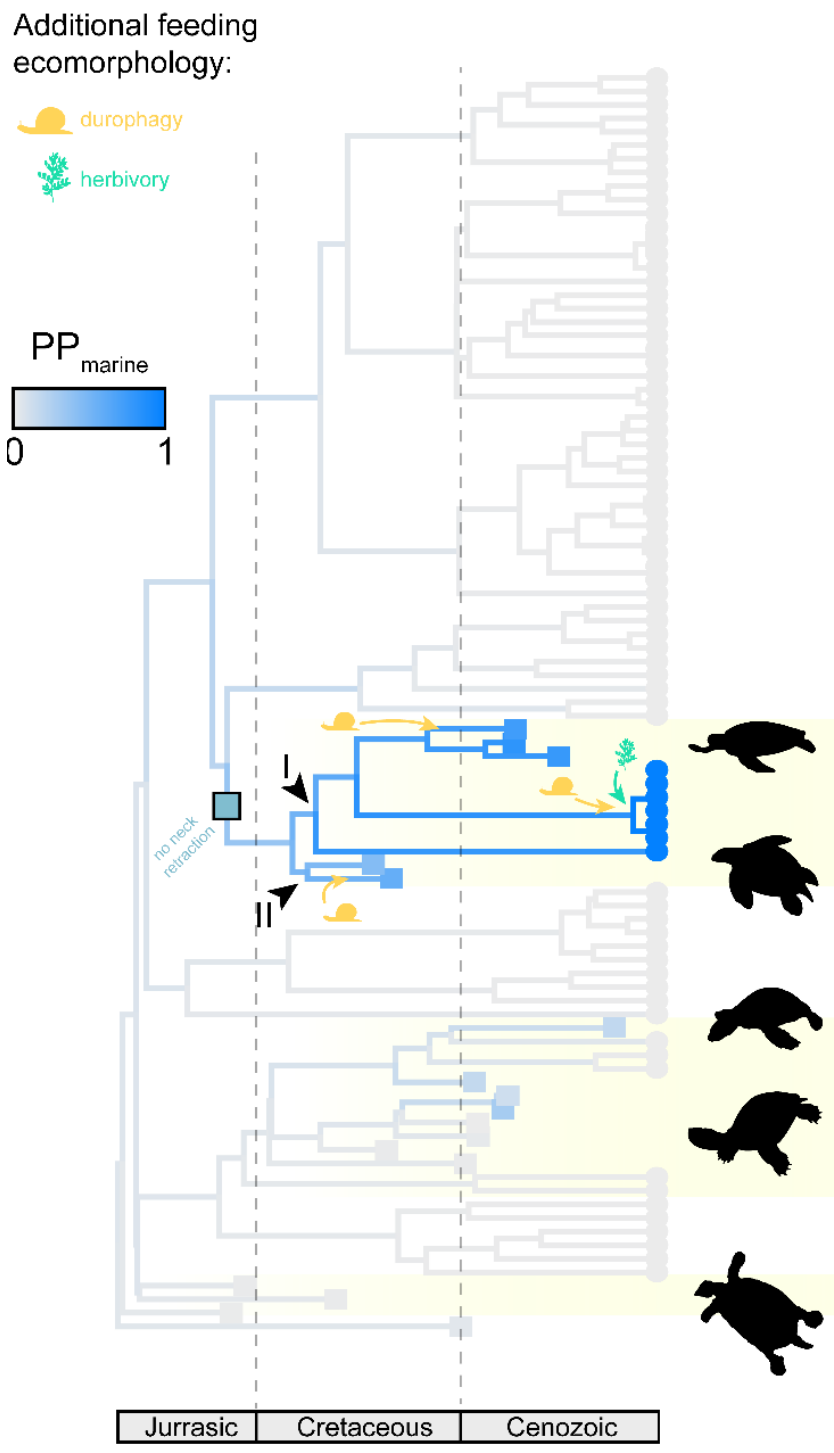

B
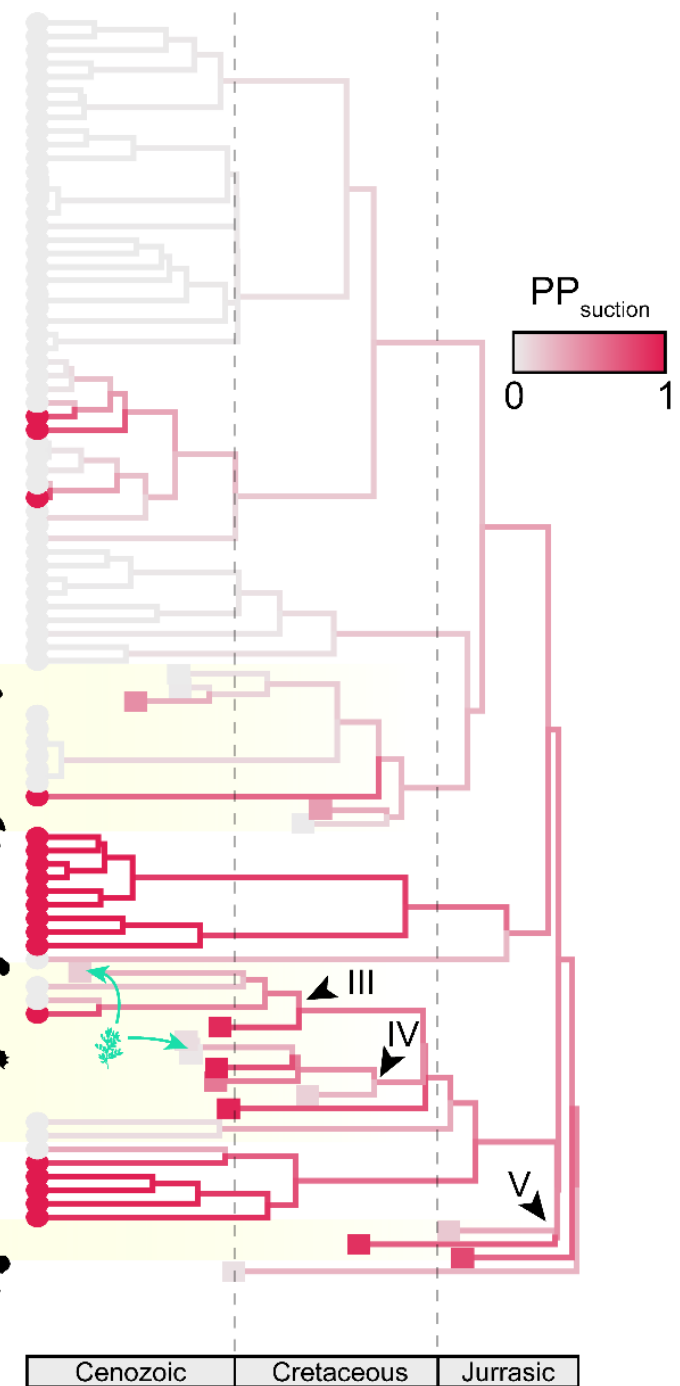

Figure 12. Evolution of feeding ecomorphologies in different marine clades. Posterior probabilities (PP) for the presence of (A) 'marine' and (B) 'suction' traits mapped on my topology. Scale bars indicate PPs calculated for fossils only, whereas extant taxa are scored as absence/presence. Highlighted in yellow are lineages hypothesised to have evolved 'marine' or 'nearshore marine' lifestyles such as angolachelonians (bottom), pelomedusoids (middle), and chelonioids (top), in which numbered nodes correspond to (I) crown-Chelonioidea, (II) Protostegidae, (III) Podocnemididae, (IV) Bothremydidae, and (V) Angolachelonia. 
The predictions for marine pelomedusoids corroborate previous interpretations of a greater diversity of ecological attributes in the past if compared to recent forms (Gaffney et al. 2006; Ferreira et al. 2015; Foth et al. 2017). Besides the presence of suction-feeding in Labrostochelys galkini, other unrelated pelomedusoid taxa evolved herbivory as extinct analogues to the modern Chelonia mydas, namely the podocnemidid Bairdemys hartsteini and the bothremydids Ummulisani rutgersensis and Phosphatochelys tedfordi. This argues for a broader niche occupation by, for instance, the hypothesised durophagous Bairdemys (Gaffney et al. 2011; Ferreira et al. 2015) and for previously unaccounted herbivorous diets for bothremydids (but see Foth et al. 2017). In fact, this trait might have been more common in taphrosphyine bothremydids (lineage that includes $U$. rutgersensis and P. tedfordi), considering other representatives of this clade (e.g. Acleistochelys maliensis, Azabbaremys moragjonesi; Gaffney et al. 2006; 2007; O’Leary et al. 2019) exhibited from small corrugations to accessory ridges on the triturating surface as in herbivorous turtles (Pritchard 1979). Whereas the evolution of herbivory in B. hartsteini could mean a reversion to the hypothetical herbivorous ancestral condition of podocnemidids (Moll \& Moll 2004), this dietary preference possibly has a single evolutionary origin (in taphrosphyines) amongst bothremydids.

Overall, I find that apart from stem-cheloniids, all the remaining extinct marine turtles have a skull shape that deviate to some degree from that of modern sea turtles. This shows that despite certainly (e.g. protostegids; Tong et al. 2006; Evers et al. 2019a) or possibly (e.g. marine pleurodires; Weems \& Knight 2013; Yoshida \& Hirayama 2015) presenting the key appendicular adaptations to a full marine lifestyle, the skulls of these species lack characters consistently present in cheloniids (e.g. no secondary palate in protostegids, smaller orbits in pleurodires; Gaffney et al. 2006; Matzke 2009). This might indicate that such characteristics are independent of a marine lifestyle and that they are 
probably associated to other aspects of the natural history of sea turtles. Furthermore, I show that marine turtles have not always been unable to retract their necks, indicating that the absence of such trait in chelonioids is possibly unique among marine chelonians.

\section{Conclusions}

Compared to their diapsid ancestors, turtles have a deeply modified skull that throughout their evolutionary history was prone to different selective pressures. This leads to modifications directly (e.g. type of food, feeding medium; Claude et al. 2004; Werneburg 2012; 2019) or indirectly (e.g. evolution of neck and carapace anatomy; Werneburg 2015; Werneburg \& Maier 2019; Ferreira et al. 2020) associated to skull anatomy, resulting in a diverse array of shapes (e.g. Gaffney 1979; Pritchard 1979; Werneburg 2012; Ferreira \& Werneburg 2019). I provided here the first study to explicitly test hypotheses of skull shape correlation with different ecological factors, applying multivariate statistic on 3D CT-data and taking their historical relationships into account.

My comparative analysis of the turtle skull indicates that besides phylogenetic constraints, a set of numerous ecological factors act in parallel affecting cranial shape, including allometry and dietary traits (suction-feeding, durophagy and herbivory), but that likewise having non-retractile necks also plays an important role in shaping the skull. Although I also found that the marine trait influences skull shape (Table 3; Appendix 6), it should be emphasised that my prediction for its presence in fossils was based exclusively on modern taxa that exhibit it, in this case chelonioid turtles. Therefore, because only a single monophyletic group of extant turtles are adapted to life on sea, it is possible that my findings depict instead a relationship of shape with the clade (Chelonioidea) rather than with ecology (i.e. marine habits), which is further hinted at by 
my pFDA results (Table 4), in which only extinct cheloniids are unequivocally inferred as being marine. Nevertheless, it is important to stress that my study demonstrates major morphological aspects of the turtle skull can be used as proxies for inferring functional attributes in extinct taxa, but I recommend caution when doing so, given the great ecological variation between some closely related species (e.g. Rhodin et al. 1981a; Herrel et al. 2002). With that mind, it should be understood that when hypothesis testing is not available, inferred ecomorphological associations remain but speculative.

Finally, considering the multiple times turtles shifted their habitats towards marine ecosystems, my findings suggest a scenario in which some extinct lineages evolved the capacity to inhabit such environment without modifying skull shape aspects that match those found in modern marine chelonians. Nonetheless, they were similarly adapted to feeding ecomorphologies convergent to those observed in living sea turtles (Fig. 12). In that respect, although competition with durophagous chelonioids might have contributed to the extinction of marine pleurodires in the past (Ferreira et al. 2015), their overall greater ecomorphological diversity as evidenced by my results suggests additional unaccounted factors could also have influenced their demise.

\section{References}

Adams, D.C. (2014) A method for assessing phylogenetic least squares models for shape and other high-dimensional multivariate data. Evolution, 68, 2675-2688.

Adams, D.C., Collyer, M.L. (2018) Multivariate phylogenetic comparative methods: evaluations, comparisons, and recommendations. Systematic Biology, 67(1), 14-31.

Adams, D.C., Collyer, M.L. (2019) Phylogenetic comparative methods and the evolution of multivariate phenotypes. Annual Review of Ecology, Evolution, and Systematics, 50, 405425 .

Adams, D.C., Felice, R.N. (2014) Assessing trait covariation and morphological integration on phylogenies using evolutionary covariance matrices. PLoS ONE, 9(4), e94335.

Adams, D.C. Rohlf, F.J., Slice, D.E. (2013) A field comes of age: geometric morphometrics in the 21st century. Hystrix, the Italian Journal of Mammalogy, 24(1), 7-14. 
Adams, D.C., Collyer, M.L., Kaliontzopoulou, A. (2020) Geomorph: Software for geometric morphometric analyses. $\mathrm{R}$ package version 3.2.1. https://cran.rproject.org/package $=$ geomorph.

Aerts, P., Van Damme, J., Herrel, A. (2001) Intrinsic mechanics and control of fast cranio-cervical movements in aquatic feeding turtles. American Zoologist, 41(6), 1299-1310.

Akaike, H. (1974) A new look at the statistical model identification. IEEE Transactions on Automatic Control, 19, 716-723.

Alcalde, L., Derocco, N.N., Rosset, S.D. (2010) Feeding in syntopy: diet of Hydromedusa tectifera and Phrynops hilarii (Chelidae). Chelonian Conservation and Biology, 9(1), 3344.

Anquetin, J., Püntener, C., Joyce, W.G. (2017a) A review of the fossil record of turtles of the clade Thalassochelydia. Bulletin of the Peabody Museum of Natural History, 58(2), 317 369 .

Anquetin, J., Tong, H., Claude, J. (2017b) A Jurassic stem pleurodire sheds light on the functional origin of neck retraction in turtles. Scientific Reports, 7(1), 1-10.

Arbour, J.H., Curtis, A.A., Santana, S.E. (2019) Signatures of echolocation and dietary ecology in the adaptive evolution of skull shape in bats. Nature Communications, 10(1), 1-13.

Bardet, N., Jalil, N.E., de Broin, F.L., Germain, D., Lambert, O., Amaghzaz, M. (2013) A giant chelonioid turtle from the Late Cretaceous of Morocco with a suction feeding apparatus unique among tetrapods. PLOS ONE, 8(7), e63586.

Bardua, C., Felice, R.N., Watanabe, A. Fabre, A.C., Goswami, A. (2019) A practical guide to sliding and surface semilandmarks in morphometric analyses. Integrative Organismal Biology, 1(1), obz016.

Barr W.A. (2018) Ecomorphology. In Croft D., Su D., Simpson S. (eds.), Methods in Paleoecology, Vertebrate Paleobiology and Paleoanthropology. Springer, pp. 339-349.

Belkin, D.A., Gans, C. (1968) An unusual chelonian feeding niche. Ecology, 49(3), 768-769.

Bels, V.L., Davenport, J., Renous, S. (1998) Food ingestion in the estuarine turtle Malaclemys terrapin: comparison with the marine leatherback turtle Dermochelys coriacea. Journal of the Marine Biological Association of the United Kingdom, 78(3), 953-972.

Benoit, J., Legendre, L.J., Farke, A.A., Neenan, J.M., Mennecart, B., Costeur, L., Merigeaud, S., Manger, P.R. (2020) A test of the lateral semicircular canal correlation to head posture, diet and other biological traits in "ungulate" mammals. Scientific Reports, 10(1), 19602.

Benson, R.B.J., Domokos, G., Várkonyi, P.L., Reisz, R.R. (2011) Shell geometry and habitat determination in extinct and extant turtles (Reptilia: Testudinata). Paleobiology, 37(4), $547-562$.

Benson, R.B.J., Starmer-Jones, E., Close, R.A., Walsh, S.A. (2017) Comparative analysis of vestibular ecomorphology in birds. Journal of Anatomy, 231(6), 990-1018.

Berry, J.F., Iverson, J.B. (2011) Kinosternon scorpioides (Linnaeus 1766) - Scorpion Mud Turtle. In Rhodin, A.G.J., Pritchard, P.C.H., van Dijk, P.P., Saumure, R.A., Buhlmann, K.A., Iverson, J.B., Mittermeier, R.A. (eds.), Conservation Biology of Freshwater Turtles and Tortoises: A Compilation Project of the IUCN/SSC Tortoise and Freshwater Turtle Specialist Group. Chelonian Research Monographs, 5, pp. 063.1-063.15. doi:10.3854/crm.5.063.scorpioides.v1.2011. 
Bertolero, A., Busack, S.D. (2017) Mauremys leprosa (Schoepff in Schweigger 1812) Mediterranean Pond Turtle, Spanish Terrapin, Mediterranean Stripe-necked Terrapin. In Rhodin, A.G.J., Iverson, J.B., van Dijk, P.P., Buhlmann, K.A., Pritchard, P.C.H., Mittermeier, R.A. (eds.), Conservation Biology of Freshwater Turtles and Tortoises: A Compilation Project of the IUCN/SSC Tortoise and Freshwater Turtle Specialist Group. Chelonian Research Monographs, 5(10), pp. 102.1-19. doi:10.3854/crm.5.102.leprosa.v1.2017.

Bever, G.S. (2008) Comparative growth in the postnatal skull of the extant North American turtle Pseudemys texana (Testudinoidea: Emydidae). Acta Zoologica, 89(2), 107-131.

Bever, G.S. (2009) Postnatal ontogeny of the skull in the extant North American turtle Sternotherus odoratus (Cryptodira: Kinosternidae). Bulletin of the American Museum of Natural History, 330, 1-97.

Bjorndal, K.A. (1979) Cellulose digestion and volatile fatty acid production in the green turtle, Chelonia mydas. Comparative Biochemistry and Physiology--Part A: Physiology, 63(1), 127-133.

Bjorndal, K.A. (1987) Digestive efficiency in a temperate herbivorous reptile, Gopherus polyphemus. Copeia, 714-720.

Blake, S., Wikelski, M., Cabrera, F., Guezou, A., Silva, M., Sadeghayobi, E., Yackulic, C.B., Jaramillo, P. (2012) Seed dispersal by Galápagos tortoises. Journal of Biogeography, 39(11), 1961-1972.

Bonin, F., Devaux, B., Dupré, A. (2006) Turtles of the World. Johns Hopkins University Press.

Bookstein, F.L. (1991) Morphometric tools for landmark data. Cambridge University Press, New York.

Bramble, D.M., Wake, D.B. (1985) Feeding mechanisms of lower tetrapods. In Hildebrand, M., Bramble, D.M., Liem, K.F., Wake, D.B. (eds.), Functional Vertebrate Morphology, pp. 230-261.

Brinkman, D., Hart, M., Jamniczky, H., Colbert, M. (2006) Nichollsemys baieri gen. et sp. nov, a primitive chelonioid turtle from the late Campanian of North America. Paludicola, 5(4), 111-124.

Brinkman, D.B., Nessov, L.A., Peng, J.H. (1993) Khunnuchelys gen. nov., a new trionychid (Testudines: Trionychidae) from the Late Cretaceous of Inner Mongolia and Uzbekistan. Canadian Journal of Earth Sciences, 30(10), 2214-2223.

Burnham, K.P., Anderson, D. (2002) Model Selection and Multi-Model Inference: a Practical Information-Theoretic Approach. Springer, New York, 488 p.

Cadena, E., Parham, J.F. (2015) Oldest known marine turtle? A new protostegid from the Lower Cretaceous of Colombia. PaleoBios, 32(1), 1-421.

Chapelle, K.E.J., Benson, R.B.J., Stiegler, J., Otero, A., Zhao, Q., Choiniere, J.N. (2020) A quantitative method for inferring locomotory shifts in amniotes during ontogeny, its application to dinosaurs and its bearing on the evolution of posture. Palaeontology, 63(2), 229-242.

Claude, J., Paradis, E., Tong, H., Auffray, J.C. (2003) A geometric morphometric assessment of the effects of environment and cladogenesis on the evolution of the turtle shell. Biological Journal of the Linnean Society, 79(3), 485-501. 
Claude, J., Pritchard, P.C., Tong, H., Paradis, E., Auffray, J.C. (2004) Ecological correlates and evolutionary divergence in the skull of turtles: a geometric morphometric assessment. Systematic Biology, 53(6), 933-948.

Clavel, J., Morlon H. (2020) Reliable phylogenetic regressions for multivariate comparative data: illustration with the MANOVA and application to the effect of diet on mandible morphology in phyllostomid bats. Systematic Biology, 69(5), 927-943.

Collyer, M.L., Adams, D.C. (2018) RRPP: An R package for fitting linear models to highdimensional data using residual randomization. Methods in Ecology and Evolution, 9(2), 1772-1779.

Collyer, M.L., Adams, D.C. (2020) RRPP: Linear Model Evaluation with Randomized Residuals in a Permutation Procedure. https://CRAN.R-project.org/package=RRPP.

Cooney, C.R., Bright, J.A., Capp, E.J., Chira, A.M., Hughes, E.C., Moody, C.J., Nouri, L.O., Varley, Z.K., Thomas, G.H. (2017) Mega-evolutionary dynamics of the adaptive radiation of birds. Nature, 542(7641), 344-347.

Corn, K.A., Martinez, C.M., Burress, E.D., Wainwright, P.C. (2020) A multifunction trade-off has constraining effects on the evolution of form and function. Systematic Biology, DOI: https://doi.org/10.1093/sysbio/syaa091.

Dalrymple, G.H. (1977) Intraspecific variation in the cranial feeding mechanism of turtles of the genus Trionyx (Reptilia, Testudines, Trionychidae). Journal of Herpetology, 11(3), 255285 .

Dalrymple, G.H. (1979) Packaging problems of head retraction in trionychid turtles. Copeia, 1979(4), 655-660.

Das, I., Singh, S. (2009) Chitra indica (Gray 1830) - narrow-headed softshell turtle. In Rhodin, A.G.J., Pritchard, P.C.H., van Dijk, P.P., Saumure, R.A., Buhlmann, K.A., Iverson, J.B., Mittermeier, R.A. (eds.), Conservation Biology of Freshwater Turtles and Tortoises: A Compilation Project of the IUCN/SSC Tortoise and Freshwater Turtle Specialist Group. Chelonian Research Monographs, 5, pp. 027.1-027.7. doi:10.3854/crm.5.027.indica.v1.2009.

Davenport, J., Wong, T.M., East, J. (1992) Feeding and digestion in the omnivorous estuarine turtle Batagur baska (Gray). Herpetological Journal, 2(4),133-139.

Depecker, M., Berge, C., Penin, X., Renous, S. (2006) Geometric morphometrics of the shoulder girdle in extant turtles (Chelonii). Journal of Anatomy, 208(1), 35-45.

Dickson, B.V., Pierce, S.E. (2019) Functional performance of turtle humerus shape across an ecological adaptive landscape. Evolution, 73(6), 1265-1277.

Drake, A.G., Klingenberg, C.P. (2008) The pace of morphological change: historical transformation of skull shape in St Bernard dogs. Proceedings of the Royal Society B: Biological Sciences, 275(1630), 71-76.

Dryden, I.L., Mardia, K.V. (2016) Statistical shape analysis: with applications in R. John Wiley \& Sons, UK, $482 \mathrm{p}$.

Dumont, M., Wall, C.E., Botton-Divet, L., Goswami, A., Peigné, S., Fabre, A.C. (2016) Do functional demands associated with locomotor habitat, diet, and activity pattern drive skull shape evolution in musteloid carnivorans?. Biological Journal of the Linnean Society, 117(4), 858-878.

Dziomber, L., Joyce, W.G., Foth, C. (2020) The ecomorphology of the shell of extant turtles and its applications for fossil turtles. PeerJ, 8, e10490. 
Ebel, R., Müller, J., Ramm, T., Hipsley, C., Amson, E. (2020) First evidence of convergent lifestyle signal in reptile skull roof microanatomy. BMC Evolutionary Biology, 18, 185.

Eisemberg, C.C., Reynolds, S.J., Christian, K.A., Vogt, R.C. (2017) Diet of Amazon river turtles (Podocnemididae): a review of the effects of body size, phylogeny, season and habitat. Zoology, 120, 92-100.

Ernst, C.H. (1986) Ecology of the turtle Sternotherus odoratus, in southeastern Pennsylvania. Journal of Herpetology, 20(3), 341-352.

Evers, S.W., Barrett, P.M., Benson, R.B.J. (2019a) Anatomy of Rhinochelys pulchriceps (Protostegidae) and marine adaptation during the early evolution of chelonioids. PeerJ, 7, e6811.

Evers, S.W., Benson, R.B.J. (2019) A new phylogenetic hypothesis of turtles with implications for the timing and number of evolutionary transitions to marine lifestyles in the group. Palaeontology, 62(1), 93-134.

Evers, S.W., Joyce, W.G. (2020) A re-description of Sandownia harrisi (Testudinata: Sandownidae) from the Aptian of the Isle of Wight based on computed tomography scans. Royal Society Open Science, 7(2), 191936.

Evers, S.W., Neenan, J.M., Ferreira, G.S., Werneburg, I., Barrett, P.M., Benson, R.B.J. (2019b) Neurovascular anatomy of the protostegid turtle Rhinochelys pulchriceps and comparisons of membranous and endosseous labyrinth shape in an extant turtle. Zoological Journal of the Linnean Society, 187(3), 800-828.

Fabre, A. C., Bardua, C., Bon, M., Clavel, J., Felice, R. N., Streicher, J. W., Bonnel, J., Stanley, E.L., Blackburn, D.C., Goswami, A. (2020) Metamorphosis shapes cranial diversity and rate of evolution in salamanders. Nature Ecology \& Evolution, 4(8), 1129-1140.

Felice, R.N., Tobias, J. A., Pigot, A.L., Goswami, A. (2019) Dietary niche and the evolution of cranial morphology in birds. Proceedings of the Royal Society B, 286(1897), 20182677.

Feilich, K.L., López-Fernández, H. (2019) When does form reflect function? Acknowledging and supporting ecomorphological assumptions. Integrative and Comparative Biology, 59(2), 358-370.

Felsenstein, J. (1985) Phylogenies and the comparative method. The American Naturalist, 125(1), $1-15$.

Ferreira, G.S., Lautenschlager, S., Evers, S.W., Pfaff, C., Kriwet, J., Raselli, I., Werneburg, I. (2020) Feeding biomechanics suggests progressive correlation of skull architecture and neck evolution in turtles. Scientific reports, 10(1), 1-11.

Ferreira, G.S., Rincón, A.D., Solórzano, A., Langer, M.C. (2015) The last marine pelomedusoids (Testudines: Pleurodira): a new species of Bairdemys and the paleoecology of Stereogenyina. PeerJ, 3, e1063.

Ferreira, G.S., Werneburg, I. (2019) Evolution, diversity, and development of the craniocervical system in turtles with special reference to jaw musculature. In Ziermann, J., Diaz Jr., R., Diogo, R. (eds.), Heads, Jaws, and Muscles, Springer, pp. 171-206.

Ferry-Graham, L.A., Lauder, G.V. (2001) Aquatic prey capture in ray-finned fishes: a century of progress and new directions. Journal of Morphology, 248(2), 99-119.

Foth, C., Rabi, M., Joyce, W.G. (2017) Skull shape variation in extant and extinct Testudinata and its relation to habitat and feeding ecology. Acta Zoologica, 98(3), 310-325.

Gaffney, E.S. (1975) A phylogeny and classification of the higher categories of turtles. Bulletin of the American Musem of Natural History, 155(5), 387-436. 
Gaffney, E.S. (1979) Comparative cranial morphology of Recent and fossil turtles. Bulletin of the American Museum of National History, 164, 65-376.

Gaffney, E.S. (1990) The comparative osteology of the Triassic turtle Proganochelys. Bulletin of the American Museum of Natural History, 194, 1-176.

Gaffney, E.S., Deblieux, D.D., Simons, E.L., Sánchez-Villagra, M.R., Meylan, P.A. (2002) Redescription of the skull of Dacquemys Williams, 1954, a podocnemidid side-necked turtle from the Late Eocene of Egypt. American Museum Novitates, 3372, 1-16.

Gaffney, E.S., Meylan, P.A., Wood, R.C., Simons, E., Campos, D.A. (2011) Evolution of the side-necked turtles: the family Podocnemididae. Bulletin of the American Museum of natural History, 350, 1-237.

Gaffney, E.S., Roberts, E., Sissoko, F., Bouaré, M.L., Tapanila, L., O'Leary, M.A. (2007) Acleistochelys, a new side-necked turtle (Pelomedusoides: Bothremydidae) from the Paleocene of Mali. American Museum Novitates, 2007(3549), 1-24.

Gaffney, E.S., Tong, H., Meylan, P.A. (2006) Evolution of the side-necked turtles: the families Bothremydidae, Euraxemydidae, and Araripemydidae. Bulletin of the American Museum of Natural History, 300, 1-698.

Gentry, A.D., Ebersole, J.A., Kiernan, C.R. (2019) Asmodochelys parhami, a new fossil marine turtle from the Campanian Demopolis Chalk and the stratigraphic congruence of competing marine turtle phylogenies. Royal Society Open Science, 6(12), 191950.

Godoy, P.L. (2020) Crocodylomorph cranial shape and its relationship with body size and ecology. Journal of Evolutionary Biology, 33(1), 4-21.

Goswami, A., Watanabe, A., Felice, R.N., Bardua, C., Fabre, A.C., Polly, P.D. (2019) Highdensity morphometric analysis of shape and integration: the good, the bad, and the notreally-a-problem. Integrative and Comparative Biology, 59(3), 669-683.

Grafen, A. (1989) The phylogenetic regression. Philosophical Transactions of the Royal Society of London B: Biological Sciences, 326, 119-157.

Grafen, A., Hails, R. (2002) Modern Statistics for the Life Sciences. Oxford University Press, Oxford, UK, 368 p.

Grant, P.R., Grant, B.R. (2006) Evolution of character displacement in Darwin's finches. Science, 313(5784), 224-226.

Gray, J.A., Sherratt, E., Hutchinson, M.N., Jones, M.E.H. (2019) Evolution of cranial shape in a continental-scale evolutionary radiation of Australian lizards. Evolution, 73(11), 22162229.

Gunz, P., Mitteroecker, P. (2013) Semilandmarks: a method for quantifying curves and surfaces. Hystrix, the Italian Journal of Mammalogy, 24(1), 103-109.

Heiss, E., Aerts, P., Van Wassenbergh, S. (2018) Aquatic-terrestrial transitions of feeding systems in vertebrates: a mechanical perspective. Journal of Experimental Biology, 221(8), 154427.

Herrel, A., O'Reilly, J.C., Richmond, A.M. (2002) Evolution of bite performance in turtles. Journal of Evolutionary Biology, 15(6), 1083-1094.

Herrel, A., Petrochic, S., Draud, M. (2018) Sexual dimorphism, bite force and diet in the diamondback terrapin. Journal of Zoology, 304(3), 217-224. 
Herrel, A., Soons, J., Aerts, P., Dirckx, J., Boone, M., Jacobs, P., Adriaens, D., Podos, J. (2010) Adaptation and function of the bills of Darwin's finches: divergence by feeding type and sex. Emu-Austral Ornithology, 110(1), 39-47.

Herrel, A., Van Damme, J., Aerts, P. (2008) Cervical anatomy and function in turtles. In Wyneken, J., Godfrey, M.H., Bels, V. (eds.), Biology of Turtles, CRC Press, pp. 163-185.

Herrel, A., Vincent, S.E., Alfaro, M.E., Van Wassenbergh, S., Vanhooydonck, B., Irschick, D.J. (2008) Morphological convergence as a consequence of extreme functional demands: examples from the feeding system of natricine snakes. Journal of Evolutionary Biology, 21(5), 1438-1448.

Hirayama, R. (1998) Oldest known sea turtle. Nature, 392(6677), 705-708.

Iordansky, N.N. (2010) Pterygoideus muscles and other jaw adductors in amphibians and reptiles. Biology Bulletin, 37(9), 905-914.

Ives, A.R. (2019) R² for correlated data: phylogenetic models, LMMs, and GLMMs. Systematic Biology, 68(2), 234-251.

Jones, M.E.H., Werneburg, I., Curtis, N., Penrose, R., O’Higgins, P., Fagan, M.J., Evans, S.E. (2012) The head and neck anatomy of sea turtles (Cryptodira: Chelonioidea) and skull shape in Testudines. PLoS ONE, 7(11), e47852.

Joyce, W.G., Gauthier, J.A. (2004) Palaeoecology of Triassic stem turtles sheds new light on turtle origins. Proceedings of the Royal Society of London. Series B: Biological Sciences, 271(1534), 1-5.

Joyce, W.G., Lyson, T.R. (2015) A review of the fossil record of turtles of the clade Baenidae. Bulletin of the Peabody Museum of Natural History, 56(2), 147-183.

Joyce, W.G., Parham, J.F., Lyson, T.R., Warnock, R.C.M., Donoghue, P.C.J. (2013) A divergence dating analysis of turtles using fossil calibrations: an example of best practices. Journal of Paleontology, 87(4), 612-634.

Joyce, W.G., Rabi, M., Clark, J.M., Xu, X. (2016) A toothed turtle from the Late Jurassic of China and the global biogeographic history of turtles. BMC Evolutionary Biology, 16, 236.

Kummer, S., Heiss, E., Singer, K., Lemell, P., Natchev, N. (2017) Feeding behaviour and feeding motorics in subadult European pond turtles, Emys orbicularis (Linnaeus, 1758). Acta Zoologica Bulgarica, 10, 77-84.

Lauder, G.V. (1985) Aquatic feeding in lower vertebrates. In In Hildebrand, M., Bramble, D.M., Liem, K.F., Wake, D.B. (eds.), Functional Vertebrate Morphology, pp. 210-229.

Lauder, G.V. (1995) On the inference of function from structure. In Thomason, J.J. (ed.), Functional morphology in vertebrate paleontology, Cambridge University Press, New York, pp. 1-18.

Lauder, G.V., Prendergast, T. (1992) Kinematics of aquatic prey capture in the snapping turtle Chelydra serpentina. Journal of Experimental Biology, 164(1), 55-78.

Lautenschlager, S., Ferreira, G.S., Werneburg, I. (2018) Sensory evolution and ecology of early turtles revealed by digital endocranial reconstructions. Frontiers in Ecology and Evolution, 6,7 .

Lemell, P., Beisser, C.J., Gumpenberger, M., Snelderwaard, P., Gemel, R., Weisgram, J. (2010) Feeding apparatus of Chelus fimbriatus (Pleurodira; Chelidae) - adaptation perfected? Amphibia-Reptilia, 31, 97-107. 
Lemell, P., Beisser, C.J., Weisgram, J. (2000) Morphology and function of the feeding apparatus of Pelusios castaneus (Chelonia; Pleurodira). Journal of Morphology, 244(2), 127-135.

Lemell, P., Lemell, C., Snelderwaard, P., Gumpenberger, M., Wochesländer, R., Weisgram, J. (2002) Feeding patterns of Chelus fimbriatus (Pleurodira: Chelidae). Journal of Experimental Biology, 205(10), 1495-1506.

Lemell, P., Natchev, N., Beisser, C.J., Heiss, E. (2019) Feeding in turtles: understanding terrestrial and aquatic feeding in a diverse but monophyletic group. In Bels, V., Whishaw, I. (eds.), Feeding in Vertebrates, Springer, pp. 611-642.

Lindeman, P.V. (2000) Evolution of the relative width of the head and alveolar surfaces in map turtles (Testudines: Emydidae: Graptemys). Biological Journal of the Linnean Society, 69(4), 549-576.

Lyson, T.L. \& Bever, G.S. (2020) Origin and evolution of the turtle body plan. Annual Review of Ecology, Evolution, and Systematics, 51, 143-166.

MacLeod, N. (2002) Landmarks and semilandmarks: differences without meaning and meaning without difference. Palaeontological Association Newsletter, 81, 40-48.

Mahmoud, I.Y. (1968) Feeding behavior in kinosternid turtles. Herpetologica, 24, 300-305.

Marshall, C.D., Guzman, A., Narazaki, T., Sato, K., Kane, E.A., Sterba-Boatwright, B.D. (2012) The ontogenetic scaling of bite force and head size in loggerhead sea turtles (Caretta caretta): implications for durophagy in neritic, benthic habitats. Journal of Experimental Biology, 215(23), 4166-4174.

Martín-Jiménez, M., Codrea, V., Pérez-García, A. (2020) Neuroanatomy of the European uppermost Cretaceous stem turtle Kallokibotion bajazadi. Cretaceous Research, 104720. DOI:10.1016/j.cretres.2020.104720.

Matzke, A.T. (2009) Osteology of the skull of Toxochelys (Testudines, Chelonioidea). Palaeontographica Abteilung A, 93-150.

Marugán-Lobón. J., Watanabe, A., Kawabe, S. (2016) Studying avian encephalization with geometric morphometrics. Journal of Anatomy, 229, 191-203.

Meylan, A. (1988) Spongivory in hawksbill turtles: a diet of glass. Science, 239(4838), 393-395.

Moll, D., Moll, E.O. (2004) The Ecology, Exploitation, and Conservation of River Turtles. Oxford University Press, Oxford, UK, 393 pp.

Monteiro, L.R. (1999) Multivariate regression models and geometric morphometrics: the search for causal factors in the analysis of shape. Systematic Biology, 48(1), 192-199.

Monteiro, L.R., Nogueira, M.R. (2011) Evolutionary patterns and processes in the radiation of phyllostomid bats. BMC Evolutionary Biology, 11(1), 137.

Motani, R., Chen, X., Jiang, D., Cheng, L., Tintori, A., Rieppel, O. (2015) Lunge feeding in early marine reptiles and fast evolution of marine tetrapod feeding guilds. Scientific Reports, 5 , 8900 .

Motani, R., Ji, C., Tomita, T., Kelley, N., Maxwell, E., Jiang, D., Sander, P.M. (2013) Absence of suction feeding ichthyosaurs and its implications for Triassic mesopelagic paleoecology. PLoS ONE, 8(12), e66075.

Motani, R., Schmitz, L. (2011) Phylogenetic versus functional signals in the evolution of formfunction relationships in terrestrial vision. Evolution, 65(8), 2245-2257. 
Natchev, N., Heiss, E., Singer, K., Kummer, S., Salaberger, D., Weisgram, J. (2011) Structure and function of the feeding apparatus in the common musk turtle Sternotherus odoratus (Chelonia, Kinosternidae). Contributions to Zoology, 80(2), 143-156.

Natchev, N., Lemell, P., Heiss, E., Beisser, C., Weisgram, J. (2010) Aquatic feeding in a terrestrial turtle: a functional-morphological study of the feeding apparatus in the Indochinese box turtle Cuora galbinifrons (Testudines, Geoemydidae). Zoomorphology, 129(2), 111-119.

Natchev, N., Tzankov, N., Werneburg, I., Heiss, E. (2015) Feeding behaviour in a 'basal' tortoise provides insights on the transitional feeding mode at the dawn of modern land turtle evolution. PeerJ, 3, e1172.

Navalón, G., Bright, J.A., Marugán-Lobón, J., Rayfield, E.J. (2019) The evolutionary relationship among beak shape, mechanical advantage, and feeding ecology in modern birds. Evolution, 73(3), 422-435.

Neenan, J.M., Reich, T., Evers, S.W., Druckenmiller, P.S., Voeten, D.F.A.E., Choiniere, J.N., Barrett, P.M., Pierce, S.E., Benson, R.B.J. (2017) Evolution of the sauropterygian labyrinth with increasingly pelagic lifestyles. Current Biology, 27(24), 3852-3858.

Nishizawa, H., Asahara, M., Kamezaki, N., Arai, N. (2010) Differences in the skull morphology between juvenile and adult green turtles: implications for the ontogenetic diet shift. Current Herpetology, 29(2), 97-101.

O'Leary, M.A., Bouaré, M.L., Claeson, K.M., Heilbronn, K., Hill, R.V., McCartney, J., Sessa, J.A., Sissoko, F., Tapanila, L., Wheeler, E., Roberts, E.M. (2019) Stratigraphy and paleobiology of the upper Cretaceous-lower Paleogene sediments from the trans-Saharan seaway in Mali. Bulletin of the American Museum of Natural History, 436, 1-183.

Olsen, A. (2017) Feeding ecology is the primary driver of beak shape diversification in waterfowl. Functional Ecology, 31, 1985-1995.

Pagel, M.D. (1999) Inferring the historical patterns of biological evolution. Nature, 401, 877-884.

Paradis, E., Schliep, K. (2019) ape 5.0: an environment for modern phylogenetics and evolutionary analyses in R. Bioinformatics, 35(3), 526-528.

Parham, J.F., Pyenson, N.D. (2010) New sea turtle from the Miocene of Peru and the iterative evolution of feeding ecomorphologies since the Cretaceous. Journal of Paleontology, 84(2), 231-247.

Pereira, A.G., Sterli, J., Moreira, F.R., Schrago, C.G. (2017) Multilocus phylogeny and statistical biogeography clarify the evolutionary history of major lineages of turtles. Molecular Phylogenetics and Evolution, 113, 59-66.

Pérez-Eman, J. L., Paolillo, A. (1997) Diet of the pelomedusid turtle Peltocephalus dumerilianus in the Venezuelan Amazon. Journal of Herpetology, 173-179.

Petrov, K., Lewis, J., Malkiewicz, N., Van Dyke, J.U., Spencer, R.J. (2018) Food abundance and diet variation in freshwater turtles from the mid-Murray River, Australia. Australian Journal of Zoology, 66(1), 67-76.

Pfaller, J.B., Herrera, N.D., Gignac, P.M., Erickson, G.M. (2010) Ontogenetic scaling of cranial morphology and bite-force generation in the loggerhead musk turtle. Journal of Zoology, 280(3), 280-289.

Pincheira-Donoso, D., Bauer, A.M., Meiri, S., Uetz, P. (2013) Global taxonomic diversity of living reptiles. PloS ONE, 8(3), e59741. 
Pinheiro J., Bates D., DebRoy S., Sarkar D., R Core Team (2020) nlme: Linear and Nonlinear Mixed Effects Models. $\mathrm{R}$ package version 3.1-151, https://CRAN.Rproject.org/package $=$ nlme.

Platt, S. G., Berezin, A.R., Miller, D.J., Rainwater, T.R. (2016) A dietary study of the roughfooted mud turtle (Kinosternon hirtipes) in Texas, USA. Herpetological Conservation and Biology, 11(1), 142-149.

Pritchard, P.C.H. (1979) Encyclopedia of Turtles. New Jersey: TFH Publications, 895 p.

Pritchard, P.C.H. (1984) Piscivory in turtles, and evolution of the long-necked Chelidae. Symposia of the Zoological Society of London, 52, 87-110.

Pritchard, P.C.H. (1993) Carapacial pankinesis in the Malayan softshell turtle, Dogania subplana. Chelonian Conservation and Biology, 1(1), 31-36.

Pritchard, P.C.H. (2001). Observations on body size, sympatry, and niche divergence in softshell turtles (Trionychidae). Chelonian Conservation and Biology, 4(1), 5-27.

R Core Team. (2020) $R$ : a language and environment for statistical computing. R Foundation for Statistical Computing (Austria: Vienna). http://www.r-project.org.

Rabi, M., Sukhanov, V.B., Egorova, V.N., Danilov, I., Joyce, W.G. (2014) Osteology, relationships, and ecology of Annemys (Testudines, Eucryptodira) from the Late Jurassic of Shar Teg, Mongolia, and phylogenetic definitions for Xinjiangchelyidae, Sinemydidae, and Macrobaenidae. Journal of Vertebrate Paleontology, 34(2), 327-352.

Rabi, M., Tong, H., Botfalvai, G. (2012) A new species of the side-necked turtle Foxemys (Pelomedusoides: Bothremydidae) from the Late Cretaceous of Hungary and the historical biogeography of the Bothremydini. Geological Magazine, 149(4), 662-674.

Raselli, I. (2018) Comparative cranial morphology of the Late Cretaceous protostegid sea turtle Desmatochelys lowii. PeerJ, 6, e5964.

Reeves, J.C., Moon, B.C., Benton, M.J., Stubbs, T.L. (2020) Evolution of ecospace occupancy by Mesozoic marine tetrapods. Palaeontology, DOI: 10.1111/pala.12508.

Revell, L.J. (2009) Size correction and principal components for interspecific comparative studies. Evolution, 63, 3258-3268.

Revell, L.J. (2010). Phylogenetic signal and linear regression on species data. Methods in Ecology and Evolution, 1(4), 319-329.

Revell, L.J. (2012). phytools: an R package for phylogenetic comparative biology (and other things). Methods in Ecology and Evolution, 3(2), 217-223.

Rhodin, A.G.J., Medem, F., Mittermeier, R.A. (1981a) The occurrence of neustophagia among podocnemine turtles. British Journal of Herpetology, 6, 175-176.

Rhodin, A.G.J., Ogden, J.A., Conlogue, G.J. (1981b) Chondro-osseous morphology of Dermochelys coriacea, a marine reptile with mammalian skeletal features. Nature, 290(5803), 244-246.

Richter, S., Auer, M., Fritz, U. (2007) Variation of hyoid morphology in geoemydid terrapins. Amphibia-Reptilia, 28(1), 148-153.

Rieppel, O. (2002) Feeding mechanics in Triassic stem-group sauropterygians: the anatomy of a successful invasion of Mesozoic seas. Zoological Journal of the Linnean Society, 135, 3363 . 
Rohlf, F.J., Corti, M. (2000) Use of two-block partial least-squares to study covariation in shape. Systematic Biology 49, 740-753.

Rohlf, F.J., Marcus, L.F. (1993) A revolution in morphometrics. Trends in Ecology \& Evolution, $8(4), 129-132$.

Rohlf, F.J., Slice, D. (1990) Extensions of the Procrustes method for the optimal superimposition of landmarks. Systematic Biology, 39(1), 40-59.

Sasaki, T., Yasukawa, Y., Takahashi, K., Miura, S., Shedlock, A.M., Okada, N. (2006) Extensive morphological convergence and rapid radiation in the evolutionary history of the family Geoemydidae (Old World pond turltes) revealed by SINE insertion analysis. Systematic Biology, 55(6), 912-927.

Scheyer, T.M., Sander, P.M. (2007) Shell bone histology indicates terrestrial palaeoecology of basal turtles. Proceedings of the Royal Society B: Biological Sciences, 274(1620), 18851893.

Schlager, S. (2017) Morpho and Rvcg-Shape Analysis in R: R packages for geometric morphometrics, shape analysis and surface manipulations. In Zheng, G., Li S., Szekely, G. (eds.), Statistical Shape and Deformation Analysis, Academic Press, pp. 217-256.

Schumacher, G.H. (1973) The head muscles and hyolaryngeal skeleton of turtles and crocodilians. In Gans, C., Parsons, T. (eds.), Biology of the Reptilia, Morphology D, vol. 4, Academic Press, London, UK, pp. 101-199.

Segall, M., Cornette, R., Fabre, A.C., Godot-Diana, R., Herrel, A. (2016) Does aquatic foraging impact head shape evolution in snakes? Proceedings of the Royal Society B, 283, 20161645.

Souza, F.L. (2004) Uma revisão sobre padrões de atividade, reprodução e alimentação de cágados brasileiros (Testudines, Chelidae). Phyllomedusa, 3(1), 15-27.

Sterli, J. (2015) A review of the fossil record of Gondwanan turtles of the clade Meiolaniformes. Bulletin of the Peabody Museum of Natural History, 56(1), 21-45.

Sterli, J., de la Fuente, M.S. (2011) A new turtle from the La Colonia Formation (CampanianMaastrichtian), Patagonia, Argentina, with remarks on the evolution of the vertebral column in turtles. Palaeontology, 54(1), 63-78.

Sterli, J., de la Fuente, M.S., Rougier, G.W. (2018) New remains of Condorchelys antiqua (Testudinata) from the Early-Middle Jurassic of Patagonia: anatomy, phylogeny, and paedomorphosis in the early evolution of turtles. Journal of Vertebrate Paleontology, $38(4), 1-17$.

Stubbs, T.L., Benton, M.J. (2016) Ecomorphological diversifications of Mesozoic marine reptiles: the roles of ecological opportunity and extinction. Paleobiology, 42(4), 547-573.

Taylor, G., Thomas, A. (2014) Evolutionary Biomechanics. Oxford University Press, Oxford.

Tong, H., Hirayama, R., Makhoul, E., Escuillié, F. (2006) Rhinochelys (Chelonioidea: Protostegidae) from the Late Cretaceous (Cenomanian) of Nammoura, Lebanon. Atti della Società italiana di scienze naturali e del museo civico di storia naturale di Milano, 147, 113-38.

Tong, H., Li, L. (2019) A revision of the holotype of Nanhsiungchelys wuchingensis, Ye, 1966 (Testudines: Cryptodira: Trionychoidae: Nanhsiungchelyidae). Cretaceous Research, 95, 151-163. 
TTWG [Turtle Taxonomy Working Group]. (2017) Turtles of the World: annotated checklist and atlas of taxonomy, synonymy, distribution, and conservation status. Chelonian Research Monographs, 7, 1-292.

Van Damme, J., Aerts, P. (1997) Kinematics and functional morphology of aquatic feeding in Australian snake-necked turtles (Pleurodira; Chelodina). Journal of Morphology, 233(2), 113-125.

Webster, M., Sheets, H.D. (2010) A practical introduction to landmark-based geometric morphometrics. The Paleontological Society Papers, 16, 163-188.

Weems, R.E., Knight, J.L. (2013) A new species of Bairdemys (Pelomedusoides: Podocnemididae) from the Oligocene (Early Chattian) Chandler Bridge Formation of South Carolina, USA, and its paleobiogeographic implications for the genus. In Brinkman, D., Holroyd, P., Gardner, J. (eds.), Morphology and Evolution of Turtles, Vertebrate Paleobiology and Paleoanthropology series, Springer, pp. 289-303.

Welsh, M.A., Doody, J.S., Georges, A. (2017) Resource partitioning among five sympatric species of freshwater turtles from the wet-dry tropics of northern Australia. Wildlife Research, 44(3), 219-229.

Werneburg, I. (2012) Temporal bone arrangements in turtles: an overview. Journal of Experimental Zoology Part B: Molecular and Developmental Evolution, 318, 235-249.

Werneburg, I. (2015) Neck motion in turtles and its relation to the shape of the temporal skull region. Comptes Rendus Palevol, 14(6-7), 527-548.

Werneburg, I. (2019) Morphofunctional categories and ontogenetic origin of temporal skull openings in amniotes. Frontiers in Earth Science, 7, 13.

Werneburg, I., Maier, W. (2019) Diverging development of akinetic skulls in cryptodire and pleurodire turtles: an ontogenetic and phylogenetic study. Vertebrate Zoology, 69(2), 113 143.

Werneburg, I., Wilson, L.A.B., Parr, W.C.H., Joyce, W.G. (2015) Evolution of neck vertebral shape and neck retraction at the transition to modern turtles: an integrated geometric morphometric approach. Systematic Biology, 64(2), 187-204.

Wilman, H., Belmaker, J., Simpson, J., de la Rosa, C., Rivadeneira, M.M., Jetz, W. (2014) EltonTraits 1.0: Species-level foraging attributes of the world's birds and mammals. Ecological Archives, 95(7), 2027-2027.

Wilson, L.A.B., Sánchez-Villagra, M.R. (2011) Evolution and phylogenetic signal of growth trajectories: the case of chelid turtles. Journal of Experimental Zoology Part B: Molecular and Developmental Evolution, 316(1), 50-60.

Winkler, J.D., Sánchez-Villagra, M.R. (2006) A nesting site and egg morphology of a Miocene turtle from Urumaco, Venezuela: evidence of marine adaptations in Pelomedusoides. Palaeontology, 49(3), 641-646.

Yoshida, M., Hirayama, R. (2015) New species of the side-necked turtle Bothremys (Pleurodira: Podocnemidoidea: Bothremydidae) from the Upper Cretaceous of Morocco. PeerJ PrePrints, DOI:10.7287/peerj.preprints.959v1.

Zangerl, R. (1953) The vertebrate fauna of the Selma Formation of Alabama. Part III. The turtles of the family Protostegidae. Fieldiana. Geology Memoirs, 3(3), 63-133.

Zimmerman, L.C., Tracy, C.R. (1989) Interactions between the environment and ectothermy and herbivory in reptiles. Physiological Zoology, 62(2), 374-409. 


\section{Appendix 1}

Set of composite phylogenies used in this study.

A

$$
\text { Evers et al. (2019a) }
$$

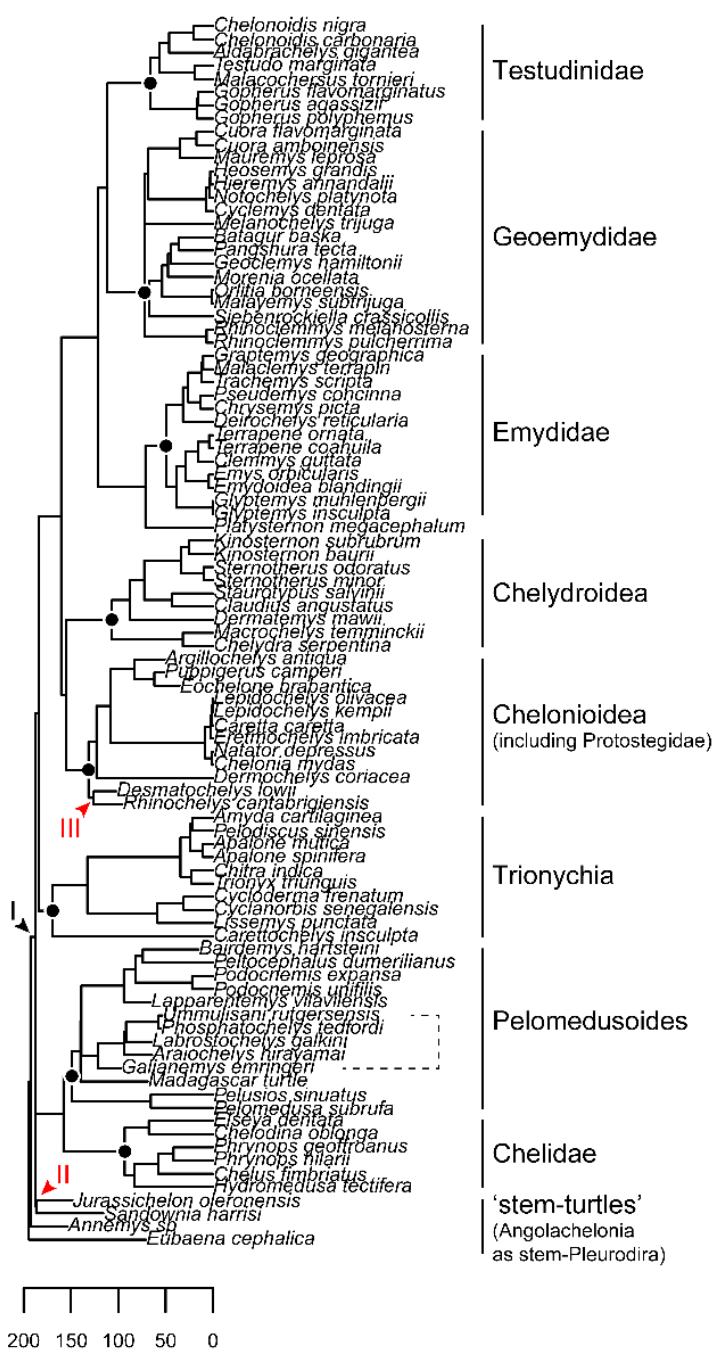

B

Sterli et al. (2018)

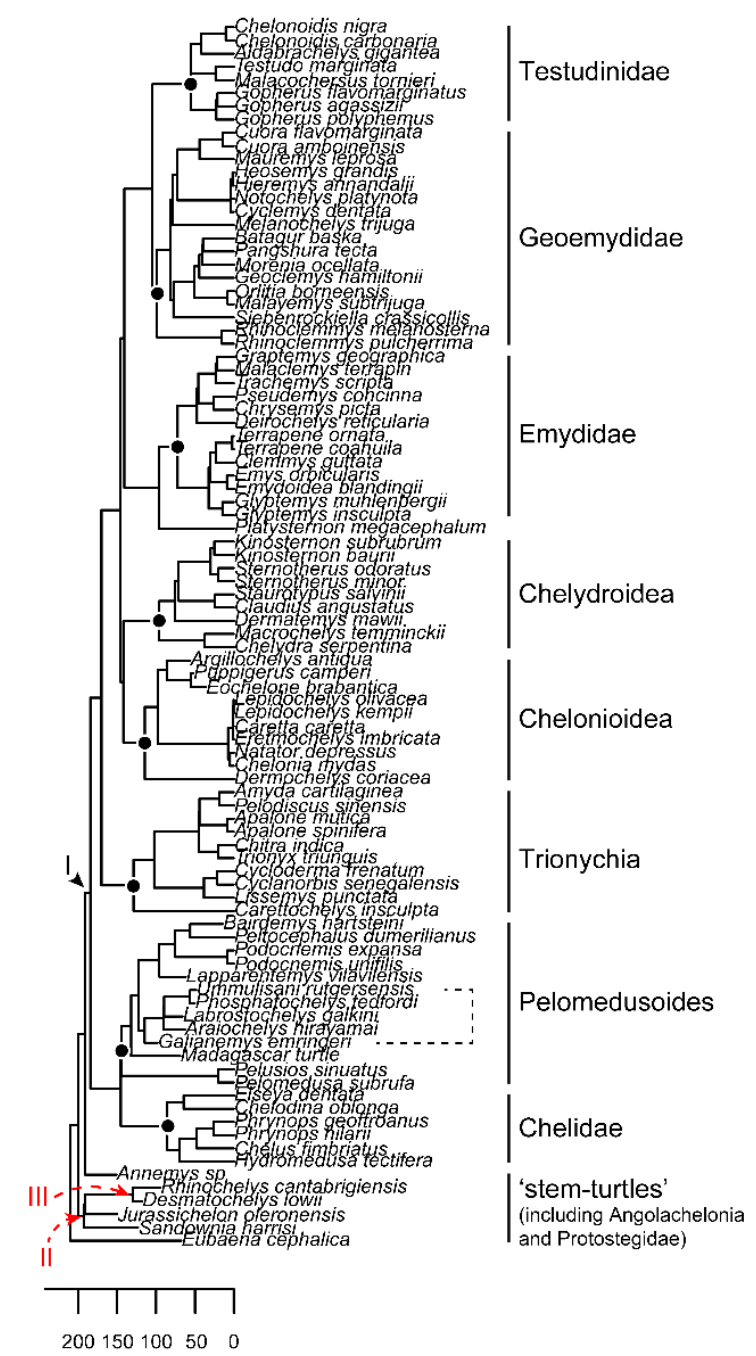

Figure A1.1. Composite trees used in this study (B. Farina, unpublished data), based on the topologies of (A) Evers et al. (2019a) and (B) Sterli et al. (2018). Roman numbers indicate the clades (I) Testudines, (II) Angolachelonia, and (III) Protostegidae. In red are the clades of which phylogenetic position vary according to the topology. Dashed lines circumscribe the clade Bothremydidae. 


\section{Appendix 2}

Below are shown the results of the pFDA classifications for extinct (as a figure) and extant (as a table) taxa after 100 iterations ran for each ecological predictor of the best D-PGLS model using the partial dataset (see Main Text).
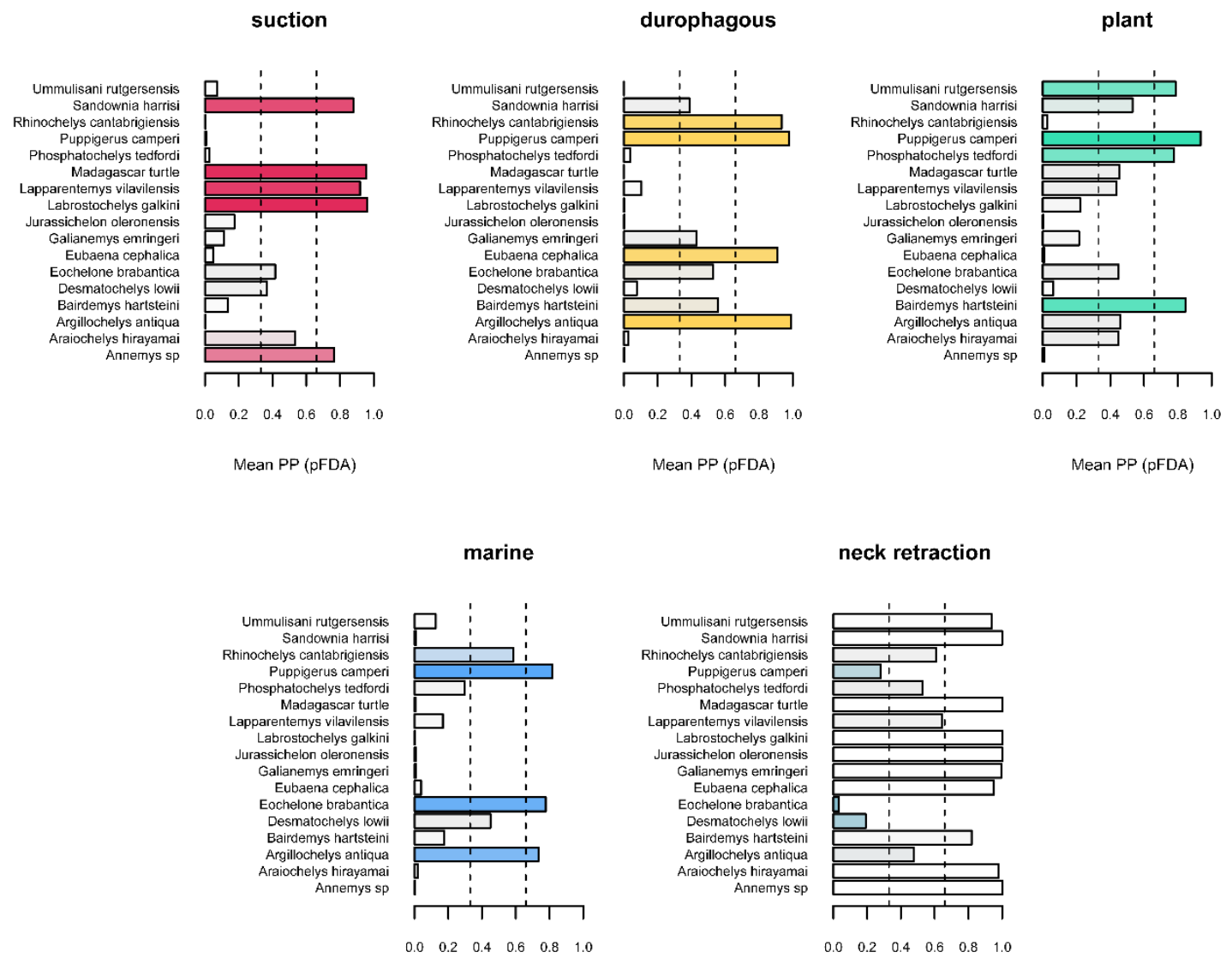

Mean PP (pFDA)

Mean PP (pFDA)

Figure A2.1. Results of pFDA based on the topology of Evers et al. (2019a) showing the mean posterior probability (PP) for the presence of ecological attributes in fossil turtles. These results are the same as those presented in Table 4 (Main Text). 

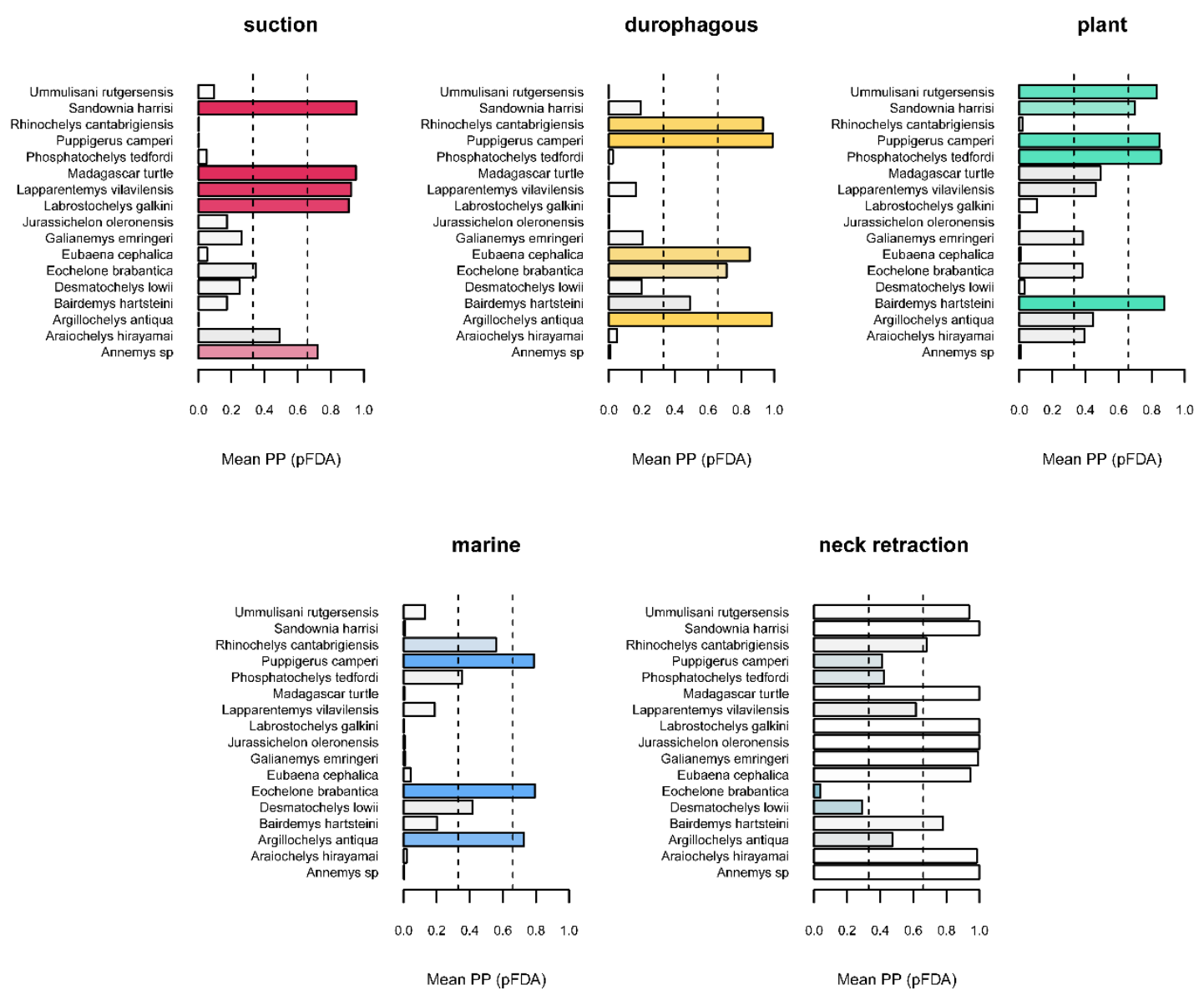

Figure A2.2. Results of pFDA based on the topology of Sterli et al. (2018) showing the mean posterior probability (PP) for the presence of ecological attributes in fossil turtles.

Table A2.1. Mean posterior probabilities (PP) calculated in pFDA analyses (using Evers et al. 2019a topology) for the presence of each ecological trait in extant turtles. Traits correspond to predictors from the best D-PGLS model using the partial landmark dataset. Numbers in bold indicate incorrect classifications, i.e. they denote 'absence' when the taxon was actually scored as 'presence' and vice-versa.

\begin{tabular}{lccccc}
\hline \multirow{2}{*}{\multicolumn{1}{c}{ Taxon }} & \multicolumn{5}{c}{ Ecological attributes } \\
\cline { 2 - 6 } & suction & durophagous & plant & marine & neck retraction \\
\hline Rhinoclemmys_pulcherrima & 0.366 & 0.007 & 0.271 & 0.077 & 0.899 \\
Rhinoclemmys_melanosterna & 0.099 & 0.070 & 0.033 & 0.049 & 0.968 \\
Melanochelys_trijuga & 0.115 & 0.002 & $\mathbf{0 . 7 8 9}$ & 0.048 & 0.998 \\
Mauremys_leprosa & 0.151 & 0.057 & 0.300 & 0.029 & 0.993 \\
Cuora_flavomarginata & 0.072 & 0.187 & 0.145 & 0.216 & 0.729 \\
Cuora_amboinensis & 0.162 & 0.009 & 0.535 & 0.055 & 0.986 \\
Cyclemys_dentata & 0.169 & 0.012 & $\mathbf{0 . 2 4 3}$ & 0.148 & 0.945 \\
Hieremys_annandalii & 0.116 & 0.117 & $\mathbf{0 . 5 8 9}$ & 0.062 & 0.960 \\
Heosemys_grandis & 0.168 & 0.014 & 0.190 & 0.064 & 0.899 \\
Notochelys_platynota & 0.109 & 0.074 & $\mathbf{0 . 4 8 9}$ & 0.397 & $\mathbf{0 . 3 4 8}$ \\
Malayemys_subtrijuga & 0.064 & 0.997 & 0.133 & 0.150 & 0.881 \\
Orlitia_borneensis & 0.090 & 0.236 & 0.084 & 0.029 & 0.971 \\
Geoclemys_hamiltonii & 0.006 & 0.906 & 0.295 & 0.179 & 0.933 \\
Pangshura_tecta & 0.150 & 0.127 & 0.894 & 0.033 & 0.993
\end{tabular}




\begin{tabular}{|c|c|c|c|c|c|}
\hline Batagur_baska & 0.102 & 0.833 & 0.786 & 0.137 & 0.863 \\
\hline Morenia_ocellata & 0.055 & 0.658 & 0.973 & 0.061 & 0.993 \\
\hline Siebenrockiella_crassicollis & 0.057 & 0.013 & 0.684 & 0.092 & 0.977 \\
\hline Malacochersus_tornieri & 0.144 & 0.017 & 0.576 & 0.026 & 0.993 \\
\hline Testudo_marginata & 0.272 & 0.014 & 0.645 & 0.123 & 0.911 \\
\hline Chelonoidis_nigra & 0.261 & 0.004 & 0.946 & 0.080 & 0.990 \\
\hline Chelonoidis_carbonaria & 0.031 & 0.066 & 0.449 & 0.103 & 0.987 \\
\hline Aldabrachelys_gigantea & 0.241 & 0.001 & 0.996 & 0.416 & 0.729 \\
\hline Gopherus_flavomarginatus & 0.304 & 0.010 & 0.960 & 0.061 & 0.993 \\
\hline Gopherus_polyphemus & 0.103 & 0.013 & 0.635 & 0.083 & 0.939 \\
\hline Gopherus_agassizii & 0.183 & 0.014 & 0.931 & 0.086 & 0.997 \\
\hline Platysternon_megacephalum & 0.093 & 0.592 & 0.074 & 0.504 & 0.119 \\
\hline Glyptemys_insculpta & 0.241 & 0.294 & 0.266 & 0.307 & 0.524 \\
\hline Glyptemys_muhlenbergii & 0.180 & 0.043 & 0.145 & 0.110 & 0.945 \\
\hline Emys_orbicularis & 0.029 & 0.234 & 0.031 & 0.052 & 0.982 \\
\hline Emydoidea_blandingii & 0.894 & 0.035 & 0.139 & 0.217 & 0.763 \\
\hline Terrapene_ornata & 0.082 & 0.188 & 0.215 & 0.222 & 0.872 \\
\hline Terrapene_coahuila & 0.025 & 0.375 & 0.022 & 0.024 & 0.998 \\
\hline Clemmys_guttata & 0.046 & 0.076 & 0.068 & 0.150 & 0.966 \\
\hline Deirochelys_reticularia & 0.987 & 0.015 & 0.275 & 0.313 & 0.669 \\
\hline Trachemys_scripta & 0.224 & 0.083 & 0.440 & 0.057 & 0.952 \\
\hline Graptemys_geographica & 0.140 & 0.939 & 0.254 & 0.082 & 0.948 \\
\hline Malaclemys_terrapin & 0.352 & 0.751 & 0.058 & 0.039 & 0.956 \\
\hline Chrysemys_picta & 0.394 & 0.043 & 0.650 & 0.023 & 0.984 \\
\hline Pseudemys_concinna & 0.179 & 0.122 & 0.945 & 0.094 & 0.992 \\
\hline Dermochelys_coriacea & 0.004 & 0.022 & 0.758 & 0.729 & 0.018 \\
\hline Caretta_caretta & 0.005 & 0.967 & 0.565 & 0.893 & 0.010 \\
\hline Lepidochelys_olivacea & 0.017 & 0.486 & 0.541 & 0.953 & 0.043 \\
\hline Lepidochelys_kempii & 0.018 & 0.759 & 0.361 & 0.967 & 0.058 \\
\hline Eretmochelys_imbricata & 0.010 & 0.993 & 0.009 & 0.970 & 0.009 \\
\hline Chelonia_mydas & 0.087 & 0.745 & 0.883 & 0.990 & 0.009 \\
\hline Natator_depressus & 0.048 & 0.649 & 0.752 & 0.933 & 0.114 \\
\hline Macrochelys_temminckii & 0.200 & 0.930 & 0.017 & 0.643 & 0.005 \\
\hline Chelydra_serpentina & 0.921 & 0.035 & 0.176 & 0.054 & 0.913 \\
\hline Dermatemys_mawii & 0.099 & 0.199 & 0.914 & 0.161 & 0.875 \\
\hline Staurotypus_salvinii & 0.035 & 0.963 & 0.039 & 0.066 & 0.936 \\
\hline Claudius_angustatus & 0.064 & 0.839 & 0.006 & 0.086 & 0.898 \\
\hline Sternotherus_minor & 0.007 & 0.995 & 0.213 & 0.165 & 0.930 \\
\hline Sternotherus_odoratus & 0.024 & 0.747 & 0.204 & 0.118 & 0.900 \\
\hline Kinosternon_subrubrum & 0.014 & 0.906 & 0.052 & 0.099 & 0.982 \\
\hline Kinosternon_baurii & 0.006 & 0.941 & 0.057 & 0.098 & 0.968 \\
\hline Carettochelys_insculpta & 0.234 & 0.111 & 0.158 & 0.015 & 0.980 \\
\hline Trionyx_triunguis & 0.837 & 0.026 & 0.622 & 0.038 & 0.977 \\
\hline Chitra_indica & 0.998 & 0.416 & 0.096 & 0.141 & 0.720 \\
\hline Apalone_mutica & 0.948 & 0.056 & 0.380 & 0.018 & 0.987 \\
\hline Apalone_spinifera & 0.944 & 0.153 & 0.578 & 0.050 & 0.951 \\
\hline Amyda_cartilaginea & 0.942 & 0.089 & 0.658 & 0.073 & 0.955 \\
\hline Pelodiscus_sinensis & 0.975 & 0.065 & 0.427 & 0.032 & 0.993 \\
\hline Cycloderma_frenatum & 0.904 & 0.164 & 0.263 & 0.025 & 0.967 \\
\hline Cyclanorbis_senegalensis & 0.977 & 0.164 & 0.765 & 0.020 & 0.995 \\
\hline
\end{tabular}




\begin{tabular}{llllll} 
Lissemys_punctata & 0.681 & 0.361 & 0.539 & 0.001 & 1.000 \\
Pelomedusa_subrufa & 0.511 & 0.011 & 0.115 & 0.025 & 0.986 \\
Pelusios_sinuatus & 0.417 & 0.048 & 0.082 & 0.006 & 0.997 \\
Peltocephalus_dumerilianus & $\mathbf{0 . 7 3 1}$ & 0.344 & 0.471 & $\mathbf{0 . 6 6 5}$ & 0.091 \\
Podocnemis_expansa & $\mathbf{0 . 8 5 8}$ & 0.233 & $\mathbf{0 . 6 2 9}$ & 0.082 & 0.883 \\
Podocnemis_unifilis & 0.708 & 0.190 & $\mathbf{0 . 2 0 2}$ & 0.028 & 0.979 \\
Elseya_dentata & 0.587 & 0.063 & $\mathbf{0 . 3 6 3}$ & 0.241 & 0.667 \\
Chelodina_oblonga & 0.877 & 0.049 & 0.004 & 0.007 & 0.998 \\
Hydromedusa_tectifera & 0.976 & 0.004 & 0.034 & 0.001 & 1.000 \\
Chelus_fimbriatus & 0.991 & 0.002 & 0.038 & 0.014 & 0.992 \\
Phrynops_hilarii & 0.818 & 0.003 & 0.258 & 0.006 & 0.994 \\
Phrynops_geoffroanus & $\mathbf{0 . 6 3 9}$ & 0.006 & 0.193 & 0.014 & 0.996 \\
\hline
\end{tabular}

Table A2.2. Mean posterior probabilities (PP) calculated in pFDA analyses (using Sterli et al. 2018 topology) for the presence of each ecological trait in extant turtles. Traits correspond to predictors from the best D-PGLS model using the partial landmark dataset. Numbers in bold indicate incorrect classifications, i.e. they denote 'absence' when the taxon was actually scored as 'presence' and vice-versa.

\begin{tabular}{lccccc}
\hline \multirow{2}{*}{ Taxon } & \multicolumn{5}{c}{ Ecological attributes } \\
\cline { 2 - 6 } & suction & durophagous & plant & marine & neck retraction \\
\hline Rhinoclemmys_pulcherrima & 0.337 & 0.015 & 0.251 & 0.078 & 0.912 \\
Rhinoclemmys_melanosterna & 0.094 & 0.080 & 0.033 & 0.051 & 0.968 \\
Melanochelys_trijuga & 0.123 & 0.002 & 0.822 & 0.051 & 0.998 \\
Mauremys_leprosa & 0.141 & 0.078 & 0.289 & 0.026 & 0.994 \\
Cuora_flavomarginata & 0.070 & 0.220 & 0.148 & 0.219 & 0.733 \\
Cuora_amboinensis & 0.150 & 0.012 & 0.511 & 0.053 & 0.989 \\
Cyclemys_dentata & 0.132 & 0.037 & $\mathbf{0 . 1 7 5}$ & 0.143 & 0.961 \\
Hieremys_annandalii & 0.113 & 0.144 & $\mathbf{0 . 6 0 3}$ & 0.062 & 0.963 \\
Heosemys_grandis & 0.179 & 0.019 & 0.212 & 0.066 & 0.902 \\
Notochelys_platynota & 0.081 & 0.154 & $\mathbf{0 . 4 4 3}$ & 0.370 & $\mathbf{0 . 4 5 9}$ \\
Malayemys_subtrijuga & 0.051 & 0.998 & 0.116 & 0.131 & 0.899 \\
Orlitia_borneensis & 0.086 & 0.295 & 0.078 & 0.027 & 0.976 \\
Geoclemys_hamiltonii & 0.006 & 0.835 & 0.316 & 0.173 & 0.927 \\
Pangshura_tecta & 0.149 & 0.173 & 0.900 & 0.033 & 0.993 \\
Batagur_baska & 0.092 & 0.856 & 0.762 & 0.138 & 0.874 \\
Morenia_ocellata & 0.043 & 0.700 & 0.967 & 0.047 & 0.995 \\
Siebenrockiella_crassicollis & 0.057 & 0.017 & $\mathbf{0 . 7 1 9}$ & 0.082 & 0.979 \\
Malacochersus_tornieri & 0.144 & 0.024 & $\mathbf{0 . 5 6 1}$ & 0.026 & 0.994 \\
Testudo_marginata & 0.260 & 0.023 & $\mathbf{0 . 6 4 0}$ & 0.127 & 0.923 \\
Chelonoidis_nigra & 0.234 & 0.007 & 0.944 & 0.079 & 0.992 \\
Chelonoidis_carbonaria & 0.022 & 0.127 & 0.368 & 0.097 & 0.992 \\
Aldabrachelys_gigantea & 0.220 & 0.005 & 0.995 & 0.422 & 0.791 \\
Gopherus_flavomarginatus & 0.295 & 0.022 & 0.961 & 0.055 & 0.994 \\
Gopherus_polyphemus & 0.129 & 0.014 & 0.692 & 0.094 & 0.925 \\
Gopherus_agassizii & 0.181 & 0.022 & 0.939 & 0.089 & 0.997 \\
Platysternon_megacephalum & 0.089 & 0.644 & 0.074 & 0.498 & 0.124 \\
Glyptemys_insculpta & 0.145 & 0.588 & 0.158 & 0.275 & 0.669 \\
Glyptemys_muhlenbergii & 0.128 & 0.088 & 0.109 & 0.105 & 0.963 \\
Emys_orbicularis & 0.029 & 0.217 & 0.032 & 0.046 & 0.981 \\
Emydoidea_blandingii & 0.877 & 0.123 & 0.127 & 0.218 & 0.779 \\
& & & & &
\end{tabular}




\begin{tabular}{|c|c|c|c|c|c|}
\hline Terrapene_ornata & 0.077 & 0.206 & 0.209 & 0.226 & 0.879 \\
\hline Terrapene_coahuila & 0.021 & 0.400 & 0.016 & 0.027 & 0.998 \\
\hline Clemmys_guttata & 0.038 & 0.102 & 0.056 & 0.145 & 0.967 \\
\hline Deirochelys_reticularia & 0.987 & 0.033 & 0.302 & 0.338 & 0.669 \\
\hline Trachemys_scripta & 0.327 & 0.050 & 0.571 & 0.085 & 0.913 \\
\hline Graptemys_geographica & 0.135 & 0.904 & 0.245 & 0.090 & 0.947 \\
\hline Malaclemys_terrapin & 0.327 & 0.743 & 0.052 & 0.039 & 0.958 \\
\hline Chrysemys_picta & 0.376 & 0.052 & 0.659 & 0.025 & 0.984 \\
\hline Pseudemys_concinna & 0.206 & 0.089 & 0.959 & 0.104 & 0.989 \\
\hline Dermochelys_coriacea & 0.005 & 0.049 & 0.813 & 0.772 & 0.012 \\
\hline Caretta_caretta & 0.005 & 0.965 & 0.574 & 0.906 & 0.009 \\
\hline Lepidochelys_olivacea & 0.017 & 0.508 & 0.589 & 0.954 & 0.038 \\
\hline Lepidochelys_kempii & 0.019 & 0.740 & 0.396 & 0.970 & 0.045 \\
\hline Eretmochelys_imbricata & 0.007 & 0.989 & 0.006 & 0.960 & 0.013 \\
\hline Chelonia_mydas & 0.078 & 0.762 & 0.901 & 0.991 & 0.009 \\
\hline Natator_depressus & 0.042 & 0.668 & 0.763 & 0.920 & 0.122 \\
\hline Macrochelys_temminckii & 0.193 & 0.953 & 0.013 & 0.644 & 0.005 \\
\hline Chelydra_serpentina & 0.941 & 0.034 & 0.234 & 0.068 & 0.894 \\
\hline Dermatemys_mawii & 0.108 & 0.205 & 0.921 & 0.186 & 0.865 \\
\hline Staurotypus_salvinii & 0.039 & 0.893 & 0.046 & 0.056 & 0.930 \\
\hline Claudius_angustatus & 0.094 & 0.701 & 0.009 & 0.087 & 0.871 \\
\hline Sternotherus_minor & 0.007 & 0.989 & 0.223 & 0.142 & 0.925 \\
\hline Sternotherus_odoratus & 0.027 & 0.637 & 0.226 & 0.114 & 0.895 \\
\hline Kinosternon_subrubrum & 0.009 & 0.847 & 0.038 & 0.090 & 0.986 \\
\hline Kinosternon_baurii & 0.008 & 0.880 & 0.080 & 0.089 & 0.963 \\
\hline Carettochelys_insculpta & 0.179 & 0.175 & 0.114 & 0.012 & 0.987 \\
\hline Trionyx_triunguis & 0.848 & 0.056 & 0.583 & 0.036 & 0.979 \\
\hline Chitra_indica & 0.998 & 0.584 & 0.072 & 0.149 & 0.724 \\
\hline Apalone_mutica & 0.945 & 0.069 & 0.337 & 0.030 & 0.988 \\
\hline Apalone_spinifera & 0.941 & 0.166 & 0.543 & 0.050 & 0.955 \\
\hline Amyda_cartilaginea & 0.953 & 0.115 & 0.685 & 0.087 & 0.943 \\
\hline Pelodiscus_sinensis & 0.968 & 0.122 & 0.351 & 0.038 & 0.995 \\
\hline Cycloderma_frenatum & 0.890 & 0.370 & 0.188 & 0.024 & 0.973 \\
\hline Cyclanorbis_senegalensis & 0.976 & 0.192 & 0.714 & 0.015 & 0.995 \\
\hline Lissemys_punctata & 0.693 & 0.341 & 0.501 & 0.001 & 1.000 \\
\hline Pelomedusa_subrufa & 0.637 & 0.006 & 0.200 & 0.032 & 0.978 \\
\hline Pelusios_sinuatus & 0.499 & 0.026 & 0.117 & 0.007 & 0.997 \\
\hline Peltocephalus_dumerilianus & 0.750 & 0.433 & 0.480 & 0.684 & 0.079 \\
\hline Podocnemis_expansa & 0.904 & 0.222 & 0.710 & 0.108 & 0.843 \\
\hline Podocnemis_unifilis & 0.753 & 0.131 & 0.250 & 0.044 & 0.974 \\
\hline Elseya_dentata & 0.613 & 0.090 & 0.381 & 0.260 & 0.648 \\
\hline Chelodina_oblonga & 0.891 & 0.037 & 0.005 & 0.007 & 0.998 \\
\hline Hydromedusa_tectifera & 0.974 & 0.005 & 0.035 & 0.001 & 1.000 \\
\hline Chelus_fimbriatus & 0.991 & 0.008 & 0.041 & 0.017 & 0.991 \\
\hline Phrynops_hilarii & 0.835 & 0.004 & 0.308 & 0.007 & 0.994 \\
\hline Phrynops_geoffroanus & 0.659 & 0.007 & 0.223 & 0.012 & 0.996 \\
\hline
\end{tabular}




\section{Appendix 3}

\section{List of specimens and ecological traits}

The following table refer to the specimen numbers of the taxa used in my work, as well as the ecological traits scored as ' 0 ' (absence) and ' 1 ' (presence) for each taxon. The ecological traits are described in Supplementary File 3 ('Description of binary ecological traits'). For fossil species, $N A$ s were scored ('non-applicable').

Institutional abbreviations: AMNH, American Museum of Natural History, New York, USA; CAMSM, Sedgwick Museum of Earth Sciences, Cambridge, UK; DMNH, Denver Museum of Nature and Science, Denver, USA; FMNH, Field Museum of Natural History, Chicago, USA; IRSN, Royal Belgian Institute of Natural Sciences, Brussels, Belgium; IVPPV, Institute of Vertebrate Paleontology and Paleoanthropology, Beijing, China; IW, Ingmar Werneburg personal collection; KUVP, University of Kansas, Lawrence, USA; LIRP, Laboratório de Ictiologia de Ribeirão Preto, Ribeirão Preto, Brazil; MAD, Madagascar; MIWG, Museum of Isle of Wight Geology, Sandown, Isle of Wight; NHMUK, Natural History Museum, London, UK; PCHP, Peter Pritchard personal collection; PIMUZ, Paläontologisches Institut und Museum of the University of Zurich, Zurich, Switzerland; SMF, Senckenberg Research Institute, Frankfurt, Germany; SMNS, Staatliches Museum für Naturkunde, Stuttgart, Germany; UF, Vertebrate Paleontology Collection, Florida Museum of National History, University of Florida, Gainesville, USA; UMCZ, University Museum of Zoology, Cambridge, UK; WGJ, Walter G. Joyce personal collection; YPM VZ, Yale Peabody Museum of Natural History, New Haven, USA; ZM, Zoological Museum of the University of Zurich, Zurich, Switzerland.

\begin{tabular}{lclcccc}
\hline \multicolumn{1}{c}{ Taxon } & Specimen & Type & Seeds_fruits & Flowers & Stems & Terrestrial_leaves \\
\hline Aldabrachelys_gigantea & NHMUK 7711122 & Extant & 1 & 0 & 0 & 1 \\
Amyda_cartilaginea & FMNH 244117 & Extant & 1 & 0 & 0 & 0 \\
Apalone_mutica & PCHP 2746 & Extant & 0 & 0 & 0 & 0 \\
Apalone_spinifera & FMNH 22178 & Extant & 0 & 0 & 0 & 0 \\
Batagur_baska & NHMUK 679287 & Extant & 1 & 0 & 0 & 0 \\
Caretta_caretta & NHMUK 1938191 & Extant & 0 & 0 & 0 & 0 \\
Carettochelys_insculpta & NHMUK 19037101 & Extant & 1 & 1 & 1 & 0 \\
Chelodina_oblonga & NHMUK 641222 & Extant & 0 & 0 & 0 & 0 \\
Chelonia_mydas & NHMUK 1969776 & Extant & 0 & 0 & 0 & 0 \\
Chelonoidis_carbonaria & uncataloged & Extant & 1 & 1 & 0 & 1 \\
Chelonoidis_nigra & SMF 67582* & Extant & 1 & 0 & 0 & 1 \\
Chelus_fimbriatus & NHMUK 819274 & Extant & 0 & 0 & 0 & 0 \\
Chelydra_serpentina & UCMZ uncataloged & Extant & 1 & 0 & 0 & 0 \\
Chitra_indica & NHMUK 192612161 & Extant & 0 & 0 & 0 & 0 \\
Chrysemys_picta & NHMUK 7613119 & Extant & 1 & 0 & 0 & 0 \\
Claudius_angustatus & SMNS 14380 & Extant & 0 & 0 & 0 & 0 \\
Clemmys_guttata & FMNH 22114 & Extant & 0 & 0 & 0 & 0 \\
Cuora_amboinensis & PCHP 5077 & Extant & 1 & 0 & 0 & 1 \\
Cuora_flavomarginata & FMNH 21515 & Extant & 1 & 0 & 0 & 1
\end{tabular}




\begin{tabular}{|c|c|c|c|c|c|c|}
\hline Cyclanorbis_senegalensis & NHMUK 655921 & Extant & 0 & 0 & 0 & 0 \\
\hline Cyclemys_dentata & NHMUK 9711223 & Extant & 1 & 0 & 1 & 0 \\
\hline Cycloderma_frenatum & NHMUK 84241 & Extant & 0 & 0 & 0 & 0 \\
\hline Deirochelys_reticularia & FMNH 98754 & Extant & 0 & 0 & 0 & 0 \\
\hline Dermatemys_mawii & SMF 59453 & Extant & 1 & 0 & 0 & 1 \\
\hline Dermochelys_coriacea & UMZC R3031 & Extant & 0 & 0 & 0 & 0 \\
\hline Elseya_dentata & NHMUK 7651977 & Extant & 1 & 0 & 0 & 0 \\
\hline Emydoidea_blandingii & FMNH 22144 & Extant & 0 & 0 & 0 & 0 \\
\hline Emydura_subglobosa & PIMUZ 2009.37 & Extant & 0 & 1 & 0 & 0 \\
\hline Emys_orbicularis & WGJ1987a & Extant & 1 & 0 & 1 & 0 \\
\hline Eretmochelys_imbricata & FMNH 22242 & Extant & 0 & 0 & 0 & 0 \\
\hline Geoclemys_hamiltonii & NHMUK 879301 & Extant & 0 & 0 & 0 & 0 \\
\hline Glyptemys_insculpta & FMNH 22240 & Extant & 1 & 1 & 0 & 1 \\
\hline Glyptemys_muhlenbergii & UF 85274 & Extant & 1 & 0 & 0 & 1 \\
\hline Gopherus_agassizii & FMNH 216746 & Extant & 0 & 1 & 1 & 1 \\
\hline Gopherus_flavomarginatus & FMNH 98916 & Extant & 0 & 1 & 1 & 1 \\
\hline Gopherus_polyphemus & FMNH 211815 & Extant & 0 & 1 & 1 & 1 \\
\hline Graptemys_geographica & NHMUK 5512611 & Extant & 0 & 0 & 0 & 0 \\
\hline Heosemys_grandis & uncataloged & Extant & 0 & 0 & 0 & 1 \\
\hline Hieremys_annandalii & FMNH 260389 & Extant & 1 & 0 & 0 & 0 \\
\hline Hydromedusa_tectifera & SMF 70500 & Extant & 0 & 0 & 0 & 0 \\
\hline Kinosternon_baurii & FMNH 211705 & Extant & 1 & 0 & 0 & 0 \\
\hline Kinosternon_subrubrum & FMNH 211711 & Extant & 0 & 0 & 0 & 0 \\
\hline Lepidochelys_kempii & M 00908 & Extant & 0 & 0 & 0 & 0 \\
\hline Lepidochelys_olivacea & SMNS 11070 & Extant & 0 & 0 & 0 & 0 \\
\hline Lissemys_punctata & SMF 74141 & Extant & 1 & 0 & 0 & 0 \\
\hline Macrochelys_temminckii & FMNH 22111 & Extant & 1 & 0 & 0 & 0 \\
\hline Malaclemys_terrapin & FMNH 57803 & Extant & 0 & 0 & 0 & 0 \\
\hline Malacochersus_tornieri & $\begin{array}{l}\text { ZM } 100102 \\
\text { NHMUK }\end{array}$ & Extant & 0 & 0 & 0 & 1 \\
\hline Malayemys_subtrijuga & $\begin{array}{c}19201202545 \\
\text { NHMUK }\end{array}$ & Extant & 0 & 0 & 0 & 0 \\
\hline Mauremys_leprosa & unnumbered & Extant & 1 & 0 & 0 & 0 \\
\hline Melanochelys_trijuga & YPM VZ 014519 & Extant & 1 & 0 & 0 & 0 \\
\hline Morenia_ocellata & NHMUK 873117 & Extant & 0 & 0 & 0 & 0 \\
\hline Natator_depressus & R 112123 & Extant & 0 & 0 & 0 & 0 \\
\hline Notochelys_platynota & FMNH 224048 & Extant & 1 & 0 & 0 & 0 \\
\hline Orlitia_borneensis & NHMUK 19493429 & Extant & 1 & 0 & 0 & 0 \\
\hline Pangshura_tecta & NHMUK 1889261 & Extant & 0 & 0 & 0 & 0 \\
\hline Pelodiscus_sinensis & IW 5762 & Extant & 0 & 0 & 0 & 0 \\
\hline Pelomedusa_subrufa & SMF 70504 & Extant & 1 & 0 & 0 & 0 \\
\hline Peltocephalus_dumerilianus & uncataloged & Extant & 1 & 0 & 0 & 0 \\
\hline Pelusios_sinuatus & USNM 42144 & Extant & 0 & 0 & 0 & 0 \\
\hline Phrynops_geoffroanus & SMF 45470 & Extant & 1 & 0 & 0 & 0 \\
\hline Phrynops_hilarii & NHMUK 913161 & Extant & 0 & 0 & 0 & 0 \\
\hline Platysternon_megacephalum & SMF 69684 & Extant & 1 & 0 & 0 & 0 \\
\hline Podocnemis_expansa & LIRP unnumbered & Extant & 1 & 1 & 1 & 0 \\
\hline Podocnemis_unifilis & SMF 55470 & Extant & 1 & 1 & 1 & U \\
\hline
\end{tabular}


Pseudemys_concinna

Pseudemys_floridana

Rhinoclemmys_melanosterna

Rhinoclemmys_pulcherrima

Siebenrockiella_crassicollis

Staurotypus_salvinii

Sternotherus_minor

Sternotherus_odoratus

Terrapene_coahuila

Terrapene_ornata

Testudo_marginata

Trachemys_scripta

Trionyx_triunguis

Annemys_sp

Araiochelys_hirayamai

Argillochelys_antiqua

Bairdemys_hartsteini

Desmatochelys_lowii

Eochelone_brabantica

Eubaena_cephalica

Galianemys_emringeri

Jurassichelon_oleronensis

Labrostochelys_galkini

Lapparentemys_vilavilensis

Madagascar_turtle

Phosphatochelys_tedfordi

Puppigerus_camperi

Rhinochelys_cantabrigiensis

Sandownia_harrisi

Ummulisani rutgersensis

\begin{tabular}{|c|c|c|c|c|c|}
\hline FMNH 22146 & Extant & 0 & 0 & 0 & 0 \\
\hline FMNH 8222 & Extant & 0 & 0 & 0 & 0 \\
\hline FMNH 44446 & Extant & 1 & 0 & 1 & 1 \\
\hline PCHP unnumbered & Extant & 1 & 1 & 0 & 1 \\
\hline NHMUK 18649247 & Extant & 1 & 0 & 0 & 0 \\
\hline NHMUK 1879175 & Extant & 0 & 0 & 0 & 0 \\
\hline FMNH 211696 & Extant & 0 & 0 & 0 & 0 \\
\hline YPM VZ 019736 & Extant & 0 & 0 & 0 & 0 \\
\hline FMNH 47372 & Extant & 0 & 0 & 0 & 0 \\
\hline FMNH 23014 & Extant & 1 & 1 & 0 & 1 \\
\hline FMNH 51672 & Extant & 1 & 1 & 0 & 1 \\
\hline uncataloged & Extant & 1 & 1 & 1 & 0 \\
\hline PCHP 4559 & Extant & 0 & 0 & 0 & 0 \\
\hline IVPPV 18106 & Fossil & NA & NA & NA & NA \\
\hline AMNH 30778 & Fossil & NA & NA & NA & NA \\
\hline NHMUK R38955 & Fossil & NA & NA & NA & NA \\
\hline AMNH FR27222 & Fossil & NA & NA & NA & NA \\
\hline KUVP 1200 & Fossil & NA & NA & NA & NA \\
\hline IRSN BR 0061 & Fossil & NA & NA & NA & NA \\
\hline DMNH 96004 & Fossil & NA & NA & NA & NA \\
\hline AMNH 30035 & Fossil & NA & NA & NA & NA \\
\hline PIMUZ AIII 514 & Fossil & NA & NA & NA & NA \\
\hline AMNH 30043 & Fossil & NA & NA & NA & NA \\
\hline AMNH 14444 & Fossil & NA & NA & NA & NA \\
\hline MAD 153359 & Fossil & NA & NA & NA & NA \\
\hline AMNH 30008 & Fossil & NA & NA & NA & NA \\
\hline IRSN BR 0076 & Fossil & NA & NA & NA & NA \\
\hline CAMSM B55783 & Fossil & NA & NA & NA & NA \\
\hline MIWG 3480 & Fossil & NA & NA & NA & NA \\
\hline AMNH 30569 & Fossil & NA & NA & NA & NA \\
\hline
\end{tabular}

Taxon

Aquatic_leaves Mostly_vegetable_matter Fungi Vertebrates Jellyfish

Aldabrachelys_gigantea

Amyda_cartilaginea

$0 \quad 1$

Apalone_mutica

Apalone_spinifera

Batagur_baska

Caretta_caretta

Carettochelys_insculpta

Chelodina_oblonga

Chelonia_mydas

Chelonoidis_carbonaria

Chelonoidis_nigra

Chelus fimbriatus

Chelydra_serpentina

Chitra_indica

Chrysemys_picta

1 0

1 0

$0 \quad 0$

1

0

1

0

1

0

0

0

1

0

1

0

0

0

1

0

0

$$
0
$$

1

\section{0}

1

0

0

0

0

0

0

0

0

0

0

0

0

0

0

0

0
1

1

0

0

0

0

0




\begin{tabular}{|c|c|c|c|c|}
\hline Claudius_angustatus & 0 & 0 & 0 & 0 \\
\hline Clemmys_guttata & 0 & 0 & 0 & 0 \\
\hline Cuora_amboinensis & 1 & 0 & 1 & 0 \\
\hline Cuora_flavomarginata & 0 & 0 & 0 & 0 \\
\hline Cyclanorbis_senegalensis & 0 & 0 & 0 & 1 \\
\hline Cyclemys_dentata & 1 & 1 & 0 & 0 \\
\hline Cycloderma_frenatum & 0 & 0 & 0 & 1 \\
\hline Deirochelys_reticularia & 0 & 0 & 0 & 0 \\
\hline Dermatemys_mawii & 1 & 1 & 0 & 0 \\
\hline Dermochelys_coriacea & 0 & 0 & 0 & 0 \\
\hline Elseya_dentata & 1 & 1 & 0 & 0 \\
\hline Emydoidea_blandingii & 0 & 0 & 0 & 1 \\
\hline Emydura_subglobosa & 1 & 0 & 0 & 0 \\
\hline Emys_orbicularis & 0 & 0 & 0 & 1 \\
\hline Eretmochelys_imbricata & 0 & 0 & 0 & 0 \\
\hline Geoclemys_hamiltonii & 0 & 0 & 0 & 0 \\
\hline Glyptemys_insculpta & 0 & 0 & 1 & 0 \\
\hline Glyptemys_muhlenbergii & 0 & 0 & 0 & 0 \\
\hline Gopherus_agassizii & 0 & 1 & 0 & 0 \\
\hline Gopherus_flavomarginatus & 0 & 1 & 0 & 0 \\
\hline Gopherus_polyphemus & 0 & 1 & 0 & 0 \\
\hline Graptemys_geographica & 0 & 0 & 0 & 0 \\
\hline Heosemys_grandis & 1 & 0 & 0 & 1 \\
\hline Hieremys_annandalii & 1 & 1 & 0 & 0 \\
\hline Hydromedusa_tectifera & 0 & 0 & 0 & 0 \\
\hline Kinosternon_baurii & 0 & 0 & 0 & 0 \\
\hline Kinosternon_subrubrum & 0 & 0 & 0 & 1 \\
\hline Lepidochelys_kempii & 0 & 0 & 0 & 0 \\
\hline Lepidochelys_olivacea & 0 & 0 & 0 & 1 \\
\hline Lissemys_punctata & 0 & 0 & 0 & 1 \\
\hline Macrochelys_temminckii & 0 & 0 & 0 & 1 \\
\hline Malaclemys_terrapin & 0 & 0 & 0 & 0 \\
\hline Malacochersus_tornieri & 0 & 1 & 0 & 0 \\
\hline Malayemys_subtrijuga & 0 & 0 & 0 & 0 \\
\hline Mauremys_leprosa & 1 & 0 & 0 & 0 \\
\hline Melanochelys_trijuga & 1 & 0 & 0 & 0 \\
\hline Morenia_ocellata & 1 & 1 & 0 & 0 \\
\hline Natator_depressus & 0 & 0 & 0 & 0 \\
\hline Notochelys_platynota & 1 & 1 & 0 & 0 \\
\hline Orlitia_borneensis & 1 & 0 & 0 & 1 \\
\hline Pangshura_tecta & 1 & 1 & 0 & 0 \\
\hline Pelodiscus_sinensis & 1 & 0 & 0 & 1 \\
\hline Pelomedusa_subrufa & 0 & 0 & 0 & 1 \\
\hline Peltocephalus_dumerilianus & 1 & 0 & 0 & 1 \\
\hline Pelusios_sinuatus & 0 & 0 & 0 & 1 \\
\hline Phrynops_geoffroanus & 1 & 0 & 0 & 1 \\
\hline Phrynops_hilarii & 0 & 0 & 0 & 0 \\
\hline Platysternon_megacephalum & 0 & 0 & 0 & 0 \\
\hline
\end{tabular}


Podocnemis_expansa

Podocnemis_unifilis

Pseudemys_concinna

Pseudemys_floridana

Rhinoclemmys_melanosterna

Rhinoclemmys_pulcherrima

Siebenrockiella_crassicollis

Staurotypus_salvinii

Sternotherus_minor

Sternotherus_odoratus

Terrapene_coahuila

Terrapene_ornata

Testudo_marginata

Trachemys_scripta

Trionyx_triunguis

Annemys_sp

Araiochelys_hirayamai

Argillochelys_antiqua

Bairdemys_hartsteini

Desmatochelys_lowii

Eochelone_brabantica

Eubaena_cephalica

Galianemys_emringeri

Jurassichelon_oleronensis

Labrostochelys_galkini

Lapparentemys_vilavilensis

Madagascar_turtle

Phosphatochelys_tedfordi

Puppigerus_camperi

Rhinochelys_cantabrigiensis

Sandownia_harrisi

Ummulisani_rutgersensis
NA

$\begin{array}{ccc}0 & 0 & 0 \\ 0 & 0 & 0 \\ 0 & 0 & 0 \\ 0 & 0 & 0 \\ 0 & 0 & 0 \\ 0 & 0 & 0 \\ 0 & 1 & 0 \\ 0 & 1 & 0 \\ 0 & 0 & 0 \\ 0 & 0 & 0 \\ 1 & 0 & 0 \\ 0 & 0 & 0 \\ 0 & 0 & 0 \\ 0 & 0 & 0 \\ 0 & 1 & 0 \\ \text { NA } & \text { NA } & \text { NA } \\ \text { NA } & \text { NA } & \text { NA }\end{array}$

NA

NA

NA

NA

NA

NA

NA

NA

NA

NA

NA

NA

NA

NA

NA

NA

NA
NA NA

NA NA

NA NA

NA NA

NA NA

NA NA

NA NA

NA NA

NA NA

NA NA

NA NA

NA NA

NA NA

NA NA

NA NA

NA
0

0

0

0

0

0

0

0

0

0

0

0

0

0

0

NA

NA

NA

NA

NA

NA

NA

NA

NA

NA

NA

NA

NA

NA

NA

NA

NA

\section{Taxon}

Aquatic_insects Terrestrial_arthropods Worms Mollusks Crustaceans

Aldabrachelys_gigantea

Aquatic_insects Terrestrial

Amyda_cartilaginea

1

Apalone_mutica

Apalone_spinifera

0

0

Batagur_baska

1

1

Caretta_caretta

Carettochelys_insculpta

Chelodina_oblonga

0

0

0

Chelonia_mydas

Chelonoidis_carbonaria

Chelonoidis_nigra

Chelus fimbriatus

Chelydra_serpentina

1

1

0

0

0

0

1

0
0
0
0
0
0
0
1
0
0
0

$\begin{array}{lll}0 & & 0 \\ 0 & & 0 \\ 0 & & 0 \\ 0 & & 0 \\ 0 & & 1 \\ 0 & & 1 \\ 0 & & 1 \\ 0 & & 0 \\ 0 & & 0 \\ 0 & & 0 \\ 0 & & 0 \\ 0 & & 0 \\ 0 & & 1\end{array}$

\section{0}

1

1

1




\begin{tabular}{|c|c|c|c|c|}
\hline Chitra_indica & 1 & 0 & 0 & 0 \\
\hline Chrysemys_picta & 1 & 0 & 0 & 0 \\
\hline Claudius_angustatus & 1 & 1 & 0 & 0 \\
\hline Clemmys_guttata & 1 & 0 & 1 & 1 \\
\hline Cuora_amboinensis & 0 & 1 & 1 & 0 \\
\hline Cuora_flavomarginata & 0 & 1 & 1 & 1 \\
\hline Cyclanorbis_senegalensis & 0 & 0 & 0 & 1 \\
\hline Cyclemys_dentata & 0 & 0 & 0 & 0 \\
\hline Cycloderma_frenatum & 0 & 0 & 0 & 1 \\
\hline Deirochelys_reticularia & 1 & 0 & 0 & 0 \\
\hline Dermatemys_mawii & 0 & 0 & 0 & 0 \\
\hline Dermochelys_coriacea & 0 & 0 & 0 & 0 \\
\hline Elseya_dentata & 0 & 0 & 0 & 0 \\
\hline Emydoidea_blandingii & 1 & 0 & 0 & 0 \\
\hline Emydura_subglobosa & 1 & 0 & 0 & 1 \\
\hline Emys_orbicularis & 1 & 0 & 1 & 0 \\
\hline Eretmochelys_imbricata & 0 & 0 & 0 & 1 \\
\hline Geoclemys_hamiltonii & 0 & 0 & 0 & 1 \\
\hline Glyptemys_insculpta & 0 & 1 & 1 & 1 \\
\hline Glyptemys_muhlenbergii & 1 & 1 & 1 & 0 \\
\hline Gopherus_agassizii & 0 & 0 & 0 & 0 \\
\hline Gopherus_flavomarginatus & 0 & 0 & 0 & 0 \\
\hline Gopherus_polyphemus & 0 & 0 & 0 & 0 \\
\hline Graptemys_geographica & 0 & 0 & 0 & 1 \\
\hline Heosemys_grandis & 1 & 0 & 1 & 1 \\
\hline Hieremys_annandalii & 0 & 0 & 0 & 0 \\
\hline Hydromedusa_tectifera & 1 & 0 & 0 & 0 \\
\hline Kinosternon_baurii & 1 & 1 & 0 & 1 \\
\hline Kinosternon_subrubrum & 0 & 0 & 0 & 1 \\
\hline Lepidochelys_kempii & 0 & 0 & 0 & 1 \\
\hline Lepidochelys_olivacea & 0 & 0 & 0 & 1 \\
\hline Lissemys_punctata & 1 & 0 & 0 & 1 \\
\hline Macrochelys_temminckii & 1 & 0 & 0 & 1 \\
\hline Malaclemys_terrapin & 0 & 0 & 0 & 1 \\
\hline Malacochersus_tornieri & 0 & 0 & 0 & 0 \\
\hline Malayemys_subtrijuga & 0 & 0 & 0 & 1 \\
\hline Mauremys_leprosa & 1 & 0 & 1 & 0 \\
\hline Melanochelys_trijuga & 1 & 0 & 0 & 1 \\
\hline Morenia_ocellata & 0 & 0 & 0 & 0 \\
\hline Natator_depressus & 0 & 0 & 0 & 1 \\
\hline Notochelys_platynota & 0 & 0 & 0 & 0 \\
\hline Orlitia_borneensis & 0 & 0 & 0 & 1 \\
\hline Pangshura_tecta & 0 & 0 & 0 & 0 \\
\hline Pelodiscus_sinensis & 1 & 1 & 0 & 1 \\
\hline Pelomedusa_subrufa & 0 & 1 & 0 & 0 \\
\hline Peltocephalus_dumerilianus & 0 & 0 & 0 & 1 \\
\hline Pelusios_sinuatus & 1 & 1 & 0 & 1 \\
\hline Phrynops_geoffroanus & 1 & 0 & 0 & 0 \\
\hline
\end{tabular}




\begin{tabular}{|c|c|c|c|c|c|}
\hline Phrynops_hilarii & 1 & 0 & 0 & 0 & 0 \\
\hline Platysternon_megacephalum & 0 & 0 & 1 & 1 & 1 \\
\hline Podocnemis_expansa & 0 & 0 & 0 & 0 & 0 \\
\hline Podocnemis_unifilis & 0 & 0 & 0 & 0 & 0 \\
\hline Pseudemys_concinna & 0 & 0 & 0 & 0 & 0 \\
\hline Pseudemys_floridana & 0 & 0 & 0 & 0 & 0 \\
\hline Rhinoclemmys_melanosterna & 0 & 0 & 1 & 0 & 0 \\
\hline Rhinoclemmys_pulcherrima & 0 & 1 & 1 & 0 & 0 \\
\hline Siebenrockiella_crassicollis & 0 & 0 & 1 & 1 & 0 \\
\hline Staurotypus_salvinii & 0 & 0 & 0 & 1 & 0 \\
\hline Sternotherus_minor & 0 & 1 & 0 & 1 & 1 \\
\hline Sternotherus_odoratus & 1 & 0 & 0 & 1 & 0 \\
\hline Terrapene_coahuila & 1 & 1 & 0 & 0 & 0 \\
\hline Terrapene_ornata & 0 & 1 & 1 & 0 & 0 \\
\hline Testudo_marginata & 0 & 0 & 0 & 0 & 0 \\
\hline Trachemys_scripta & 1 & 0 & 0 & 0 & 1 \\
\hline Trionyx_triunguis & 1 & 0 & 0 & 1 & 1 \\
\hline Annemys_sp & NA & NA & NA & NA & NA \\
\hline Araiochelys_hirayamai & NA & NA & NA & NA & NA \\
\hline Argillochelys_antiqua & NA & NA & NA & NA & NA \\
\hline Bairdemys_hartsteini & NA & NA & NA & NA & NA \\
\hline Desmatochelys_lowii & NA & NA & NA & NA & NA \\
\hline Eochelone_brabantica & NA & NA & NA & NA & NA \\
\hline Eubaena_cephalica & NA & NA & NA & NA & NA \\
\hline Galianemys_emringeri & NA & NA & NA & NA & NA \\
\hline Jurassichelon_oleronensis & NA & NA & NA & NA & NA \\
\hline Labrostochelys_galkini & NA & NA & NA & NA & NA \\
\hline Lapparentemys_vilavilensis & NA & NA & NA & NA & NA \\
\hline Madagascar_turtle & NA & NA & NA & NA & NA \\
\hline Phosphatochelys_tedfordi & NA & NA & NA & NA & NA \\
\hline Puppigerus_camperi & NA & NA & NA & NA & NA \\
\hline Rhinochelys_cantabrigiensis & NA & NA & NA & NA & NA \\
\hline Sandownia_harrisi & NA & NA & NA & NA & NA \\
\hline Ummulisani rutgersensis & NA & NA & NA & NA & NA \\
\hline
\end{tabular}

\section{Taxon}

Mostly_animal_matter Feed_on_water Feed_on_land Mostly_feed_on_land

Aldabrachelys_gigantea

Amyda_cartilaginea

$\begin{array}{ll}0 & \\ 1 \\ 1 \\ 1 \\ 0 \\ 1 \\ 0 & 1 \\ 1 & 1 \\ 0 & 1 \\ 0 & 1 \\ 0 & 0\end{array}$

Apalone_mutica

$\begin{array}{ll}0 & 0 \\ 1 & 1 \\ 1 & 1 \\ 1 & 1 \\ 0 & 1 \\ 1 & 1 \\ 0 & 1 \\ 1 & 1 \\ 0 & 1 \\ 0 & 0 \\ 0 & 0\end{array}$

Apalone_spinifera

\section{1}

Batagur_baska

1

Caretta_caretta

Carettochelys_insculpta

$\begin{array}{ll}0 & \\ 1 & 1 \\ 1 & 1 \\ 1 & \\ 0 & 1 \\ 1 & 1 \\ 0 & 1 \\ 1 & 1 \\ 0 & 1 \\ 0 & 0 \\ 0 & 0\end{array}$

$\begin{array}{ll}0 & \\ 1 \\ 1 \\ 1 \\ 0 \\ 1 \\ 0 & 1 \\ 1 & 1 \\ 0 & 1 \\ 0 & 1 \\ 0 & 0\end{array}$

Chelodina_oblonga

$\begin{array}{ll}0 & 0 \\ 1 & 1 \\ 1 & 1 \\ 1 & 1 \\ 0 & 1 \\ 1 & 1 \\ 0 & 1 \\ 1 & 1 \\ 0 & 1 \\ 0 & 0 \\ 0 & 0\end{array}$

Chelonia_mydas

Chelonoidis_carbonaria

Chelonoidis_nigra

0
1
1
1
1
1
1
1
1
0
0

1
1
1
1
1
1
1
1
0
0

and

1
0
0
0
0

1

\author{
0
}

0

0

0

0

0

0

0

1

1 
Chelus fimbriatus 1

Chelydra_serpentina $\quad 0$

Chitra_indica

Chrysemys picta

Claudius_angustatus

Clemmys_guttata

Cuora_amboinensis

Cuora_flavomarginata

Cyclanorbis_senegalensis

Cyclemys_dentata

Cycloderma frenatum

Deirochelys_reticularia

Dermatemys_mawii

Dermochelys_coriacea

Elseya_dentata

Emydoidea_blandingii

Emydura_subglobosa

Emys_orbicularis

Eretmochelys_imbricata

Geoclemys_hamiltonii

Glyptemys_insculpta

Glyptemys_muhlenbergii

Gopherus_agassizii

Gopherus flavomarginatus

Gopherus_polyphemus

Graptemys_geographica

Heosemys_grandis

Hieremys_annandalii

Hydromedusa_tectifera

Kinosternon_baurii

Kinosternon_subrubrum

Lepidochelys_kempii

Lepidochelys_olivacea

Lissemys punctata

Macrochelys_temminckii

Malaclemys_terrapin

Malacochersus_tornieri

Malayemys_subtrijuga

Mauremys_leprosa

Melanochelys_trijuga

Morenia_ocellata

Natator_depressus

Notochelys_platynota

Orlitia borneensis

Pangshura_tecta

Pelodiscus_sinensis

Pelomedusa_subrufa

Peltocephalus_dumerilianus

\begin{tabular}{|c|c|}
\hline 1 & 0 \\
\hline 1 & 0 \\
\hline 1 & 0 \\
\hline 1 & 0 \\
\hline 1 & 0 \\
\hline 1 & 0 \\
\hline 1 & 1 \\
\hline 1 & 1 \\
\hline 1 & 0 \\
\hline 1 & 0 \\
\hline 1 & 0 \\
\hline 1 & 0 \\
\hline 1 & 0 \\
\hline 1 & 0 \\
\hline 1 & 0 \\
\hline 1 & 0 \\
\hline 1 & 0 \\
\hline 1 & 0 \\
\hline 1 & 0 \\
\hline 1 & 0 \\
\hline 1 & 1 \\
\hline 1 & 1 \\
\hline 0 & 1 \\
\hline 0 & 1 \\
\hline 0 & 1 \\
\hline 1 & 0 \\
\hline 1 & 1 \\
\hline 1 & 0 \\
\hline 1 & 0 \\
\hline 1 & 0 \\
\hline 1 & 0 \\
\hline 1 & 0 \\
\hline 1 & 0 \\
\hline 1 & 0 \\
\hline 1 & 0 \\
\hline 1 & 0 \\
\hline 0 & 1 \\
\hline 1 & 0 \\
\hline 1 & 0 \\
\hline 1 & 0 \\
\hline 1 & 0 \\
\hline 1 & 0 \\
\hline 1 & 0 \\
\hline 1 & 0 \\
\hline 1 & 0 \\
\hline 1 & 0 \\
\hline 1 & 0 \\
\hline 1 & 0 \\
\hline
\end{tabular}


Pelusios_sinuatus

Phrynops_geoffroanus

Phrynops_hilarii

Platysternon_megacephalum

Podocnemis_expansa

Podocnemis_unifilis

Pseudemys_concinna

Pseudemys floridana

Rhinoclemmys_melanosterna

Rhinoclemmys_pulcherrima

Siebenrockiella_crassicollis

Staurotypus_salvinii

Sternotherus_minor

Sternotherus_odoratus

Terrapene_coahuila

Terrapene_ornata

Testudo_marginata

Trachemys_scripta

Trionyx_triunguis

Annemys_sp

Araiochelys_hirayamai

Argillochelys_antiqua

Bairdemys_hartsteini

Desmatochelys_lowii

Eochelone_brabantica

Eubaena_cephalica

Galianemys_emringeri

Jurassichelon_oleronensis

Labrostochelys_galkini

Lapparentemys_vilavilensis

Madagascar_turtle

Phosphatochelys_tedfordi

Puppigerus_camperi

Rhinochelys_cantabrigiensis

Sandownia_harrisi

Ummulisani_rutgersensis

\begin{tabular}{|c|c|c|c|}
\hline 1 & 1 & 0 & 0 \\
\hline 0 & 1 & 0 & 0 \\
\hline 1 & 1 & 0 & 0 \\
\hline 0 & 1 & 0 & 0 \\
\hline 0 & 1 & 0 & 0 \\
\hline 0 & 1 & 0 & 0 \\
\hline 0 & 1 & 0 & 0 \\
\hline 0 & 1 & 0 & 0 \\
\hline 0 & 1 & 1 & 1 \\
\hline 0 & 1 & 1 & 1 \\
\hline 0 & 1 & 0 & 0 \\
\hline 1 & 1 & 0 & 0 \\
\hline 1 & 1 & 0 & 0 \\
\hline 1 & 1 & 0 & 0 \\
\hline 0 & 1 & 0 & 0 \\
\hline 0 & 0 & 1 & 1 \\
\hline 0 & 0 & 1 & 1 \\
\hline 0 & 1 & 0 & 0 \\
\hline 1 & 1 & 0 & 0 \\
\hline NA & NA & NA & NA \\
\hline NA & NA & NA & NA \\
\hline NA & NA & NA & NA \\
\hline NA & NA & NA & NA \\
\hline NA & NA & NA & NA \\
\hline NA & NA & NA & NA \\
\hline NA & NA & NA & NA \\
\hline NA & NA & NA & NA \\
\hline NA & NA & NA & NA \\
\hline NA & NA & NA & NA \\
\hline NA & NA & NA & NA \\
\hline NA & NA & NA & NA \\
\hline NA & NA & NA & NA \\
\hline NA & NA & NA & NA \\
\hline NA & NA & NA & NA \\
\hline NA & NA & NA & NA \\
\hline NA & NA & NA & NA \\
\hline
\end{tabular}

\begin{tabular}{lccccc}
\hline \multicolumn{1}{c}{ Taxon } & Suction_feeding & Mostly_hard_food & Marine & Neck_retraction & Clade \\
\hline Aldabrachelys_gigantea & 0 & 0 & 0 & 1 & Testudinidae \\
Amyda_cartilaginea & 1 & 0 & 0 & 1 & Trionychia \\
Apalone_mutica & 1 & 0 & 0 & 1 & Trionychia \\
Apalone_spinifera & 1 & 0 & 0 & 1 & Trionychia \\
Batagur_baska & 0 & 0 & 0 & 1 & Geoemydidae \\
Caretta_caretta & 0 & 1 & 1 & 0 & Chelonioidea \\
Carettochelys_insculpta & 0 & 0 & 0 & 1 & Trionychia \\
Chelodina_oblonga & 1 & 0 & 0 & 1 & Chelidae \\
Chelonia_mydas & 0 & 0 & 1 & 0 & Chelonioidea
\end{tabular}




\begin{tabular}{|c|c|c|c|c|c|}
\hline Chelonoidis_carbonaria & 0 & 0 & 0 & 1 & Testudinidae \\
\hline Chelonoidis_nigra & 0 & 0 & 0 & 1 & Testudinidae \\
\hline Chelus_fimbriatus & 1 & 0 & 0 & 1 & Chelidae \\
\hline Chelydra_serpentina & 0 & 0 & 0 & 1 & Chelydroidea \\
\hline Chitra_indica & 1 & 0 & 0 & 1 & Trionychia \\
\hline Chrysemys_picta & 1 & 0 & 0 & 1 & Emydidae \\
\hline Claudius_angustatus & 0 & 0 & 0 & 1 & Chelydroidea \\
\hline Clemmys_guttata & 0 & 0 & 0 & 1 & Emydidae \\
\hline Cuora_amboinensis & 0 & 0 & 0 & 1 & Geoemydidae \\
\hline Cuora_flavomarginata & 0 & 0 & 0 & 1 & Geoemydidae \\
\hline Cyclanorbis_senegalensis & 1 & 0 & 0 & 1 & Trionychia \\
\hline Cyclemys_dentata & 0 & 0 & 0 & 1 & Geoemydidae \\
\hline Cycloderma_frenatum & 1 & 1 & 0 & 1 & Trionychia \\
\hline Deirochelys_reticularia & 1 & 0 & 0 & 1 & Emydidae \\
\hline Dermatemys_mawii & 0 & 0 & 0 & 1 & Chelydroidea \\
\hline Dermochelys_coriacea & 1 & 0 & 1 & 0 & Chelonioidea \\
\hline Elseya_dentata & 0 & 0 & 0 & 1 & Chelidae \\
\hline Emydoidea_blandingii & 1 & 0 & 0 & 1 & Emydidae \\
\hline Emydura_subglobosa & 0 & 0 & 0 & 1 & Chelidae \\
\hline Emys_orbicularis & 0 & 0 & 0 & 1 & Emydidae \\
\hline Eretmochelys_imbricata & 0 & 1 & 1 & 0 & Chelonioidea \\
\hline Geoclemys_hamiltonii & 0 & 1 & 0 & 1 & Geoemydidae \\
\hline Glyptemys_insculpta & 0 & 0 & 0 & 1 & Emydidae \\
\hline Glyptemys_muhlenbergii & 0 & 0 & 0 & 1 & Emydidae \\
\hline Gopherus_agassizii & 0 & 0 & 0 & 1 & Testudinidae \\
\hline Gopherus_flavomarginatus & 0 & 0 & 0 & 1 & Testudinidae \\
\hline Gopherus_polyphemus & 0 & 0 & 0 & 1 & Testudinidae \\
\hline Graptemys_geographica & 0 & 1 & 0 & 1 & Emydidae \\
\hline Heosemys_grandis & 0 & 0 & 0 & 1 & Geoemydidae \\
\hline Hieremys_annandalii & 0 & 0 & 0 & 1 & Geoemydidae \\
\hline Hydromedusa_tectifera & 1 & 0 & 0 & 1 & Chelidae \\
\hline Kinosternon_baurii & 0 & 0 & 0 & 1 & Chelydroidea \\
\hline Kinosternon_subrubrum & 0 & 1 & 0 & 1 & Chelydroidea \\
\hline Lepidochelys_kempii & 0 & 1 & 1 & 0 & Chelonioidea \\
\hline Lepidochelys_olivacea & 0 & 1 & 1 & 0 & Chelonioidea \\
\hline Lissemys_punctata & 1 & 0 & 0 & 1 & Trionychia \\
\hline Macrochelys_temminckii & 0 & 0 & 0 & 0 & Chelydroidea \\
\hline Malaclemys_terrapin & 0 & 1 & 0 & 1 & Emydidae \\
\hline Malacochersus_tornieri & 0 & 0 & 0 & 1 & Testudinidae \\
\hline Malayemys_subtrijuga & 0 & 1 & 0 & 1 & Geoemydidae \\
\hline Mauremys_leprosa & 0 & 0 & 0 & 1 & Geoemydidae \\
\hline Melanochelys_trijuga & 0 & 0 & 0 & 1 & Geoemydidae \\
\hline Morenia_ocellata & 0 & 0 & 0 & 1 & Geoemydidae \\
\hline Natator_depressus & 0 & 0 & 1 & 0 & Chelonioidea \\
\hline Notochelys_platynota & 0 & 0 & 0 & 1 & Geoemydidae \\
\hline Orlitia_borneensis & 0 & 0 & 0 & 1 & Geoemydidae \\
\hline Pangshura_tecta & 0 & 0 & 0 & 1 & Geoemydidae \\
\hline Pelodiscus_sinensis & 1 & 0 & 0 & 1 & Trionychia \\
\hline
\end{tabular}




\begin{tabular}{|c|c|c|c|c|c|}
\hline Pelomedusa_subrufa & 0 & 0 & 0 & 1 & Pelomedusoides \\
\hline Peltocephalus_dumerilianus & 0 & 0 & 0 & 0 & Pelomedusoides \\
\hline Pelusios_sinuatus & 0 & 0 & 0 & 1 & Pelomedusoides \\
\hline Phrynops_geoffroanus & 1 & 0 & 0 & 1 & Chelidae \\
\hline Phrynops_hilarii & 1 & 0 & 0 & 1 & Chelidae \\
\hline Platysternon_megacephalum & 0 & 0 & 0 & 0 & Emydidae \\
\hline Podocnemis_expansa & 0 & 0 & 0 & 1 & Pelomedusoides \\
\hline Podocnemis_unifilis & 1 & 0 & 0 & 1 & Pelomedusoides \\
\hline Pseudemys_concinna & 0 & 0 & 0 & 1 & Emydidae \\
\hline Pseudemys floridana & 0 & 0 & 0 & 1 & Emydidae \\
\hline Rhinoclemmys_melanosterna & 0 & 0 & 0 & 1 & Geoemydidae \\
\hline Rhinoclemmys_pulcherrima & 0 & 0 & 0 & 1 & Geoemydidae \\
\hline Siebenrockiella_crassicollis & 0 & 0 & 0 & 1 & Geoemydidae \\
\hline Staurotypus_salvinii & 0 & 1 & 0 & 1 & Chelydroidea \\
\hline Sternotherus_minor & 0 & 1 & 0 & 1 & Chelydroidea \\
\hline Sternotherus_odoratus & 0 & 0 & 0 & 1 & Chelydroidea \\
\hline Terrapene_coahuila & 0 & 0 & 0 & 1 & Emydidae \\
\hline Terrapene_ornata & 0 & 0 & 0 & 1 & Emydidae \\
\hline Testudo_marginata & 0 & 0 & 0 & 1 & Testudinidae \\
\hline Trachemys_scripta & 0 & 0 & 0 & 1 & Emydidae \\
\hline Trionyx_triunguis & 1 & 0 & 0 & 1 & Trionychia \\
\hline Annemys_sp & NA & NA & NA & NA & Stem \\
\hline Araiochelys_hirayamai & NA & NA & NA & NA & Pelomedusoides \\
\hline Argillochelys_antiqua & NA & NA & NA & NA & Chelonioidea \\
\hline Bairdemys_hartsteini & NA & NA & NA & NA & Pelomedusoides \\
\hline Desmatochelys_lowii & NA & NA & NA & NA & Chelonioidea \\
\hline Eochelone_brabantica & NA & NA & NA & NA & Chelonioidea \\
\hline Eubaena_cephalica & NA & NA & NA & NA & Stem \\
\hline Galianemys_emringeri & NA & NA & NA & NA & Pelomedusoides \\
\hline Jurassichelon_oleronensis & NA & NA & NA & NA & Stem \\
\hline Labrostochelys_galkini & NA & NA & NA & NA & Pelomedusoides \\
\hline Lapparentemys_vilavilensis & NA & NA & NA & NA & Pelomedusoides \\
\hline Madagascar_turtle & NA & NA & NA & NA & Pelomedusoides \\
\hline Phosphatochelys_tedfordi & NA & NA & NA & NA & Pelomedusoides \\
\hline Puppigerus_camperi & NA & NA & NA & NA & Chelonioidea \\
\hline Rhinochelys_cantabrigiensis & NA & NA & NA & NA & Chelonioidea \\
\hline Sandownia_harrisi & NA & NA & NA & NA & Stem \\
\hline Ummulisani_rutgersensis & NA & NA & NA & NA & Pelomedusoides \\
\hline
\end{tabular}

This table can also be provided upon request in Excel format for better visualisation. All references used to score presence/absence for the ecological traits are listed in Appendix 5 ('Description of binary ecological traits'). 


\section{Appendix 4}

\section{Landmarks description}

\section{Introductory comments}

In the following landmark list, landmarks are numbered and associated with a short title (in bold) that represents my working nomenclature for landmarks used in the Avizo files, in which I landmarked the data. These short-titles sometimes include abbreviations that do not appropriately describe the landmarks, as the landmark definitions evolved during this process whereas initial names of landmark objects were kept as there is no straight forward way to rename landmark object names across different files. However, as each

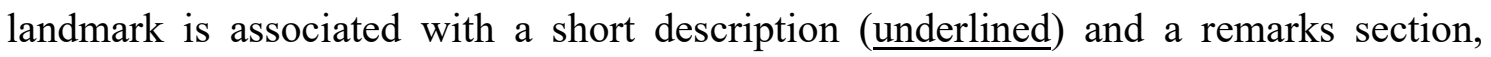
landmark definitions should be clear irrespective of their titles. Most landmarks used herein are type I landmarks, for which homology is supported by a unique topological arrangement of the bones that define the respective landmark. However, in some instances I also use type II landmarks, for which evidence for the homology only comes from geometric arguments, whereas the bony composition of the landmarked region may vary between turtles. Type II landmarks were necessary in order to bound open semilandmark series, which are used to capture specific geometric properties of the skulls that are generally considered useful when comparing skull geometries. For instance, LM1 is a type II landmark, because it defined the anterior end of the skull roof above the external naris, irrespective of whether this point is formed by the nasal, or by the prefrontal (if nasals are lost). This landmark further bounds SLM5 anteriorly, which extends across the skull roof and captures variation in skull length, and shape of the skull roof. For geometric comparisons of skull length of skull roof flexure, it is irrelevant if the anteriormost point of the compared entity is formed by the nasal or prefrontal, and thus the usage of type II landmarks is justified for my study.

\section{Landmarks}

1.Skull-anteriormost: anteriormost median junction between the bones that form the dorsal margin of the external nares

Remarks: This landmark usually is between the prefrontals or nasals, depending on which of these bones form the anterior margin of the skull dorsal to the nares.

2.FR-anteriormost: anteriormost contact between the frontals 
Remarks: This landmark is placed on the quadruple-junction of right and left frontals with anteriorly adjacent bones (prefrontals or nasals).

3.PA-anteriormost: anteriormost contact between the parietals

Remarks: This landmark is placed on the quadruple-junction of right and left parietals with anteriorly adjacent bones, which are usually the frontals.

4.PA-posteriormost-roof: posteriormost contact between the parietals on the skull roof Remarks: This landmark is usually placed on a triple junction between the parietals and supraoccipital. Whenever the supraoccipital is completely covered by the parietals, the landmark is in the posterior skull roof margin.

5.SO-posteriormost: posteriormost point of the supraoccipital

Remarks: This landmark is mostly placed at the posterior end of the supraoccipital crest. However, in Hydromedusa, a dorsal extension of the exoccipitals (see landmarks 26/27 below) restricts the supraoccipital to be present only in the skull roof, so that the landmark is not the posteriormost point of the skull along the skull midline.

6.Left-FR-orbit: anteriormost point of the lateral process of the left frontal which extends towards the orbit rim

Remarks (this applies for landmarks 6 and 7): Turtles show variation regarding whether the frontal extends laterally into the orbital margin or not. When the frontal extends into the orbit, the landmark is placed in the orbital margin between the frontal and the anteriorly adjacent bone, usually the prefrontal. this condition is present, the landmark is placed in the anterior suture of the frontal that contacts the orbital margin. When the lateral frontal process is retracted from contributing to the orbit, the homologous point is the frontal-prefrontal-postorbital triple junction somewhat medially to the orbit. When the latter condition is present, landmarks 6 and 7 are placed in the same spot as landmarks 67 and 70 (see below).

7.Right-FR-orbit: anteriormost point of the lateral process of the right frontal which extends towards the orbit rim

Remarks: See remarks of landmark 6.

8.Left-MX-orbit: anteriormost contact of the left maxilla in the orbit rim 
Remarks: This landmark is usually positioned on the interception of the maxillaprefrontal suture with the orbital margin.

9.Right-MX-orbit: anteriormost contact of the right maxilla in the orbit rim

Remarks: See remarks for landmark 8.

10.Left-FR-PA-posterolateral: lateralmost contact between the left frontal and the left parietal

Remarks: In most turtles, this landmark is positioned in the triple junction between frontal, parietal, and postorbital, but the post

11.Right-FR-PA-posterolateral: $\underline{\text { lateralmost contact between the right frontal and the }}$ right parietal

Remarks: See remarks for landmark 10.

\section{Left-SQ-posteriormost: posteriormost point of the left squamosal}

Remarks: In most turtles, the posterior part of a squamosal either forms a pointed tip or a curved, vertical ridge. In the latter case, this landmark is placed along the ridge in the posteriormost possible position.

13.Right-SQ-posteriormost: posteriormost point of the right squamosal

Remarks: See remarks for landmark 12.

14.Left-QU-SQ-Temporal-margin: contact between left squamosal and adjacent bone within margin of the temporal emargination

Remarks: The squamosal always forms the post posterolaterally positioned element in all turtle skulls, and thus always forms the posterior part of the temporal emargination. This landmark is placed in the margin of the temporal emargination, at the contact of the squamosal with the anteriorly (or laterally) adjacent bone. Depending on the extent of the temporal emargination, this contact can be with the parietal (e.g. when the emargination is weak as in chelonioids), but more often is with the quadrate and/or quadratojugal at the anterior end of the squamosal.

15.Right- QU-SQ-Temporal-margin: contact between right squamosal and adjacent bone within margin of the temporal emargination 
Remarks: See remarks for landmark 14.

16.Left-PO-orbit: anteriormost contact of the left postorbital in the orbit rim

Remarks: This landmark always is positioned within the orbital margin, and between the postorbital and frontal or prefrontal, depending on if the frontal contributes to the orbit or is retracted from the orbital margin. In the former case, landmarks 16 and 17 coincide with landmarks 67 and 70 (see below).

17.Right-PO-orbit: anteriormost contact of the right postorbital in the orbit rim

Remarks: See remarks for landmark 16.

18.Left-PA-SO-PR: left contact between parietal-supraoccipital-prootic

Remarks: This landmark is positioned on the dorsal surface of the otic capsule. Dermochelys presents a unique condition in which its descending parietal process is not ossified. Because of this, it lacks the triple contact between the parietal, supraoccipital and prootic bones. However, the supraoccipital and prootic are still in contact in Dermochelys, and this landmark is placed at the anteriormost point where these bones contact each other. Therefore, despite of the unusual ossification of such taxon, the landmark still follows the same homology criterion.

19.Right-PA-SO-PR: right contact between parietal-supraoccipital-prootic

Remarks: See remarks for landmark 18.

\section{Left-SO-PR-OP: left contact between supraoccipital-prootic-opisthotic}

Remarks: This is positioned on the dorsal surface of the otic capsule. In cyclanorbine trionychids (e.g. Cyclanorbis, Cycloderma and Lissemys) and Chelonoidis carbonaria, the parietal has an unusually long posterior extension that reaches over the supraoccipital, prootic and opisthotic bones, hereby concealing the triple contact between these bones. However, as this contact is actually just concealed by a thin sheet of the parietal, I digitally removed the parietal extension and placed the landmark for these turtles. For these taxa, landmarks 20 and 21 coincide with the positions of landmarks 18 and 19. This landmark combination thus acknowledges both the extreme posterior extent of the parietal, but also the homology with other turtles in the general presence of a triple junction between prootic-opisthotic-supraoccipital in the otic capsule. 
21.Right-SO-PR-OP: right contact between supraoccipital-prootic-opisthotic

Remarks: See remarks for landmarl 20.

22.Left-QU-PR: left posteriormost junction between the prootic and the quadrate on the surface of the otic chamber

Remarks: The prootic and quadrate mediolaterally abut one another in the otic capsule of all turtles. Posteriorly, these bones usually form a triple junction with the opisthotic, but the latter can be substituted for different bones. Thus, this landmark is defined only in terms of the prootic and quadrate, and usually lies in the central portion of the otic capsule, on its dorsal surface.

23.Right-QU-PR: right posteriormost junction between the prootic and the quadrate on the surface of the otic chamber

Remarks: See remarks for landmark 22.

24.Left-SO-EX-OP: left junction between supraoccipital-exoccipital-opisthotic

Remarks: This landmark is positioned in the posterior aspect of the dorsal surface of the otic capsule.

25.Right-SO-EX-OP: right junction between supraoccipital-exoccipital-opisthotic

Remarks: See remarks for landmark 24.

26.Left-EX-Foramen-magnum: most posterodorsal point of the left exoccipital in the margin of the foramen magnum

Remarks: This landmark is usually positioned in the exoccipital-supraoccipital suture along the margin of the foramen magnum. However, in most chelid turtles, the exoccipitals each possess a dorsal process that, when present, contact one other in the skull midline, excluding the supraoccipital from contributing to the foramen magnum. When this condition occurs, landmarks 26 and 27 are placed in the same spot.

27.Right-EX-Foramen-magnum: most posterodorsal point of the right exoccipital in the margin of the foramen magnum

Remarks: See remarks for landmark 26. 
28.PM-anterodorsal: Point of contact between the right and left premaxillae in the ventral margin of the external nares

Remarks: This landmark is an unpaired, median landmark and can usually be identified by the dorsal end of the interpremaxillary suture. When the premaxillae are fused, this landmark is placed in a median position in the ventral margin of the external naris.

29.PM-Labial-ridge: Point of contact between the right and left premaxillae in the labial ridge of the triturating surface

Remarks: This landmark is an unpaired, median landmark and can usually be identified by the ventral end of the interpremaxillary suture. When the premaxillae are fused, this landmark is placed in a median position in the labial margin of the skull.

30.Anteromedian-Triturating-surf: median point of contact between the medial margins of the right and left triturating surface

Remarks: This landmark specifies the anteromedial termination of each triturating surface, and primarily is to capture variation in the depth of the triturating surface. I thus defined this landmark as the median point between the triturating surfaces. It always lies at the border of triturating surfaces and the internal narial openings. In turtles with clearly distinguished right and left triturating surfaces (i.e., in absence of a secondary palate), the landmark is usually positioned at the posterior end of the interpremaxillary contact on the palate, which often coincides with the premaxilla-premaxilla-vomer triple junction. However, in turtles with extensive secondary palates, such as chelonioids, the landmark lies on the vomer, and in the posterior margin of the secondary palate. As the secondary palate basically represents an extension of palatal bones and a merging of the triturating surface, I believe that this landmarks is topologically homologous despite the fact that it will lie on different bones across different turtle clades.

\section{Left-MX-lateroventral: posterior end of left maxillar labial ridge}

Remarks: In all turtles, the maxilla forms most of the anterolateral margin of the skull, including the labial ridge onto which the keratinous rhamphotheca articulates. Posteriorly, the labial ridge either ends by articulation of the maxilla with posteriorly adjacent bones, usually the jugal, or by an upturned maxillar margin that defines the beginning of the cheek emargination. This landmark is placed in this position.

32.Right-MX-lateroventral: posterior end of right maxillar labial ridge 


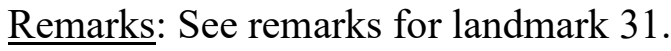

33.Left-Triturating-surf-posterior: most posteromedial point of the left triturating $\underline{\text { surface }}$

Remarks: This point is usually positioned on the maxilla, and defined the posterior end of the lingual margin of the triturating surface.

34.Right-Triturating-surf-posterior: most posteromedial point of the right triturating $\underline{\text { surface }}$

Remarks: See remarks for landmark 33.

35.Left-QU-posteroventral: anteroventral point of maximum curvature of the lateral wall of the left quadrate

Remarks: This landmark defines the posterior end of the cheek emargination, which ends in the lateroventral margin of the skull formed by the quadrate just anterior to the level of the quadrate articular processes.

36.Right-QU-posteroventral: anteroventral point of maximum curvature of the lateral wall of the right quadrate

Remarks: See remarks for landmark 35.

37.BS-anteriormost-ventral: anteriormost point of the basisphenoid on the ventral surface of the skull

Remarks: This unpaired landmark is positioned in the skull midline. Depending on the anterior structure of the palate, the landmarl lies in the triple junction between basisphenoid and right and left pterygoids, or in the basisphenoid-vomer suture.

38.BS-anteriormost-dorsal: anteriormost point of the basisphenoid on the dorsal surface of the basicranium (tip of the rostrum basisphenoidale)

Remarks: This unpaired, medial landmark is positioned on the internal of the skull.

39.Left-BS-clinoid: tip of the left clinoid process.

Remarks: This landmark is positioned on the internal of the skull.

40.Right-BS-clinoid: tip of the right clinoid process 
Remarks: See remarks for landmark 39.

41.Left-MX-PAL-anterior: most anteromedial junction between the left maxilla and the left palatine on the palate

Remarks: The palatine of turtle usually extends with anterolateral processes toward the maxilla, and contacts this bone along the lingual margin of the triturating surface. In species with extended secondary palates, this landmark is the triple junction between maxilla-palatine-vomer.

42.Right-MX-PAL-anterior: most anteromedial junction between the right maxilla and the right palatine on the palate

Remarks: See remarks for landmark 41.

43.Left-BO-BS-lateralmost: lateralmost point of contact between the basisphenoid and basioccipital on the left side

Remarks: In all turtles, the basisphenoid and basioccipital form a transverse suture in the ventral skull surface. This landmark is poitioned in the lateral end of this contact, which forms a triple junction with laterally adjacent bones that can vary between clades, but usually are either the quadrate, prootic or pterygoid.

44.Right-BO-BS-lateralmost: lateralmost point of contact between the basisphenoid and basioccipital on the right side

Remarks: See remarks for landmark 43.

45.BO-BS-medial: median point between the basisphenoid and the basioccipital on the ventral surface of the skull

Remarks: This unpaired landmark is in a median position on the suture between basisphenoid and basioccipital.

46.Left-FPCCI: position of the left foramen posterius canalis carotici interni

Remarks: This landmark marks the ventral margin of the foramen posterius canalis carotici interni, through which the internal carotid artery enters the cranium.

47.Right-FPCCI: position of the right foramen posterius canalis carotici interni

Remarks: See remarks for landmark 46. 
48.Left-basitubera: posteriormost tip on the left basituber

Remarks: The tubercula basioccipitale are formed by various combinations of bones in turtles, but usually the basioccipital is prominently involved. In all turtles, the processes can be identified easily, and the posteriormost point of the structure is landmarkes, which is often formed as a pointed tip.

49.Right-basitubera: posteriormost tip on the right basituber

Remarks: See remarks for landark 48.

50.Occipital-cond-posterior: posteriormost point on the occipital condyle

Remarks: This landmark is positioned centrally on the posterior surface of the occipital condyle, usually in the triple junction of both exoccipitals with the basioccipital.

51.Left-Cavum_tympani_posterodorsal: most posterodorsal point on the margin of the left cavum tympani

Remarks: To define a semilandmark curve around the cavum tympani, I defined a start and end landmark in the posterodorsal and posteroventral corners of the cavum tympani, respectively. The posterodorsal starting point is usually relatively easy to identify as a small lateral tip on the squamosum or quadrate, just above the posteroventral notch that often opens into the cavum tympani for the Euchstachian tube and/or stapes. The posteroventral end point lies on the quadrate. In turtles in which the cavum tympani is 'closed', start and end landmarls fall on the same position. The position in these cases is mostly indicated by a suture of the quadrate with itself, which can be traced medially into the cavum tympani and toward the incisura columella auris, which is completely surrounded by the quadrate in such turtles.

52.Left-Cavum_tympani_posteroventral: most posteroventral point on the margin of the left cavum tympani

Remarks: See remarks for landmark 51.

53.Right-Cavum_tympani_posterodorsal: most posterodorsal point on the margin of the right cavum tympani

Remarks: See remarks for landmark 51. 
54.Right-Cavum_tympani_posteroventral: most posteroventral point on the margin of the right cavum tympani

Remarks: See remarks for landmark 51.

55.Left-PR-QU-PT: left junction between the prootic, quadrate and pterygoid (or parietal) in the otic capsule region

Remarks: In all turtles, the anterior portion of the otic capsule if formed between the prootic medially and the quadrate laterally. These bones form an anteroposteriorly extending suture. Anteriorly, the suture slopes ventrally from the floor of the supratemporal fossa into the posterior wall of the subtemporal fossa. In this area, on the anterior surface of the otic capsule, the prootic-quadrate suture meets with the anteroventrally adjacent bone, which usually is the pterygoid. This landmark is placed on this triple junction.

56.Right-PR-QU-PT: right junction between the prootic, quadrate and pterygoid (or parietal) in the otic capsule region

Remarks: See remarks for landmark 55.

57.Left-JU-PO-posterior-contact: the most posterior contact between the left jugal and the left postorbital

Remarks: This landmark is found on the lateral side of the skull. The postorbital-jugal suture extends anteroposteriorly, and in its posterior end, it either forms a triple junction with the quadratojugal, but my instead merge into the margin of the upper temporal emargination.

58.Right-JU-PO-posterior-contact: the most posterior contact between the right jugal and the right postorbital

Remarks: See remarks for landmark 57.

59.Left-PAL-posteromedian: the most posteromedian contact of the left palatine in the ventral surface of the skull

Remarks: The palatines of turtles form part of the anterior region of the palate, but there is significant variation to their form and contacts to surrounding bones: the palatines may contact one another in the skull midline, or they are separated from one another by either 
the vomer, pterygoids, or basisphenoid. This landmark captures the posteriormost contact of the palatine with the bones that lie in the skull midline. When the right and left palatines have a midline contact, right and left landmarks for this point fall on the same position.

60.Right-PAL-posteromedian: the most posteromedian contact of the right palatine in the ventral surface of the skull

Remarks: See remarks of landmark 59.

61.Left-PT-base-ventral-proc: anteriormost contact of the ventral process of the left parietal with the ventrally adjacent bone

Remarks: The descending process of the parietal forms the anterior margin of the ossified braincase in turtles. Ventrally, the process contacts the palate, usually the crista pterygoidei of the pterygoid, but in some turtles the palatine. I place the landmark at the ventral end of the anterior margin of the descending process of the parietal, irrespective of which bone it contacts ventrally. This landmark captures variation pertaining to the extent of the secondary lateral braincase wall.

62.Right-PT-base-ventral-proc: anteriormost contact of the ventral process of the right parietal with the ventrally adjacent bone

Remarks: See remarks for landmark 61.

63.Left-PA-SO-posterolateral: most posterolateral contact between the left parietal and the supraoccipital on the skull roof

Remarks: In all turtles, the parietals have a midline contact in the skull roof, but contact the supraoccipital posteriorly. Depending on whether parts of the supraoccipital are integrated into the skull roof or whether most of the bone is overlain by the parietals, right and left landmarks are separated from the skull midline, or fall on the same point (together with landmark 4), respectively. This landmark serves as the medial bound for the temporal emargination.

64.Right-PA-SO-posterolateral: most posterolateral contact between the right parietal and the supraoccipital on the skull roof

Remarks: See remarks for landmark 63.

65.Left-OP-posteriormost: posteriormost point of the left opisthotic 
Remarks: The paroccipital process of the opisthotic braces against the posterior part of the otic capsule in turtles, and ends laterally near the posterior squamosal process, and may even extend beyond that level posteriorly and thus form the posteriormost point of the skull. I place this landmark at the posteriormost tip of the paroccipital process.

66.Right-OP-posteriormost: posteriormost point of the right opisthotic

Remarks: See remarks for landmark 65.

67.Left-FR-orbit-posterior: posteriormost point of the lateral process of the left frontal which extends towards the orbit rim

Remarks: Turtles show variation regarding whether the frontal extends laterally into the orbital margin or not. When the frontal extends into the orbit, the landmark is placed in the orbital margin between the frontal and the posteriorly adjacent bone, which is the postorbital. In this case, landmarks 67 and 70 are in the identical spot as landmarks 16 and 17 , which define the anteriormost point of the postorbital in the orbital margin. When the lateral frontal process is retracted from contributing to the orbit, the homologous point is the frontal-prefrontal-postorbital triple junction somewhat medially to the orbit. When the latter condition is present, landmarks 67 and 70 are placed in the same spot as landmarks 6 and 7 (see above).

68.Left-MX-orbit-posterior: posteriormost contact of the left maxilla in the orbit rim

Remarks: In all turtles, the maxilla forms parts of the ventral margin of the orbit. Posteriorly, it forms a contact with the posteriorly adjacent bone, usually the jugal, with which it forms a suture that crosses the orbital margin. This landmark is placed in this position, irrespective of whether the posterior bone is the jugal or postorbital.

69.Left-PO-orbit-posterior: ventralmost contact of the left postorbital in the orbit rim

Remarks: In all turtles, the postorbital forms parts of the posterior margin of the orbit. The postorbital has a ventral process that extends along the orbital margin until it reaches the ventrally adjacent bone, which is usually the jugal, but may be the maxilla when the jugal is retracted from contributing to the orbit. The landmark is placed in the suture with the ventrally adjacent bone within the orbital margin. When the postorbital directly contact the maxilla in the orbital margin, this landmark coincides with landmark 68. 
70.Right-FR-orbit-posterior: posteriormost point of the lateral process of the right frontal which extends towards the orbit rim

Remarks: See remarks for landmark 67.

71.Right-MX-orbit-posterior: posteriormost contact of the right maxilla in the orbit rim Remarks: See remarks for landmark 68.

72.Right-PO-orbit-posterior: ventralmost contact of the right postorbital in the orbit rim

Remarks: See remarks for landmark 69.

73.Left-PAL-anteromedian: the most anteromedian contact of the left palatine in the primary palate

Remarks: In all turtles, the palatine forms parts of the anterior palate, but significant variation exists in the form and relative position of this bone. The right and left palatines may form a midline contact, in which case this landmark is placed at the anterior end of this contact, and in which case right and left landmarks fall in the same position. However, in many turtles the palatines are separated from one another by either the vomer, pterygoids, or basisphenoid. In this case, right and left landmarks are in distinct positions to either side of the skull midline, and at the anterior end of the palatine with the medially adjacent bone. In turtles with a secondary palate, the palatine has two 'levels' that forms dorsoventrally separate plates. The ventral one is integrated into the secondary palate, whereas the dorsal one forms the roof of the internal narial passage. Both plates usually contact the vomer medially, and thus candidate positions for this landmark exist both on the primary palate (dorsal plate) and secondary palate (ventral plate). I place this landmark on the primary palate, as this surface is homologous to the part of the palate in taxa without secondary palates, which in turn are interpreted to be neomorphic structures in turtles that possess them.

74.Right-PAL-anteromedian: the most anteromedian contact of the left palatine in the primary palate

Remarks: See remarks for landmark 73.

75.Dorsal_foramen_magnum: the most dorsal point of the foramen magnum on the $\underline{\text { midline }}$ 
Remarks: The foramen magnum in turtles usually form a dorsoventrally high oval, with a narrow concave dorsal margin that is usually formed by the supraoccipital, but may be formed by the exoccipitals instead. This landmark is placed in the midline dorsal margin of the foramen magnum.

76.Ventral_foramen_magnum: the most ventral point of the foramen magnum on the $\underline{\text { midline }}$

Remarks: The foramen magnum in turtles usually form a dorsoventrally high oval, with a broad concave ventral margin that is usually formed by the basioccipital, but may be formed by the exoccipitals instead. This landmark is placed in the midline ventral margin of the foramen magnum.

\section{Series of sliding semilandmarks}

SL1.Left-Internal-nares: open curve of semilandmarks in clockwise direction from landmark 1 to landmark 28 that follows the left margin of the external nares

SL2.Right-Internal-nares: open curve of semilandmarks in anticlockwise direction from landmark 1 to landmark 28 that follows the right margin of the external nares

SL3.Left-Orbit: closed loop of semilandmarks starting in the suture the maxilla forms with the anteriorly adjacent bone (usually prefrontal) and extending around the left orbit in clockwise direction

SL4.Right-Orbit: closed loop of semilandmarks starting in the suture the maxilla forms with the anteriorly adjacent bone (usually prefrontal) and extending the left orbit in $\underline{\text { anticlockwise direction }}$

SL5.Skull-midline: open curve of semilandmarks from landmark 1 to landmark 4 that follows the skull midline

SL6.Left-Temporal_emargination_new: open curve of semilandmarks from landmark 63 to landmark 14 that follows the left temporal emargination

SL7.Right-Temporal_emargination_new: open curve of semilandmarks from landmark 64 to landmark 15 that follows the right temporal emargination 
SL8.Left-Cheek-emargination: open curve of semilandmarks from landmark 31 to 35 that follows the left cheek emargination

SL9.Right-Cheek-emargination: open curve of semilandmarks from landmark 32 to 36 that follows the right cheek emargination

SL10.Left-Labial-ridge: open curve of semilandmarks from landmark 31 to landmark 29 that follows the left labial ridge

SL11.Right-Labial-ridge: open curve of semilandmarks from landmark 32 to landmark 29 that follows the right labial ridge

SL12.Left-Triturating-surf: open curve of semilandmarks from landmark 33 to landmark 30 that follows the medial margin of the left triturating surface

SL13.Right-Triturating-surf: open curve of semilandmarks from landmark 34 to landmark 30 that follows the medial margin of the right triturating surface

SL14.Left-Cavum-tympani-loop: open curve of semilandmarks from landmark 52 to landmark 51 that follows the outline of the left cavum tympani in clockwise direction

SL15.Right-Cavum-tympani-loop: open curve of semilandmarks from landmark 53 to landmark 54 that follows the outline of the left cavum tympani in anticlockwise direction

SL16.Left-Mandibular-cond: $\underline{\text { a closed loop of semilandmarks going in clockwise }}$ direction around the left articulation facet of the condylus mandibularis, starting at the level of the contact between the condylus and the pterygoid

SL17.Right-Mandibular-cond: a closed loop of semilandmarks going in anticlockwise direction around the right articulation facet of the condylus mandibularis, starting at the level of the contact between the condylus and the pterygoid

SL18.BS-sella-turcica: open curve of semilandmarks from landmark 39 to landmark 40 that follows the outline of the dorsum sellae

Remarks: The landmark title says 'sella turcica' but I am actually landmarking the dorsum sellae between the clinoid processes.

SL19.Left-PR-QU-suture: open curve of semilandmarks from landmark 22 to landmark 55 that follows the left prootic-quadrate suture 
Remarks: This suture is landmarked because it captures variation of the form of the anterior portion of the otic capsule (and thus, in cryptodires, variation pertaining to the otic trochlea). In Rhinoclemmys pulcherrima, the parietal extends so far laterally, that it overlay the prootic completely in this region. Consequentially, the prootic is not expressed in the otic capsule. However, as the parietal does not overlap the quadrate, the quadrate-parietal suture of $R$. pulcherrima traces the suture of quadrate with the prootic directly underneath the dorsally exposed skull surface. Thus, in $R$. pulcherrima, I landmarked the quadrate-parietal suture.

SL20. Right-PR-QU-suture: open curve of semilandmarks from landmark 23 to landmark 56 that follows the left prootic-quadrate suture

Remarks: See remarks for SL19.

SL21.BS-length: open curve of semilandmarks from landmark 37 to landmark 45 that follows the basisphenoid length

SL22.Left_half_foramen_magnum: a series of semilandmarks on the left side foramen $\underline{\text { magnum rim extending from landmark } 75 \text { to landmark } 76}$

SL23.Right_half_foramen_magnum: a series of semilandmarks on the right side foramen magnum rim extending from landmark 75 to landmark 76

\section{Surface semilandmarks}

In addition to landmarks and sliding semilandmarks, I placed surface semilandmarks to capture more densely potential rugosities on the triturating surfaces of the palate, and the depth of the mandibular condyles. I followed the suggestions in Bardua et al. (2019) and used as a template the specimen of which the shape was closest to the estimated mean shape of aligned 3D Procrustes coordinates. To identify such specimen, I used the findMeanSpec () function of the R package 'geomorph' 3.2.1 (Adams et al. 2020). These surface semilandmarks were placed as follows:

Surface_palate_left: surface semilandmarks placed labio-lingually(?) on the left side triturating surface of the palate, starting close to landmark 31 until reaching the midline contact between the premaxillae 
Remarks: the triturating surfaces are the primary food-grinding structure of most turtles. Besides describing its outline with my landmark/sliding semilandmark concept (more specifically landmarks 29-34 and sliding semilandmarks 10-13), I found it important to include variation present on the surface itself, because many turtles bear one or multiple serrated rows of accessory ridges on the maxillae/palatines (Pritchard 1979). Therefore, these surface semilandmarks were placed on the left half of the triturating surface to capture these potential additional structures.

Surface_palate_right: surface semilandmarks placed labio-lingually(?) on the left side triturating surface of the palate, starting close to landmark 31 until reaching the midline contact between the premaxillae

Remarks: see remarks for 'Surface_palate_left'.

Surface_condyle_left: surface semilandmarks placed anteroposteriorly on the left mandibular condyle surface, starting on the lateralmost edge of the structure and following it medially

Surface_condyle_right: surface semilandmarks placed anteroposteriorly on the right mandibular condyle surface, starting on the lateralmost edge of the structure and following it medially

These new points were then imported back to $\mathrm{R}$ environment in which I combined the new surface semilandmark coordinates with previous ones (landmarks and sliding semilandmarks). The combined set of landmarks were used to create an 'atlas' object using the createAtlas () function of the R package 'Morpho' 2.8 (Schlager 2017). This atlas is used to define which are the landmarks that will be projected on the remaining specimens of my sample in an automated process. This last step is performed with the placePatch () function of the same abovementioned R package 'Morpho' 2.8. 

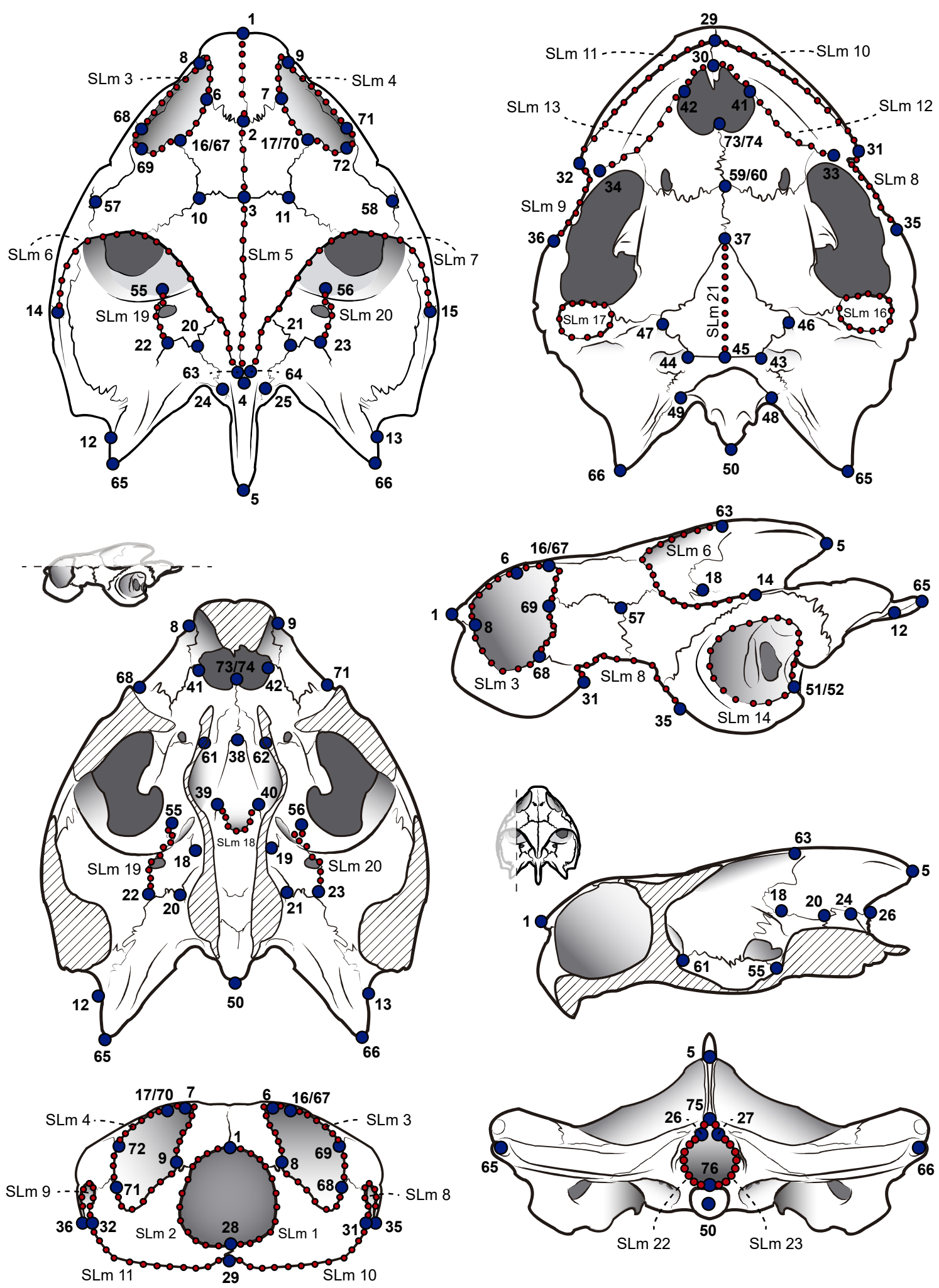

Landmarks 000 Sliding semilandmarks (SLm)

Figure A4.13. Landmark concept including type I and II landmarks and series of sliding semilandmarks. Numbers correspond to definitions in the text. Drawing based on the pleurodire Pelomedusa subrufa SMF 70504 (African helmeted turtle). 


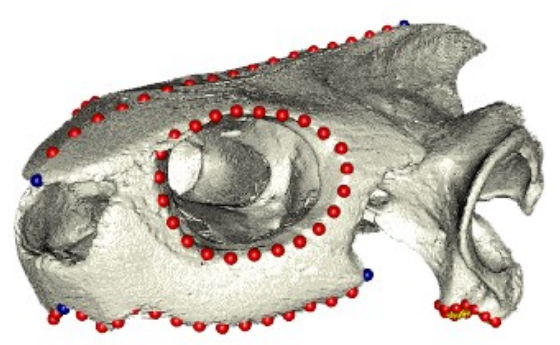

landmarks
sliding semilandmarks
surface semilandmarks

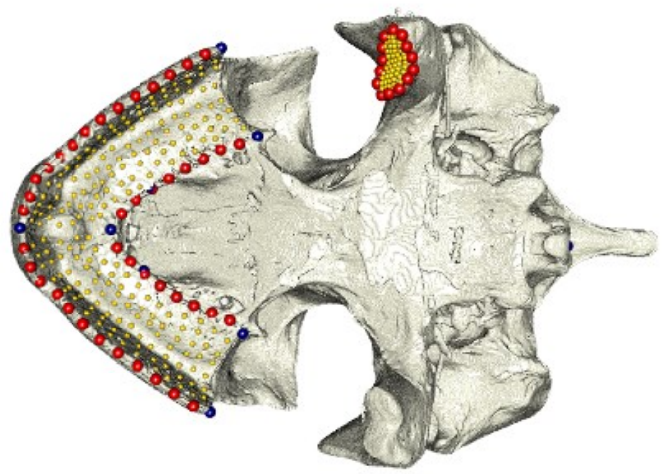

Figure A4.2. Landmark concept of the 'partial dataset' (see Main Text) illustrated in a 3D rendering of the yellow-headed temple turtle (Hieremys annandalii FMNH 260389) shown in oblique left lateral (left) and ventral (right) views.

\section{Literature cited:}

Adams, D.C., Collyer, M.L. \& Kaliontzopoulou, A. (2020) Geomorph: Software for geometric morphometric analyses. $\mathrm{R}$ package version 3.2.1. https://cran.rproject.org/package $=$ geomorph.

Bardua, C., Felice, R.N., Watanabe, A. Fabre, A.C. \& Goswami, A. (2019) A practical guide to sliding and surface semilandmarks in morphometric analyses. Integrative Organismal Biology, 1(1), obz016.

Pritchard, P.C.H. (1979) Encyclopedia of Turtles. TFH, New Jersey.

Schlager, S. (2017) Morpho and Rvcg-Shape Analysis in R: R packages for geometric morphometrics, shape analysis and surface manipulations. In Zheng, G., Li S. \& Szekely, G. (eds.), Statistical Shape and Deformation Analysis, Academic Press, pp. 217-256. 


\section{Appendix 5}

\section{Description of binary ecological traits}

To account for the multiple components of feeding aspects present in turtles' diets, I developed a multivariate scheme classification containing the main resources described in turtles' natural history surveys. For each item I attributed '0' (absent) or '1' (present). Besides food items, I also scored for the use of suction feeding, and whether the animal feeds in water or on land. This follows similar previous approaches for mammalian and avian ecology (e.g. Taylor \& Thomas 2014; Wilman 2014; Benson et al. 2017; Olsen 2017; Campuzano 2018), and recognises that multiple factors can influence skull shape in turtles.

The resulting binary matrix (Fig. S1) was transformed in a Euclidean distance matrix so it could be used as an input variable for the ordinary (2B-PLS) and phylogenetic (p2BPLS) two-block partial least squares analyses (see Main Text).

The traits match those present in Appendix 3, and correspond to the presence/absence of:

Seeds_fruits: fruits, including also the consumption of seeds and nuts;

Flowers: flowers;

Stems: plant stems, including also plant roots;

Terrestrial_leaves: leaves from terrestrial plants (e.g. bushes, grasses, riparian vegetation);

Aquatic_leaves: aquatic macrophytes, sedges, aquatic angiosperms, and algae;

Mostly_vegetable_matter: this variable was included to help distinguishing between sporadic and regular feeding on plants by turtles, according to authors' assessment on the regularity of the presence of vegetable matter in an animal's diet through a given period of time;

Fungi: mushrooms;

Vertebrates: mainly fishes and tadpoles, including also sporadic consumption of larger vertebrates (e.g. waterbirds, other turtles);

Jellyfish: jellyfish, but also free-living tunicates, for the similarity with medusae lifestyle;

Aquatic_insects: insects that rely on water for completing their life cycles (e.g. dragonflies, mayflies, dipteran chironomids), including also their larvae;

Terrestrial_arthropods: insects that mainly live on land (e.g. beetles, grasshoppers), arachnids, millipedes;

Worms: mostly oligochaetes, but can also include similar tubular-shaped animals (e.g. marine worms);

Mollusks: snails, clams, mussels;

Crustaceans: prawns, shrimps, crabs;

Mostly_animal_matter: this variable was included to help distinguishing between sporadic and regular feeding on animals by turtles, according to authors' assessment on the regularity of the presence of animal matter in an animal's diet through a given period of time;

Feed_on_water: scored 'present' for those turtles capable of feeding underwater; 
Feed_on_land: scored 'present' for those turtles capable of feeding on land; turtles that can capture food on land but need to drag it underwater to eat (e.g. Natchev et al. 2008) were scored as 'absent' (see Natchev et al. 2015 for further discussion on the subject);

Mostly_feed_on_land: this variable was included to help distinguishing between obligatory and facultative feeding on land by turtles (e.g. Natchev et al. 2015);

Suction_feeding: scored 'present' for those turtles that rely on the use of neck and oesophagus expansion to inhale prey sensu Foth et al. (2017; their 'gape-and-suction' category). I scored present for other turtles that according to literature are also capable of using suction mechanisms to capturing food (e.g. Molina et al. 1998; Bels et al. 1998), and that show signals of food ingestion by means of suction-feeding (e.g. Ribeiro et al. 2017). Yet, I also scored presence for turtles that exhibit neustophagia (e.g. Belkin \& Gans 1968; Rhodin et al. 1981), since jaw opening and pharyngeal expansion behaviours parallel those of turtles described as 'suction-feeders';

Mostly_hard_food: this variable was included to help distinguish between sporadic (e.g. Kimmel 1980; Jones \& Seminoff 2013) and regular (e.g. Bels et al. 1998; Richards-Dimitrie et al. 2013) feeding on hard food (durophagy) by turtles. This follows authors' assessment on the regularity of the presence of e.g. hard-shelled invertebrates in an animal's diet through a given period of time.

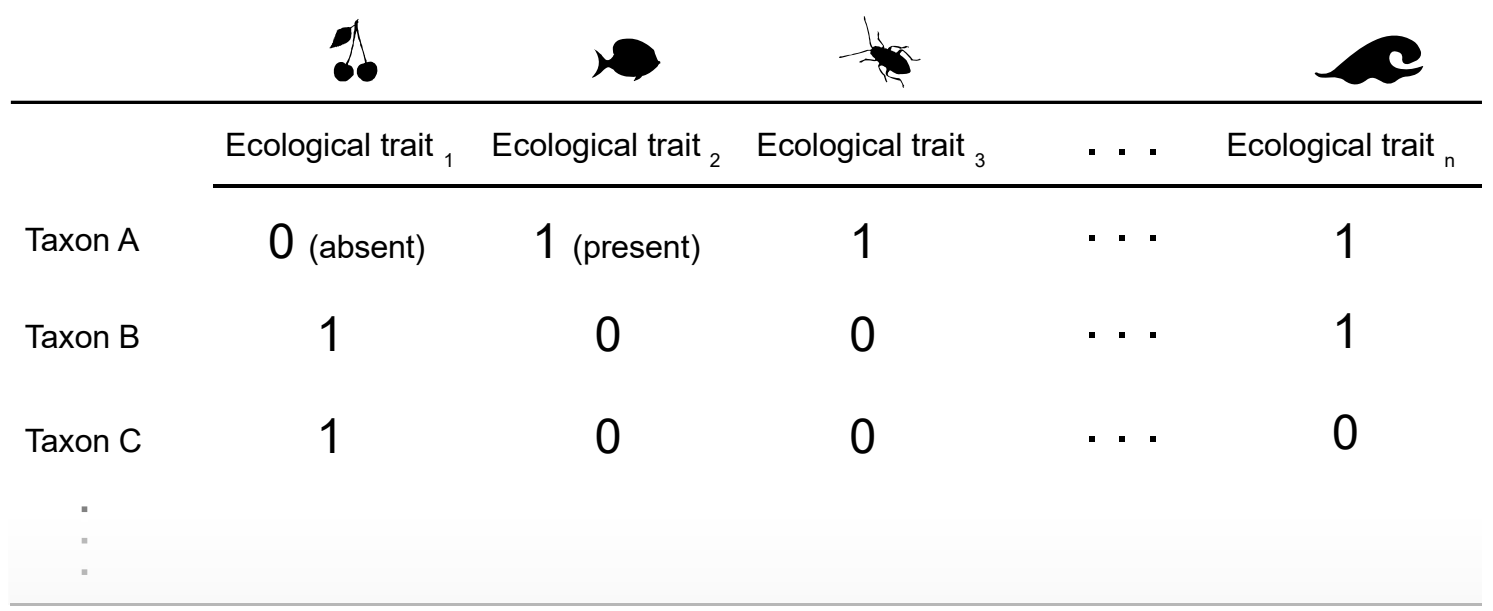

Figure A5.1. Example of the binary matrix representing my ecological multivariate classification scheme. Taxa may be assigned 'presence' (1) or 'absence' (0) to more than one ecological trait, including food items (e.g. fruits, vertebrates, insects) and feeding strategies (e.g. feeding in water).

\section{Literature cited:}

Belkin, D.A. \& Gans, C. (1968) An unusual chelonian feeding niche. Ecology, 49(3), 768-769.

Bels, V.L., Davenport, J. \& Renous, S. (1998) Food ingestion in the estuarine turtle Malaclemys terrapin: comparison with the marine leatherback turtle Dermochelys coriacea. Journal of the Marine Biological Association of the United Kingdom, 78(3), 953-972.

Benson, R.B.J., Starmer-Jones, E., Close, R.A. \& Walsh, S.A. (2017) Comparative analysis of vestibular ecomorphology in birds. Journal of Anatomy, 231(6), 990-1018.

Campuzano, C.A.E. (2018) Geometric morphometric exploration of the skull phenotypic matrix of Columbimorphae (Pteroclidiformes, Mesitornithiformes and Columbiformes): 
Allometry, heterochrony, ecological factors, modularity, biomechanics, diet, and domestication (Doctoral dissertation, University of Oxford, Oxford, UK). Retrieved from https://ora.ox.ac.uk/objects/uuid:9f7df3a9-b109-431c-b3c1-e08574568e10.

Foth, C., Rabi, M. \& Joyce, W.G. (2017) Skull shape variation in extant and extinct Testudinata and its relation to habitat and feeding ecology. Acta Zoologica, 98(3), 310-325.

Jones, T.T. \& Seminoff, J.A. (2013) Feeding biology: advances from field-based observations, physiological studies, and molecular techniques. In Wyneken, J., Lohmann, K.J. \& Musick, J.A. (eds.), The Biology of Sea Turtles, vol. 3, CRC Press, pp. 211-248.

Kimmel, C.E. (1980) A Diet and Reproductive Study for Selected Species of Malaysian Turtles (Master thesis, Eastern Illinois University, Charleston, USA.). Retrieved from https://thekeep.eiu.edu/theses/3111/.

Molina, F.B., Rocha, M.B. \& Lula, L.A.B.M. (1998) Comportamento alimentar e dieta de Phrynops hilarii (Duméril \& Bibron) em cativeiro (Reptilia, Testudines, Chelidae). Revista Brasileira de Zoologia, 15(1), 73-79.

Natchev, N., Heiss, E., Lemell, P. \& Weisgram, J. (2008) Kinematic analysis of prey capture, prey transport and swallowing in the Common Musk Turtle Sternotherus odoratus (Chelonia, Kinosternidae). Comparative Biochemistry and Physiology, Part A, 3(150), S95.

Natchev, N., Tzankov, N., Werneburg, I. \& Heiss, E. (2015) Feeding behaviour in a 'basal' tortoise provides insights on the transitional feeding mode at the dawn of modern land turtle evolution. PeerJ, 3, e1172.

Olsen, A.M. (2017) Feeding ecology is the primary driver of beak shape diversification in waterfowl. Functional Ecology, 31(10), 1985-1995.

Rhodin, A.G.J., Medem, F. \& Mittermeier, R.A. (1981) The occurrence of neustophagia among podocnemine turtles. British Journal of Herpetology, 6, 175-176.

Ribeiro, L.E.S., da Silva Utta, A.C. \& Barreto, L. (2017) Diet of Phrynops geoffroanus (Schweigger 1812) (Chelidae) in an Environmental Protection Area in the Amazon region of Maranhão state, Brazil. Herpetological Conservation and Biology, 12(2), 556-564.

Richards-Dimitrie, T., Gresens, S.E., Smith, S.A. \& Seigel, R.A. (2013) Diet of northern map turtles (Graptemys geographica): sexual differences and potential impacts of an altered river system. Copeia, 2013(3), 477-484.

Taylor, G. \& Thomas, A. (2014) Evolutionary Biomechanics. Oxford University Press, Oxford.

Wilman, H., Belmaker, J., Simpson, J., de la Rosa, C., Rivadeneira, M.M. \& Jetz, W. (2014) EltonTraits 1.0: Species-level foraging attributes of the world's birds and mammals. Ecological Archives, 95(7), 2027-2027. 


\section{Extant turtles diet bibliography}

The following references correspond to those present in the columns $\underline{\mathrm{AB}}, \underline{\mathrm{AC}}$ and $\underline{\mathrm{AD}}$ of Appendix 5 (Excel format only). In addition, I understand this list of references contributes to further the knowledge on natural history surveys of extant turtles.

Alcalde, L., Derocco, N.N. \& Rosset, S.D. (2010) Feeding in syntopy: diet of Hydromedusa tectifera and Phrynops hilarii (Chelidae). Chelonian Conservation and Biology, 9(1), 3344.

Auliya, M., van Dijk, P.P., Moll, E.O. \& Meylan, P.A. (2016) Amyda cartilaginea (Boddaert 1770) - Asiatic Softshell Turtle, Southeast Asian Softshell Turtle. In Rhodin, A.G.J., Pritchard, P.C.H., van Dijk, P.P., Saumure, R.A., Buhlmann, K.A., Iverson, J.B. \& Mittermeier, R.A. (eds.), Conservation Biology of Freshwater Turtles and Tortoises: A Compilation Project of the IUCN/SSC Tortoise and Freshwater Turtle Specialist Group. Chelonian Research Monographs 5(9), pp. 092.1-17. doi:10.3854/crm.5.092.cartilaginea.v1.2016.

Aun, P.K. (1990) Malayan Testudines. The Journal of Wildlife and Parks, vol IX, pp. 20-31.

Barrio-Amorós, C.L., \& Narbaiza, I. (2008) Turtles of the Venezuelan Estado Amazonas. Radiata, 17(1), 2-19.

Behera, S., Tripathy, B., Sivakumar, K. \& Choudhury, B.C. (2015) Stomach contents of olive ridley turtles (Lepidochelys olivacea) occurring in Gahirmatha, Odisha coast of India. Proceedings of the Zoological Society, 68(1), 91-95.

Bels, V.L., Davenport, J. \& Renous, S. (1998) Food ingestion in the estuarine turtle Malaclemys terrapin: comparison with the marine leatherback turtle Dermochelys coriacea. Journal of the Marine Biological Association of the United Kingdom, 78(3), 953-972.

Bhupathy, S., Webb, R.G \& Praschag, P. (2014) Lissemys punctata (Bonnaterre 1789) - Indian Flapshell Turtle. In Rhodin, A.G.J., Pritchard, P.C.H., van Dijk, P.P., Saumure, R.A., Buhlmann, K.A., Iverson, J.B. \& Mittermeier, R.A. (eds.), Conservation Biology of Freshwater Turtles and Tortoises: A Compilation Project of the IUCN/SSC Tortoise and Freshwater Turtle Specialist Group. Chelonian Research Monographs, 5, pp. 076.1-12. doi:10.3854/crm.5.076.punctata.v1.2014.

Bjorndal, K. A. (1985) Nutritional ecology of sea turtles. Copeia, 1985, 736-751.

Blake, S., Wikelski, M., Cabrera, F., Guezou, A., Silva, M., Sadeghayobi, E., Yackulic, C.B. \& Jaramillo, P. (2012) Seed dispersal by Galápagos tortoises. Journal of Biogeography, 39(11), 1961-1972.

Bonin, F., Devaux, B. \& Dupré, A. (2006) Turtles of the World. Johns Hopkins University Press.

Broadley, D.G. \& Sachsse, W. (2011) Cycloderma frenatum Peters 1854 - Zambezi Flapshell Turtle, Nkhasi. In Rhodin, A.G.J., Pritchard, P.C.H., van Dijk, P.P., Saumure, R.A., Buhlmann, K.A., Iverson, J.B., \& Mittermeier, R.A. (eds.), Conservation Biology of Freshwater Turtles and Tortoises: A Compilation Project of the IUCN/SSC Tortoise and Freshwater Turtle Specialist Group. Chelonian Research Monographs, 5, pp. 055.1-055.5. doi:10.3854/crm.5.055.frenatum.v1.2011.

Brown, W. (1974) Ecology of the aquatic box turtle, Terrapene coahuila (Chelonia, Emydidae) in northern Mexico. Bulletin of the Florida State Museum, Biology Science Series, 19, 167. 
Carr, A. \& Stancyk, S. (1975) Observations on the ecology and survival outlook of the hawksbill turtle. Biological Conservation, 8(3), 161-172.

Cayot, L.J. (1987) Ecology of Giant Tortoises (Geochelone elephantopus) in the Galapagos Islands (Doctoral dissertation, Syracuse University, New York, USA.). Retrieved from https://elibrary.ru/item.asp?id=7536757.

Çiçek, K. \& Ayaz, D. (2011) Food composition of the European pond turtle (Emys orbicularis) in Lake Sülüklü (Western Anatolia, Turkey). Journal of Freshwater Ecology, 26(4), 571578.

Colman, L.P., Sampaio, C.L.S., Weber, M.I. \& de Castilhos, J.C. (2014) Diet of olive ridley sea turtles, Lepidochelys olivacea, in the waters of Sergipe, Brazil. Chelonian Conservation and Biology, 13(2), 266-271.

Cunha, F.L., Bernhard, R. \& Vogt, R.C. (2020) Diet of an assemblage of four species of turtles (Podocnemis) in the Rio Uatumã, Amazonas, Brazil. Copeia, 108(1), 103-115.

Das, I. \& Bhupathy, S. (2009) Melanochelys trijuga (Schweigger 1812) - Indian black turtle. In Rhodin, A.G.J., Pritchard, P.C.H., van Dijk, P.P., Saumure, R.A., Buhlmann, K.A., Iverson, J.B. \& Mittermeier, R.A. (eds.), Conservation Biology of Freshwater Turtles and Tortoises: A Compilation Project of the IUCN/SSC Tortoise and Freshwater Turtle Specialist Group. Chelonian Research Monographs, 5, pp. 038.1-038.9. doi:10.3854/crm.5.038.trijuga.v1.2009.

Das, I. \& Bhupathy, S. (2010) Geoclemys hamiltonii (Gray 1830)-Spotted Pond Turtle, Black Pond Turtle. Chelonian Research Monographs, 5, 043-1.

Das, I. \& Sengupta, S. (2010) Morenia petersi Anderson 1879 - Indian eyed turtle. In Rhodin, A.G.J., Pritchard, P.C.H., van Dijk, P.P., Saumure, R.A., Buhlmann, K.A., Iverson, J.B. \& Mittermeier, R.A. (eds.), Conservation Biology of Freshwater Turtles and Tortoises: A Compilation Project of the IUCN/SSC Tortoise and Freshwater Turtle Specialist Group. Chelonian Research Monographs, 5, pp. 045.1-045.5. doi:10.3854/crm.5.045.petersi.v1.2010.

Das, I. (2015) A Field Guide to the Reptiles of South-East Asia. Bloomsbury Publishing.

Davenport, J., Wong, T.M. \& East, J. (1992) Feeding and digestion in the omnivorous estuarine turtle Batagur baska (Gray). Herpetological Journal, 2(4),133-139.

Degraaf, R.M. \& Rudis, D.D. (1986) New England wildlife: habitat, natural history, and distribution. U.S. Department of Agriculture, Forest Service, Northeastern Forest Experiment. $491 \mathrm{pp}$.

Demuth, J.P. \& Buhlmann, K.A. (1997) Diet of the turtle Deirochelys reticularia on the Savannah River site, South Carolina. Journal of Herpetology, 31(3), 450-453.

Diagne, T., Luiselli, L., Trape, J.-F., Rödel, M.-O., Baker, P.J., Chirio, L., Petrozzi, F. \& Segniagbeto, G. (2016) Cyclanorbis senegalensis. The IUCN Red List of Threatened Species 2016, e.T6005A96447114. http://dx.doi.org/10.2305/IUCN.UK.20162.RLTS.T6005A96447114.en.

Dreslik, M.J. (1999) Dietary notes on the red-eared slider (Trachemys scripta) and river cooter (Pseudemys concinna) from southern Illinois. Transactions of the Illinois State Academy of Science, 92(3), 233-241.

Elsey, R.M. (2006) Food habits of Macrochelys temminckii (alligator snapping turtle) from Arkansas and Louisiana. Southeastern Naturalist, 5(3), 443-452. 
Fachín-Teran, A., Vogt, R.C. \& Gomez, M.D.F.S. (1995) Food habits of an assemblage of five species of turtles in the Rio Guapore, Rondonia, Brazil. Journal of Herpetology, 536-547.

Folkerts, G.W. (1968) Food habits of the stripe-necked musk turtle, Sternotherus minor peltifer Smith and Glass. Journal of Herpetology, 2(3/4), 171-173.

Garnett, S.T., Price, I.R. \& Scott, F.J. (1985) The diet of the green turtle, Chelonia mydas (L.), in Torres Strait. Wildlife Research, 12(1), 103-112.

Georges, A., Doody, J.S., Eisemberg, C., Alacs, E.A. \&Rose, M. (2008) Carettochelys insculpta Ramsay 1886 - pig-nosed turtle, Fly River turtle. In Rhodin, A.G.J., Pritchard, P.C.H., van Dijk, P.P., Saumure, R.A., Buhlmann, K.A. \& Iverson, J.B. (eds.), Conservation Biology of Freshwater Turtles and Tortoises: A Compilation Project of the IUCN/SSC Tortoise and Freshwater Turtle Specialist Group. Chelonian Research Monographs, 5, pp. 009.1009.17. doi:10.3854/crm.5.009.insculpta.v1.2008.

Guebert-Bartholo, F.M., Barletta, M., Costa, M.F. \& Monteiro-Filho, E.L.A. (2011) Using gut contents to assess foraging patterns of juvenile green turtles Chelonia mydas in the Paranaguá Estuary, Brazil. Endangered Species Research, 13(2), 131-143.

Hamilton, J. \& Coe, M. (1982) Feeding, digestion and assimilation of a population of giant tortoises (Geochelone gigantea (Sehweigger)) on Aldabra atoll. Journal of Arid Environments, 5(2), 127-144.

Hazard, L.C., Shemanski, D.R. \& Nagy, K.A. (2010) Nutritional quality of natural foods of juvenile and adult desert tortoises (Gopherus agassizii): calcium, phosphorus, and magnesium digestibility. Journal of Herpetology, 44(1), 135-147.

Het Terrarium. 21 Aug 2020. Macrochelys temminckii. Retrieved from: https:/www.hetterrarium.com/en_GB/a-46546316/info-chelonians/macrochelystemminckii-info-care/.

Hossain, M.L. \& Sarker, M.S.U. (1995) Observations on the narrow-headed softshell turtle (Chitra indica) in Bangladesh. Journal of the Bombay Natural History Society, 92(3), 423426.

Jensen, K.A. \& Das, I. (2008) Dietary observations on the Asian softshell turtle (Amyda cartilaginea) from Sarawak, Malaysian Borneo. Chelonian Conservation and Biology, 7(1), 136-141.

Jolman, M. Rhinoclemmys pulcherrima (Painted Wood Turtle). Retrieved from https://animaldiversity.org/accounts/Rhinoclemmys_pulcherrima/

Jones, T.T. \& Seminoff, J.A. (2013) Feeding biology: advances from field-based observations, physiological studies, and molecular techniques. In Wyneken, J., Lohmann, K.J. \& Musick, J.A. (eds.), The Biology of Sea Turtles, vol. 3, CRC Press, pp. 211-248.

Kennett, R., \& Tory, O. (1996) Diet of two freshwater turtles, Chelodina rugosa and Elseya dentata (Testudines: Chelidae) from the wet-dry tropics of northern Australia. Copeia, 409419.

Kimmel, C.E. (1980) A Diet and Reproductive Study for Selected Species of Malaysian Turtles (Master thesis, Eastern Illinois University, Charleston, USA.). Retrieved from https://thekeep.eiu.edu/theses/3111/.

Kofron, C.P. \& Schreiber, A.A. (1985) Ecology of two endangered aquatic turtles in Missouri: Kinosternon flavescens and Emydoidea blandingii. Journal of Herpetology, 27-40.

Lauder, G.V. \& Prendergast, T. (1992) Kinematics of aquatic prey capture in the snapping turtle Chelydra serpentina. Journal of Experimental Biology, 164(1), 55-78. 
Legler, J., \& Vogt, R.C. (2013) The turtles of Mexico: land and freshwater forms. University of California Press.

Lemell, P., Lemell, C., Snelderwaard, P., Gumpenberger, M., Wochesländer, R. \& Weisgram, J. (2002) Feeding patterns of Chelus fimbriatus (Pleurodira: Chelidae). Journal of Experimental Biology, 205(10), 1495-1506.

Lindeman, P.V. (1996) Comparative life history of painted turtles (Chrysemys picta) in two habitats in the inland Pacific Northwest. Copeia, 114-130.

Lintner, M., Weissenbacher, A. \& Heiss, E. (2012) The oropharyngeal morphology in the semiaquatic giant Asian pond turtle, Heosemys grandis, and its evolutionary implications. PloS One, 7(9), e46344.

Luiselli, L., Akani, G.C., Politano, E., Odegbune, E. \& Bello, O. (2004) Dietary shifts of sympatric freshwater turtles in pristine and oil-polluted habitats of the Niger Delta, southern Nigeria. Herpetological Journal, 14(2), 57-64.

MacDonald, L.A. \& Mushinsky, H.R. (1988) Foraging ecology of the gopher tortoise, Gopherus polyphemus, in a sandhill habitat. Herpetologica, 345-353.

Mahmoud, I.Y. (1968) Feeding behavior in kinosternid turtles. Herpetologica, 24(4), 300-305.

Melendez, N.A., Zarate, B., Fingerut, J. \& McRobert, S.P. (2017) Diet of bog turtles (Glyptemys muhlenbergii) from northern and southern New Jersey, USA. Herpetological Conservation and Biology, 12, 272-278.

Méndez-Salgado, E., Chacón-Chaverri, D., Fonseca, L.G. \& Seminoff, J.A. (2020) Trophic ecology of hawksbill turtles (Eretmochelys imbricata) in Golfo Dulce, Costa Rica: integrating esophageal lavage and stable isotope $(\delta 13 \mathrm{C}, \delta 15 \mathrm{~N})$ analysis. Latin American Journal of Aquatic Research, 48(1), 114-130.

Meylan, A. (1988) Spongivory in hawksbill turtles: a diet of glass. Science, 239(4838), 393-395.

Molina, F.B., Rocha, M.B. \& Lula, L.A.B.M. (1998) Comportamento alimentar e dieta de Phrynops hilarii (Duméril \& Bibron) em cativeiro (Reptilia, Testudines, Chelidae). Revista Brasileira de Zoologia, 15(1), 73-79.

Moll, D. (1989) Food and feeding behavior of the turtle, Dermatemys mawei, in Belize. Journal of Herpetology, 23(4), 445-447.

Moll, E.O., Platt, K., Platt, S.G., Praschag, P. \& van Dijk, P.P. (2009) Batagur baska (Gray 1830) - northern river terrapin. In Rhodin, A.G.J., Pritchard, P.C.H., van Dijk, P.P., Saumure, R.A., Buhlmann, K.A., Iverson, J.B. \& Mittermeier, R.A. (eds.), Conservation Biology of Freshwater Turtles and Tortoises: A Compilation Project of the IUCN/SSC Tortoise and Freshwater Turtle Specialist Group. Chelonian Research Monographs, 5, pp. 037.1037.10. doi:10.3854/crm.5.037.baska.v1.2009.

Moskovits, D.K. \& Bjorndal, K.A. (1990) Diet and food preferences of the tortoises Geochelone carbonaria and G. denticulata in northwestern Brazil. Herpetologica, 207-218.

Mwaya, R.T., Moll, D., Malonza, P.K. \& Ngwava, J.M. (2018) Malacochersus tornieri (Siebenrock 1903) - Pancake Tortoise, Tornier's Tortoise, Soft-shelled Tortoise, Crevice Tortoise, Kobe Ya Mawe, Kobe Kama Chapati. In Rhodin, A.G.J., Iverson, J.B., van Dijk, P.P., Stanford, C.B., Goode, E.V., Buhlmann, K.A., Pritchard, P.C.H. \& Mittermeier, R.A. (eds.), Conservation Biology of Freshwater Turtles and Tortoises: A Compilation Project of the IUCN/SSC Tortoise and Freshwater Turtle Specialist Group. Chelonian Research Monographs, 5(12), pp. 107.1-15. doi: 10.3854/crm.5.107.tornieri.v1.2018.

Nutphand, W (1979) The Turtles of Thailand. Siamfarm Zoological Garden. 222 pp. 
Ota, H., Yasukawa, Y., Fu, J. \& Chen, T.H. (2009) Cuora flavomarginata (Gray 1863) - yellowmargined box turtle. In Rhodin, A.G.J., Pritchard, P.C.H., van Dijk, P.P., Saumure, R.A., Buhlmann, K.A., Iverson, J.B. \& Mittermeier, R.A. (eds.), Conservation Biology of Freshwater Turtles and Tortoises: A Compilation Project of the IUCN/SSC Tortoise and Freshwater Turtle Specialist Group. Chelonian Research Monographs, 5, pp. 035.1035.10. doi:10.3854/crm.5.035.flavomarginata.v1.2009.

Padgett, D.J., Carboni, J.J. \& Schepis, D.J. (2010) The dietary composition of Chrysemys picta picta (eastern painted turtles) with special reference to the seeds of aquatic macrophytes. Northeastern Naturalist, 17(2), 305-312.

Parker, D.M., Cooke, W.J. \& Balazs, G.H. (2005) Diet of oceanic loggerhead sea turtles (Caretta caretta) in the central North Pacific. Fishery Bulletin, 103(1), 142-152.

Pérez-Emán, J.L. \& Paolillo, A. (1997) Diet of the pelomedusid turtle Peltocephalus dumerilianus in the Venezuelan Amazon. Journal of Herpetology, 173-179.

Pérez-Santigosa, N., Florencio, M., Hidalgo-Vila, J. \& Díaz-Paniagua, C. (2011) Does the exotic invader turtle, Trachemys scripta elegans, compete for food with coexisting native turtles?. Amphibia-Reptilia, 32(2), 167-175.

Plummer, M.V. \& Farrar, D.B. (1981) Sexual dietary differences in a population of Trionyx muticus. Journal of Herpetology, 175-179.

Pritchard, P.C.H. (1979) Encyclopedia of Turtles. TFH, New Jersey.

Pritchard, P.C.H. (2008) Chelus fimbriata (Schneider 1783) - matamata turtle. In Rhodin, A.G.J., Pritchard, P.C.H., van Dijk, P.P., Saumure, R.A., Buhlmann, K.A. \& Iverson, J.B. (eds.), Conservation Biology of Freshwater Turtles and Tortoises: A Compilation Project of the IUCN/SSC Tortoise and Freshwater Turtle Specialist Group. Chelonian Research Monographs 5, pp. 020.1-020.10. doi:10.3854/crm.5.020.fimbriata.v1.2008.

Rasmussen, M.L., Paterson, J.E. \& Litzgus, J.D. (2009) Foraging ecology of spotted turtles (Clemmys guttata) in Ontario, Canada. Herpetological Review, 40(3), 286.

Ribeiro, L.E.S., da Silva Utta, A.C. \& Barreto, L. (2017) Diet of Phrynops geoffroanus (Schweigger 1812) (Chelidae) in an Environmental Protection Area in the Amazon region of Maranhão state, Brazil. Herpetological Conservation and Biology, 12(2), 556-564.

Richards-Dimitrie, T., Gresens, S.E., Smith, S.A. \& Seigel, R.A. (2013) Diet of northern map turtles (Graptemys geographica): sexual differences and potential impacts of an altered river system. Copeia, 2013(3), 477-484.

Rowe, J.W. (1992) Dietary habits of the Blanding's turtle (Emydoidea blandingi) in northeastern Illinois. Journal of Herpetology, 26(1), 111-114.

Rueda-Almonacid, J.V., Carr, J.L., Mittermeier, R.A., Rodríguez-Mahecha, J.V., Mast, R.B., Vogt, R.C., Rhodin, A.G.J., Ossa-Vásquez, J., Rueda, J.N. \& Mittermeier, C.G. (2007) Las tortugas y los cocodrilianos de los países andinos del trópico. Serie de guías tropicales de сатро, 6, 412-423.

Schoppe, S. \& Das, I. (2011) Cuora amboinensis (Riche in Daudin 1801) - Southeast Asian Box Turtle. In Rhodin, A.G.J., Pritchard, P.C.H., van Dijk, P.P., Saumure, R.A., Buhlmann, K.A., Iverson, J.B. \& Mittermeier, R.A. (eds.), Conservation Biology of Freshwater Turtles and Tortoises: A Compilation Project of the IUCN/SSC Tortoise and Freshwater Turtle Specialist Group. Chelonian Research Monographs, 5, pp. 053.1-053.13. doi:10.3854/crm.5.053.amboinensis.v1.2011.

Seney, E.E. \& Musick, J.A. (2005) Diet analysis of Kemp's ridley sea turtles (Lepidochelys kempii) in Virginia. Chelonian Conservation and Biology, 4(4), 864-871. 
Souza, F.L. \& Abe, A.S. (2000) Feeding ecology, density and biomass of the freshwater turtle, Phrynops geoffroanus, inhabiting a polluted urban river in south-eastern Brazil. Journal of Zoology, 252(4), 437-446.

Spawls, S., Howell, K., Hinkel, H. \& Menegon, M. (2018) Field Guide to East African Reptiles. Bloomsbury Publishing.

Stephens, J.D. \& Ryan, T.J. (2009) Diet of Trachemys scripta (red-eared slider) and Graptemys geographica (common map turtle) in an Urban Landscape. Urban Naturalist, 21, 1-11.

Strang, C.A. (1983) Spatial and temporal activity patterns in two terrestrial turtles. Journal of Herpetology, 43-47.

Sung, Y.H., Hau, B.C., \& Karraker, N.E. (2016) Diet of the endangered big-headed turtle Platysternon megacephalum. PeerJ, 4, e2784.

Thomas, R.B. \& Jansen, K.P. (2006) Pseudemys floridana. Florida cooter. Chelonian Research Monographs, 3, 338-347.

Tomas, J., Aznar, F.J. \& Raga, J.A. (2001) Feeding ecology of the loggerhead turtle Caretta caretta in the western Mediterranean. Journal of Zoology, 255(4), 525-532.

Tucker, A.D., Fitzsimmons, N.N. \& Gibbons, J.W. (1995) Resource partitioning by the estuarine turtle Malaclemys terrapin: trophic, spatial, and temporal foraging constraints. Herpetologica, 167-181.

Vogt, R.C., Polisar, J.R., Moll, D. \& Gonzalez-Porter, G. (2011) Dermatemys mawii Gray 1847 - Central American River Turtle, Tortuga Blanca, Hickatee. In Rhodin, A.G.J., Pritchard, P.C.H., van Dijk, P.P., Saumure, R.A., Buhlmann, K.A., Iverson, J.B. \& Mittermeier, R.A. (eds.), Conservation Biology of Freshwater Turtles and Tortoises: A Compilation Project of the IUCN/SSC Tortoise and Freshwater Turtle Specialist Group. Chelonian Research Monographs, 5, pp. 058.1-058.12. doi:10.3854/crm.5.058.mawii.v1.2011.

Wang, E., Donatti, C.I., Ferreira, V.L., Raizer, J. \& Himmelstein, J. (2011) Food habits and notes on the biology of Chelonoidis carbonaria (Spix 1824) (Testudinidae, Chelonia) in the southern Pantanal, Brazil. South American Journal of Herpetology, 6(1), 11-19.

Welsh, M.A., Doody, J.S. \& Georges, A. (2017) Resource partitioning among five sympatric species of freshwater turtles from the wet-dry tropics of northern Australia. Wildlife Research, 44(3), 219-229. 


\section{Appendix 6}

\section{List of D-PGLS regression models results}

My regression models are built to allow that multiple factors can influence shape aspects of the turtle skull. I first tested each predictor individually and then built more complex models including those predictors found to be statistically significant. This Supplementary File contains the summary statistics tables resulted from the D-PGLS analyses of the 'full dataset' and the 'partial dataset', as well the computed AIC scores and phylogenetic signal of the residuals for each model. For these analyses, I ran 1000 iterations for each D-PGLS model, using the 'type II' (hierarchical) sums of squares.

Abbreviations in the tables refer to: the order of models based on AIC scores (Rank), Pagel's phylogenetic signal calculated for regression residuals $(\lambda)$, AIC scores $(A I C)$, the difference in AIC score between the best model and the model being compared ( $\triangle A I C)$, degree of freedom $(D f)$, sums of squares $(S S)$, mean squares $(M S)$, coefficient of determination $\left(R^{2}\right)$, F-values $(F)$, effect-sizes $(Z)$, and $P$-values $(P$-value). 


\section{Results for the 'full dataset'}

\begin{tabular}{|c|c|c|c|c|c|c|c|c|c|c|c|}
\hline \multirow[b]{2}{*}{ Model } & \multirow[b]{2}{*}{ Rank } & \multirow[b]{2}{*}{$\lambda$} & \multirow[b]{2}{*}{ AIC } & \multirow[b]{2}{*}{$\Delta \mathrm{AIC}$} & \multicolumn{7}{|c|}{ ANOVA } \\
\hline & & & & & Df & SS & MS & $\mathbf{R}^{2}$ & $\mathbf{F}$ & $\mathbf{Z}$ & $\begin{array}{c}P \text { - } \\
\text { value }\end{array}$ \\
\hline $\begin{array}{l}\text { shape } \sim \text { skull_size }+ \text { suction }+ \\
\text { durophagous }+ \text { neck_retraction }\end{array}$ & 1 & 0.71 & -16463.6 & 0.0 & & & & & & & \\
\hline skull_size & & & & & 1 & 0.0009 & 0.0009 & 0.0458 & 3.7473 & 4.1428 & 0.0010 \\
\hline suction & & & & & 1 & 0.0010 & 0.0010 & 0.0489 & 4.0068 & 4.1073 & 0.0010 \\
\hline durophagous & & & & & 1 & 0.0010 & 0.0010 & 0.0492 & 4.0289 & 4.1504 & 0.0010 \\
\hline neck_retraction & & & & & 1 & 0.0010 & 0.0010 & 0.0502 & 4.1133 & 4.3269 & 0.0010 \\
\hline Residuals & & & & & 65 & 0.0164 & 0.0003 & 0.7940 & & & \\
\hline Total & & & & & 69 & 0.0207 & & & & & \\
\hline $\begin{array}{l}\text { shape } \sim \text { skull_size }+ \text { suction }+ \\
\text { durophagous }+ \text { plant }\end{array}$ & 2 & 0.72 & -16427.2 & 36.3 & & & & & & & \\
\hline skull_size & & & & & 1 & 0.0012 & 0.0012 & 0.0580 & 4.5978 & 4.6617 & 0.0010 \\
\hline suction & & & & & 1 & 0.0009 & 0.0009 & 0.0458 & 3.6279 & 3.8703 & 0.0010 \\
\hline durophagous & & & & & 1 & 0.0010 & 0.0010 & 0.0475 & 3.7680 & 4.0202 & 0.0010 \\
\hline plant & & & & & 1 & 0.0005 & 0.0005 & 0.0245 & 1.9409 & 2.3150 & 0.0100 \\
\hline Residuals & & & & & 65 & 0.0169 & 0.0003 & 0.8197 & & & \\
\hline Total & & & & & 69 & 0.0207 & & & & & \\
\hline shape $\sim$ durophagous & 3 & 0.85 & -15935.3 & 528.2 & & & & & & & \\
\hline durophagous & & & & & 1 & 0.0010 & 0.0010 & 0.0490 & 3.5030 & 3.6260 & 0.0010 \\
\hline Residuals & & & & & 68 & 0.0197 & 0.0003 & 0.9510 & & & \\
\hline Total & & & & & 69 & 0.0207 & & & & & \\
\hline $\begin{array}{l}\text { shape } \sim \text { skull_size }+ \text { feeds_on_water }+ \\
\text { suction }+ \text { durophagous }+\overline{\text { neck_retraction }}\end{array}$ & 4 & 0.75 & -15878.8 & 584.8 & & & & & & & \\
\hline skull_size & & & & & 1 & 0.0009 & 0.0009 & 0.0457 & 3.8002 & 4.1890 & 0.0010 \\
\hline feeds_on_water & & & & & 1 & 0.0005 & 0.0005 & 0.0236 & 1.9622 & 2.0137 & 0.0290 \\
\hline suction & & & & & 1 & 0.0010 & 0.0010 & 0.0477 & 3.9635 & 4.0617 & 0.0010 \\
\hline durophagous & & & & & 1 & 0.0010 & 0.0010 & 0.0489 & 4.0664 & 4.1442 & 0.0010 \\
\hline neck_retraction & & & & & 1 & 0.0010 & 0.0010 & 0.0504 & 4.1841 & 4.3325 & 0.0010 \\
\hline Residuals & & & & & 64 & 0.0159 & 0.0002 & 0.7703 & & & \\
\hline Total & & & & & 69 & 0.0207 & & & & & \\
\hline $\begin{array}{l}\text { shape } \sim \text { skull_size }+ \text { suction }+ \\
\text { durophagous }+ \text { plant }+ \text { neck_retraction }\end{array}$ & 5 & 0.69 & -15877.7 & 585.9 & & & & & & & \\
\hline skull_size & & & & & 1 & 0.0010 & 0.0010 & 0.0470 & 3.9046 & 4.2443 & 0.0010 \\
\hline suction & & & & & 1 & 0.0009 & 0.0009 & 0.0416 & 3.4529 & 3.7467 & 0.0020 \\
\hline durophagous & & & & & 1 & 0.0010 & 0.0010 & 0.0477 & 3.9641 & 4.1436 & 0.0010 \\
\hline plant & & & & & 1 & 0.0005 & 0.0005 & 0.0237 & 1.9706 & 2.3532 & 0.0100 \\
\hline neck_retraction & & & & & 1 & 0.0010 & 0.0010 & 0.0495 & 4.1115 & 4.2769 & 0.0010 \\
\hline Residuals & & & & & 64 & 0.0159 & 0.0002 & 0.7702 & & & \\
\hline Total & & & & & 69 & 0.0207 & & & & & \\
\hline shape $\sim$ neck_retraction & 6 & 0.85 & -15452.2 & 1011.4 & & & & & & & \\
\hline neck_retraction & & & & & 1 & 0.0013 & 0.0013 & 0.0609 & 4.4112 & 4.3008 & 0.0010 \\
\hline Residuals & & & & & 68 & 0.0194 & 0.0003 & 0.9391 & & & \\
\hline Total & & & & & 69 & 0.0207 & & & & & \\
\hline shape $\sim$ skull_size & 7 & 0.85 & -15443.1 & 1020.4 & & & & & & & \\
\hline skull_size & & & & & 1 & 0.0012 & 0.0012 & 0.0560 & 4.0372 & 4.2906 & 0.0010 \\
\hline Residuals & & & & & 68 & 0.0195 & 0.0003 & 0.9440 & & & \\
\hline
\end{tabular}




\begin{tabular}{|c|c|c|c|c|c|c|c|c|c|c|c|}
\hline Total & & & & & 69 & 0.0207 & & & & & \\
\hline shape $\sim$ plant & 8 & 0.85 & -15417.4 & 1046.2 & & & & & & & \\
\hline plant & & & & & 1 & 0.0006 & 0.0006 & 0.0295 & 2.0681 & 2.3287 & 0.0090 \\
\hline Residuals & & & & & 68 & 0.0201 & 0.0003 & 0.9705 & & & \\
\hline Total & & & & & 69 & 0.0207 & & & & & \\
\hline shape $\sim$ skull_size + plant & 9 & 0.84 & -15409.3 & 1054.3 & & & & & & & \\
\hline skull_size & & & & & 1 & 0.0012 & 0.0012 & 0.0581 & 4.2686 & 4.4287 & 0.0010 \\
\hline plant & & & & & 1 & 0.0007 & 0.0007 & 0.0316 & 2.3205 & 2.6469 & 0.0030 \\
\hline Residuals & & & & & 67 & 0.0189 & 0.0003 & 0.9124 & & & \\
\hline Total & & & & & 69 & 0.0207 & & & & & \\
\hline shape $\sim$ feeds_on_water & 10 & 0.87 & -15409.1 & 1054.5 & & & & & & & \\
\hline feeds_on_water & & & & & 1 & 0.0005 & 0.0005 & 0.0248 & 1.7264 & 1.5364 & 0.0670 \\
\hline Residuals & & & & & 68 & 0.0202 & 0.0003 & 0.9752 & & & \\
\hline Total & & & & & 69 & 0.0207 & & & & & \\
\hline shape $\sim$ suction & 11 & 0.75 & -15402.4 & 1061.2 & & & & & & & \\
\hline suction & & & & & 1 & 0.0010 & 0.0010 & 0.0498 & 3.5619 & 3.7481 & 0.0010 \\
\hline Residuals & & & & & 68 & 0.0196 & 0.0003 & 0.9502 & & & \\
\hline Total & & & & & 69 & 0.0207 & & & & & \\
\hline shape $\sim$ skull_size + suction & 12 & 0.76 & -15396.6 & 1067.0 & & & & & & & \\
\hline skull_size & & & & & 1 & 0.0012 & 0.0012 & 0.0564 & 4.2281 & 4.3879 & 0.0010 \\
\hline suction & & & & & 1 & 0.0010 & 0.0010 & 0.0501 & 3.7580 & 3.8736 & 0.0010 \\
\hline Residuals & & & & & 67 & 0.0185 & 0.0003 & 0.8938 & & & \\
\hline Total & & & & & 69 & 0.0207 & & & & & \\
\hline shape $\sim$ skull_size + durophagous & 13 & 0.84 & -15390 & 1073.6 & & & & & & & \\
\hline skull_size & & & & & 1 & 0.0011 & 0.0011 & 0.0556 & 4.1580 & 4.5357 & 0.0010 \\
\hline durophagous & & & & & 1 & 0.0010 & 0.0010 & 0.0485 & 3.6303 & 3.7885 & 0.0010 \\
\hline Residuals & & & & & 67 & 0.0185 & 0.0003 & 0.8954 & & & \\
\hline Total & & & & & 69 & 0.0207 & & & & & \\
\hline shape $\sim$ meat & 14 & 0.85 & -15383.9 & 1079.7 & & & & & & & \\
\hline meat & & & & & 1 & 0.0005 & 0.0005 & 0.0245 & 1.7086 & 1.8337 & 0.0350 \\
\hline Residuals & & & & & 68 & 0.0202 & 0.0003 & 0.9755 & & & \\
\hline Total & & & & & 69 & 0.0207 & & & & & \\
\hline shape $\sim$ feeds_on_land & 15 & 0.87 & -15381.2 & 1082.4 & & & & & & & \\
\hline feeds_on_land & & & & & 1 & 0.0003 & 0.0003 & 0.0166 & 1.1482 & 0.6114 & 0.2690 \\
\hline Residuals & & & & & 68 & 0.0203 & 0.0003 & 0.9834 & & & \\
\hline Total & & & & & 69 & 0.0207 & & & & & \\
\hline shape $\sim$ skull_size + meat & 16 & 0.85 & -15379.7 & 1083.9 & & & & & & & \\
\hline skull_size & & & & & 1 & 0.0012 & 0.0012 & 0.0560 & 4.0836 & 4.4010 & 0.0010 \\
\hline meat & & & & & 1 & 0.0005 & 0.0005 & 0.0245 & 1.7857 & 1.9909 & 0.0260 \\
\hline Residuals & & & & & 67 & 0.0190 & 0.0003 & 0.9195 & & & \\
\hline Total & & & & & 69 & 0.0207 & & & & & \\
\hline shape $\sim$ skull_size + marine & 17 & 0.86 & -15378.2 & 1085.4 & & & & & & & \\
\hline skull_size & & & & & 1 & 0.0011 & 0.0011 & 0.0540 & 3.9468 & 4.2859 & 0.0010 \\
\hline marine & & & & & 1 & 0.0006 & 0.0006 & 0.0277 & 2.0291 & 2.1594 & 0.0180 \\
\hline Residuals & & & & & 67 & 0.0189 & 0.0003 & 0.9162 & & & \\
\hline Total & & & & & 69 & 0.0207 & & & & & \\
\hline shape $\sim$ skull_size + suction + meat & 18 & 0.77 & -15339.2 & 1124.4 & & & & & & & \\
\hline skull_size & & & & & 1 & 0.0012 & 0.0012 & 0.0565 & 4.2824 & 4.4906 & 0.0010 \\
\hline
\end{tabular}


suction

meat

Residuals

Total

shape $\sim$ skull size + feeds on water + suction + durophagous $+\overline{\text { plant }}+$ marine

+ neck retraction

skull_size

feeds_on_water

suction

durophagous

plant

marine

neck_retraction

Residuals

Total

shape $\sim$ skull_size + feeds_on_water + suction + durophagous + plant + meat + neck_retraction

skull_size

feeds_on_water

suction

durophagous

plant

meat

neck_retraction

Residuals

Total

shape $\sim$ skull_size + feeds_on_land + suction + durophagous + plant + marine + neck retraction

skull_size

feeds_on_land

suction

durophagous

plant

marine

neck retraction

Residuals

Total

shape $\sim$ skull size + feeds on water +

feeds_on_land + suction + durophagous + plant + marine + neck_retraction

skull_size

feeds_on_water

feeds_on_land

suction

durophagous

plant

marine

neck_retraction $\begin{array}{lllllll}1 & 0.0010 & 0.0010 & 0.0486 & 3.6805 & 3.7887 & 0.0010\end{array}$

$\begin{array}{llllllll}1 & 0.0005 & 0.0005 & 0.0229 & 1.7383 & 1.8967 & 0.0300\end{array}$

$\begin{array}{llll}66 & 0.0180 & 0.0003 & 0.8709\end{array}$

$\begin{array}{ll}69 & 0.0207\end{array}$

$19 \quad 0.75 \quad-15247.1 \quad 1216.6$

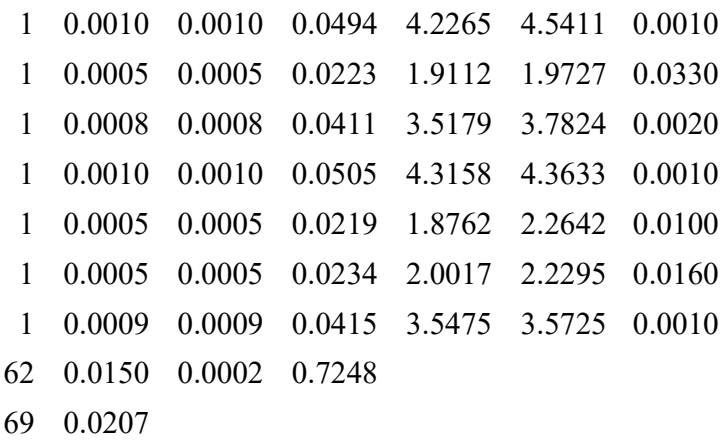

$\begin{array}{lll}0.77 & -15233.7 & 1229.9\end{array}$

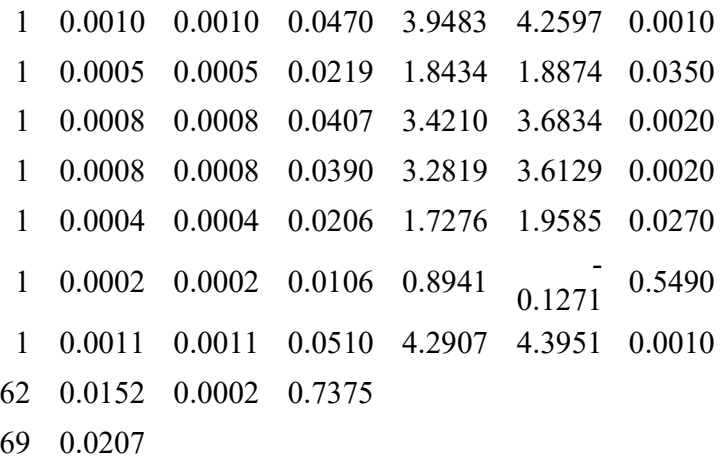

$\begin{array}{llll}21 & 0.74 & -15226.7 & 1236.9\end{array}$

$\begin{array}{lllllll}1 & 0.0010 & 0.0010 & 0.0494 & 4.1972 & 4.4748 & 0.0010\end{array}$

$\begin{array}{lllllll}1 & 0.0004 & 0.0004 & 0.0174 & 1.4764 & 1.4543 & 0.0780\end{array}$

$\begin{array}{lllllll}1 & 0.0009 & 0.0009 & 0.0416 & 3.5324 & 3.8189 & 0.0020\end{array}$

$\begin{array}{lllllll}1 & 0.0010 & 0.0010 & 0.0496 & 4.2173 & 4.3093 & 0.0010\end{array}$

$\begin{array}{lllllll}1 & 0.0005 & 0.0005 & 0.0242 & 2.0603 & 2.5296 & 0.0060\end{array}$

$\begin{array}{lllllll}1 & 0.0005 & 0.0005 & 0.0231 & 1.9648 & 2.1954 & 0.0200\end{array}$

$\begin{array}{llllllll}1 & 0.0009 & 0.0009 & 0.0413 & 3.5096 & 3.5465 & 0.0010\end{array}$

$\begin{array}{lllll}62 & 0.0151 & 0.0002 & 0.7297\end{array}$

$\begin{array}{ll}69 & 0.0207\end{array}$

$22 \quad 0.76 \quad-15166.9 \quad 1296.7$

$\begin{array}{rrrrrrr}1 & 0.0010 & 0.0010 & 0.0495 & 4.2138 & 4.4750 & 0.0010 \\ 1 & 0.0003 & 0.0003 & 0.0137 & 1.1707 & 0.6632 & 0.2440 \\ 1 & 0.0002 & 0.0002 & 0.0088 & 0.7477 & 0.7122 & 0.7580 \\ 1 & 0.0009 & 0.0009 & 0.0424 & 3.6151 & 3.8624 & 0.0020 \\ 1 & 0.0010 & 0.0010 & 0.0496 & 4.2241 & 4.3029 & 0.0010 \\ 1 & 0.0004 & 0.0004 & 0.0213 & 1.8108 & 2.1179 & 0.0140 \\ 1 & 0.0005 & 0.0005 & 0.0233 & 1.9838 & 2.1919 & 0.0180 \\ 1 & 0.0009 & 0.0009 & 0.0413 & 3.5154 & 3.5253 & 0.0010\end{array}$


Residuals

Total

shape $\sim$ skull_size + neck_retraction

skull_size

neck retraction

Residuals

Total

shape $\sim$ skull_size + feeds_on_water

skull_size

feeds_on_water

Residuals

Total

shape $\sim$ skull_size + suction +

neck_retraction

skull_size

suction

neck retraction

Residuals

Total

shape $\sim$ marine

marine

Residuals

Total

shape $\sim$ skull_size + feeds_on_land

skull_size

feeds_on_land

Residuals

Total

shape $\sim$ skull size + feeds on water + suction

skull_size

feeds_on_water

suction

Residuals

Total $\begin{array}{llll}61 & 0.0148 & 0.0002 & 0.7160\end{array}$

$\begin{array}{ll}69 & 0.0207\end{array}$

$23 \quad 0.85 \quad-14901.6 \quad 1561.9$

$\begin{array}{lllllll}1 & 0.0010 & 0.0010 & 0.0483 & 3.6301 & 3.8850 & 0.0010\end{array}$

$\begin{array}{lllllll}1 & 0.0011 & 0.0011 & 0.0531 & 3.9968 & 4.0573 & 0.0010\end{array}$

$\begin{array}{llll}67 & 0.0184 & 0.0003 & 0.8908\end{array}$

$69 \quad 0.0207$

$24 \quad 0.86 \quad-14867.2 \quad 1596.4$

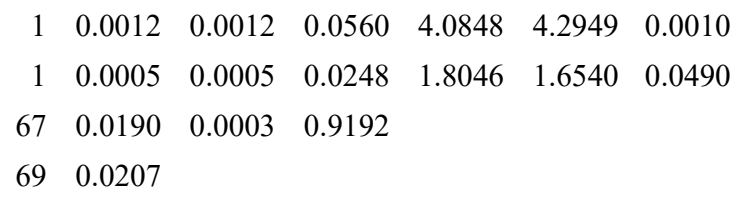

$\begin{array}{llll}25 & 0.72 & -14859.7 & 1603.9\end{array}$

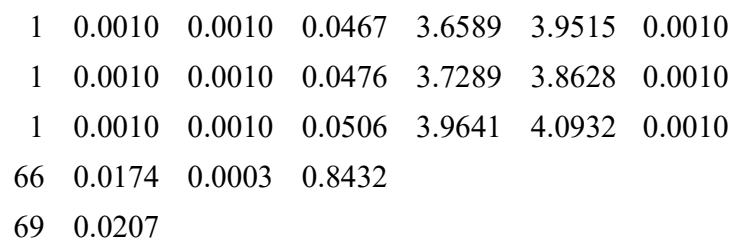

$\begin{array}{llll}26 & 0.86 & -14851.3 & 1612.3\end{array}$

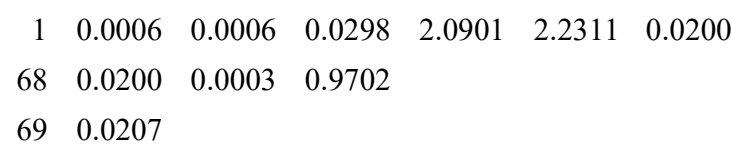

$\begin{array}{llll}27 & 0.87 & -14841.5 & 1622.1\end{array}$

$\begin{array}{lllllll}1 & 0.0012 & 0.0012 & 0.0564 & 4.0797 & 4.2921 & 0.0010\end{array}$

$\begin{array}{llllllll}1 & 0.0004 & 0.0004 & 0.0170 & 1.2290 & 0.8116 & 0.2170\end{array}$

$\begin{array}{llll}67 & 0.0192 & 0.0003 & 0.9270\end{array}$

$69 \quad 0.0207$

$\begin{array}{llll}28 & 0.78 & -14817.9 & 1645.6\end{array}$

$\begin{array}{lllllll}1 & 0.0012 & 0.0012 & 0.0564 & 4.2784 & 4.4028 & 0.0010\end{array}$

$\begin{array}{llllllll}1 & 0.0005 & 0.0005 & 0.0238 & 1.8067 & 1.7527 & 0.0480\end{array}$

$\begin{array}{llllllll}1 & 0.0010 & 0.0010 & 0.0492 & 3.7318 & 3.8111 & 0.0010\end{array}$

$\begin{array}{llll}66 & 0.0180 & 0.0003 & 0.8700\end{array}$

$\begin{array}{ll}69 & 0.0207\end{array}$ 


\section{Results for the 'partial dataset'}

\begin{tabular}{|c|c|c|c|c|c|c|c|c|c|c|c|}
\hline \multirow[b]{2}{*}{ Model } & \multirow[b]{2}{*}{ Rank } & \multirow[b]{2}{*}{$\lambda$} & \multirow[b]{2}{*}{ AIC } & \multirow[b]{2}{*}{$\Delta \mathrm{AIC}$} & \multicolumn{7}{|c|}{ ANOVA } \\
\hline & & & & & Df & SS & MS & $\mathbf{R}^{2}$ & $\mathbf{F}$ & $\mathbf{Z}$ & $\begin{array}{c}P \text { - } \\
\text { value }\end{array}$ \\
\hline $\begin{array}{l}\text { shape } \sim \text { skull_size }+ \text { suction }+ \\
\text { durophagous }+ \text { plant }+ \text { marine }+ \\
\text { neck_retraction }\end{array}$ & 1 & 0.38 & -9825.5 & 0 & & & & & & & \\
\hline skull_size & & & & & 1 & 0.0010 & 0.0010 & 0.0457 & 4.1261 & 3.6680 & 0.0010 \\
\hline suction & & & & & 1 & 0.0009 & 0.0009 & 0.0420 & 3.7946 & 3.4637 & 0.0010 \\
\hline durophagous & & & & & 1 & 0.0011 & 0.0011 & 0.0517 & 4.6667 & 4.0318 & 0.0010 \\
\hline plant & & & & & 1 & 0.0007 & 0.0007 & 0.0339 & 3.0582 & 3.0421 & 0.0010 \\
\hline marine & & & & & 1 & 0.0005 & 0.0005 & 0.0241 & 2.1753 & 2.1500 & 0.0140 \\
\hline neck_retraction & & & & & 1 & 0.0008 & 0.0008 & 0.0365 & 3.2948 & 2.8309 & 0.0020 \\
\hline Residuals & & & & & 69 & 0.0163 & 0.0002 & 0.7646 & & & \\
\hline Total & & & & & 75 & 0.0214 & & & & & \\
\hline $\begin{array}{l}\text { shape } \sim \text { skull_size }+ \text { suction }+ \\
\text { durophagous }+ \text { plant }\end{array}$ & 2 & 0.35 & -9399.4 & 426.1 & & & & & & & \\
\hline skull_size & & & & & 1 & 0.0009 & 0.0009 & 0.0408 & 3.5191 & 3.3747 & 0.0010 \\
\hline suction & & & & & 1 & 0.0010 & 0.0010 & 0.0452 & 3.8958 & 3.4594 & 0.0010 \\
\hline durophagous & & & & & 1 & 0.0010 & 0.0010 & 0.0478 & 4.1240 & 3.6794 & 0.0010 \\
\hline plant & & & & & 1 & 0.0007 & 0.0007 & 0.0349 & 3.0063 & 2.9664 & 0.0010 \\
\hline Residuals & & & & & 71 & 0.0176 & 0.0002 & 0.8234 & & & \\
\hline Total & & & & & 75 & 0.0214 & & & & & \\
\hline $\begin{array}{l}\text { shape } \sim \text { skull_size }+ \text { suction }+ \\
\text { durophagous }+ \text { plant }+ \text { marine }\end{array}$ & 3 & 0.35 & -9300.6 & 524.9 & & & & & & & \\
\hline skull_size & & & & & 1 & 0.0010 & 0.0010 & 0.0487 & 4.2567 & 3.8258 & 0.0010 \\
\hline suction & & & & & 1 & 0.0010 & 0.0010 & 0.0456 & 3.9814 & 3.5215 & 0.0010 \\
\hline durophagous & & & & & 1 & 0.0011 & 0.0011 & 0.0497 & 4.3397 & 3.8359 & 0.0010 \\
\hline plant & & & & & 1 & 0.0008 & 0.0008 & 0.0359 & 3.1338 & 3.0856 & 0.0010 \\
\hline marine & & & & & 1 & 0.0005 & 0.0005 & 0.0223 & 1.9501 & 1.9611 & 0.0240 \\
\hline Residuals & & & & & 70 & 0.0171 & 0.0002 & 0.8011 & & & \\
\hline Total & & & & & 75 & 0.0214 & & & & & \\
\hline $\begin{array}{l}\text { shape } \sim \text { skull_size }+ \text { feeds_on_water }+ \\
\text { suction }+ \text { durophagous }+ \text { plant }+ \text { marine } \\
+ \text { neck_retraction }\end{array}$ & 4 & 0.40 & -9149.2 & 676.4 & & & & & & & \\
\hline skull_size & & & & & 1 & 0.0010 & 0.0010 & 0.0460 & 4.2018 & 3.7241 & 0.0010 \\
\hline feeds_on_water & & & & & 1 & 0.0004 & 0.0004 & 0.0195 & 1.7822 & 1.5009 & 0.0690 \\
\hline suction & & & & & 1 & 0.0009 & 0.0009 & 0.0415 & 3.7922 & 3.4778 & 0.0010 \\
\hline durophagous & & & & & 1 & 0.0011 & 0.0011 & 0.0515 & 4.7007 & 4.0300 & 0.0010 \\
\hline plant & & & & & 1 & 0.0007 & 0.0007 & 0.0314 & 2.8675 & 2.9103 & 0.0010 \\
\hline marine & & & & & 1 & 0.0005 & 0.0005 & 0.0246 & 2.2490 & 2.2218 & 0.0110 \\
\hline neck_retraction & & & & & 1 & 0.0008 & 0.0008 & 0.0363 & 3.3100 & 2.8171 & 0.0030 \\
\hline Residuals & & & & & 68 & 0.0159 & 0.0002 & 0.7450 & & & \\
\hline Total & & & & & 75 & 0.0214 & & & & & \\
\hline shape $\sim$ durophagous & 5 & 0.38 & -9012.5 & 813.1 & & & & & & & \\
\hline durophagous & & & & & 1 & 0.0010 & 0.0010 & 0.0463 & 3.5952 & 3.3313 & 0.0010 \\
\hline Residuals & & & & & 74 & 0.0204 & 0.0003 & 0.9537 & & & \\
\hline Total & & & & & 75 & 0.0214 & & & & & \\
\hline
\end{tabular}



shape $\sim$ skull_size + suction +
durophagous + plant + meat + neck_retraction

skull_size
suction
durophagous
plant
meat
neck_retraction
Residuals
Total

shape $\sim$ skull size

skull_size

Residuals

Total

\section{shape $\sim$ neck_retraction}

neck_retraction

Residuals

Total

shape $\sim$ suction

suction

Residuals

Total

shape $\sim$ feeds_on_land

feeds on land

Residuals

Total

shape $\sim$ meat

meat

Residuals

Total

shape $\sim$ marine

marine

Residuals

Total

shape $\sim$ skull_size + durophagous

skull_size

durophagous

Residuals

Total

shape $\sim$ skull_size + neck_retraction

skull_size

neck retraction

Residuals

Total

shape $\sim$ skull_size + suction

skull_size

suction

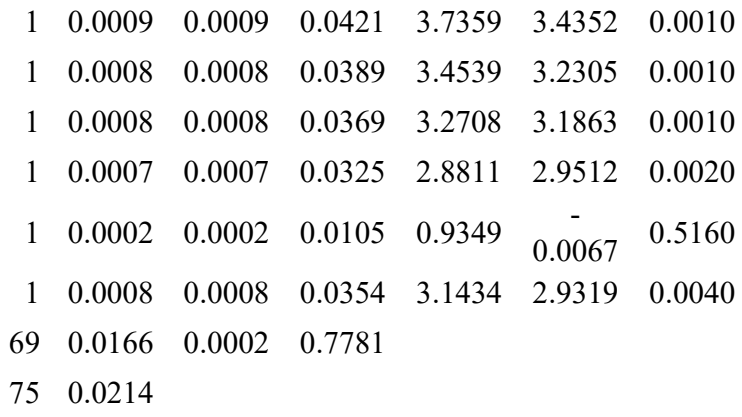

$\begin{array}{lll}0.33 & -8458.3 & 1367.3\end{array}$

$\begin{array}{lllllll}1 & 0.0008 & 0.0008 & 0.0372 & 2.8556 & 2.7545 & 0.0040\end{array}$

$\begin{array}{llll}74 & 0.0206 & 0.0003 & 0.9628\end{array}$

$75 \quad 0.0214$

$\begin{array}{llll}8 & 0.42 & -8435.4 & 1390.1\end{array}$

$\begin{array}{lllllll}1 & 0.0007 & 0.0007 & 0.0346 & 2.6556 & 2.2565 & 0.0100\end{array}$

$\begin{array}{llll}74 & 0.0206 & 0.0003 & 0.9654\end{array}$

$75 \quad 0.0214$

$\begin{array}{llll}0.37 & -8426.9 & 1398.6\end{array}$

$\begin{array}{lllllll}1 & 0.0011 & 0.0011 & 0.0526 & 4.1063 & 3.4964 & 0.0010\end{array}$

$\begin{array}{llll}74 & 0.0203 & 0.0003 & 0.9474\end{array}$

$75 \quad 0.0214$

$\begin{array}{llll}10 & 0.44 & -8410.3 & 1415.2\end{array}$

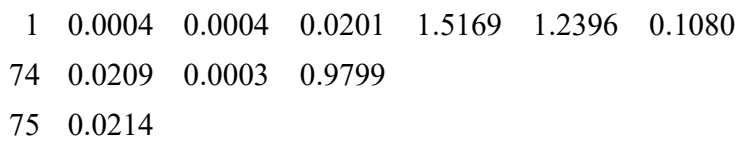

$\begin{array}{llll}11 & 0.42 & -8406.4 & 1419.2\end{array}$

$\begin{array}{lllllll}1 & 0.0006 & 0.0006 & 0.0282 & 2.1445 & 1.9881 & 0.0250\end{array}$

$\begin{array}{llll}74 & 0.0208 & 0.0003 & 0.9718\end{array}$

$75 \quad 0.0214$

$\begin{array}{llll}12 & 0.34 & -8396.0 & 1429.5\end{array}$

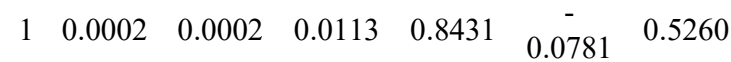

$\begin{array}{llll}74 & 0.0211 & 0.0003 & 0.9887\end{array}$

$75 \quad 0.0214$

$\begin{array}{llll}13 & 0.36 & -8387.9 & 1437.6\end{array}$

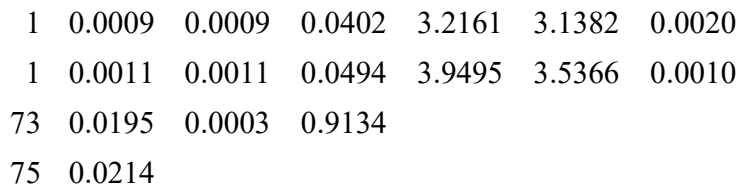

$14 \quad 0.44 \quad-8380.3 \quad 1445.3$

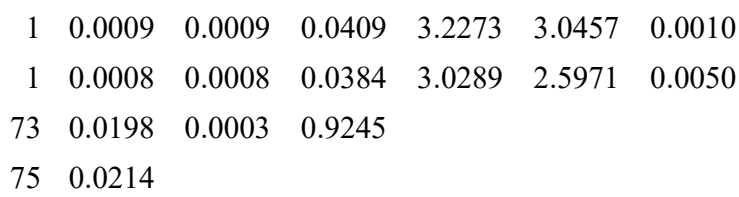

$15 \quad 0.34 \quad-8374.4 \quad 1451.1$

$\begin{array}{lllllll}1 & 0.0009 & 0.0009 & 0.0403 & 3.2397 & 3.0889 & 0.0020\end{array}$

$\begin{array}{lllllll}1 & 0.0012 & 0.0012 & 0.0557 & 4.4804 & 3.7467 & 0.0010\end{array}$ 
Residuals

Total

shape $\sim$ skull_size + feeds_on_land
skull_size
feeds_on_land
Residuals
Total

shape $\sim$ skull_size + meat

skull_size

meat

Residuals

Total

shape $\sim$ skull_size + marine

skull_size

marine

Residuals

Total

shape $\sim$ skull_size + marine + neck_retraction

skull_size

marine

neck_retraction

Residuals

Total

shape $\sim$ plant

plant

Residuals

Total

shape $\sim$ feeds_on_water

feeds_on_water

Residuals

Total

shape $\sim$ skull_size + plant

skull_size

plant

Residuals

Total

shape $\sim$ skull_size + feeds_on_water

skull_size

feeds_on_water

Residuals

Total

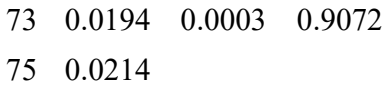

16

$\begin{array}{lll}0.42 & -8361.1 & 1464.4\end{array}$

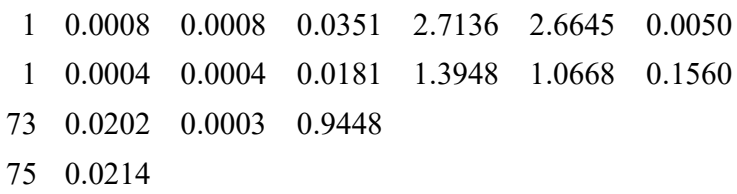

$\begin{array}{llll}17 & 0.42 & -8350.6 & 1474.9\end{array}$

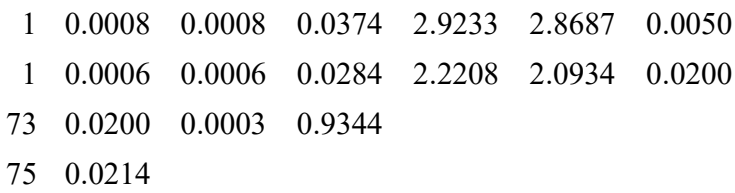

$\begin{array}{llll}18 & 0.33 & -8345.7 & 1479.9\end{array}$

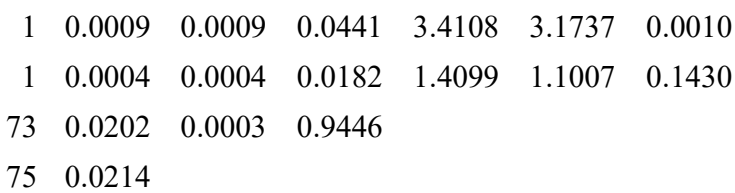

$\begin{array}{llll}19 & 0.34 & -8270.3 & 1555.3\end{array}$

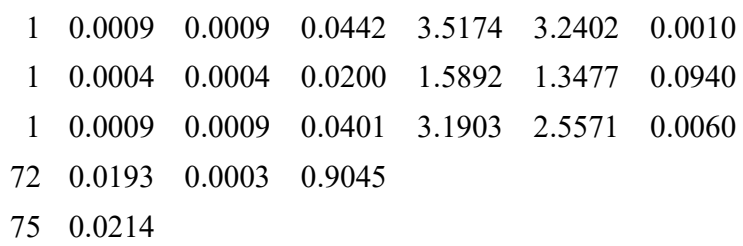

$23 \quad 0.36 \quad-7793.5 \quad 2032.1$

$\begin{array}{rrrrrrr}1 & 0.0008 & 0.0008 & 0.0373 & 2.8978 & 2.8288 & 0.0040 \\ 1 & 0.0005 & 0.0005 & 0.0235 & 1.8246 & 1.5113 & 0.0680 \\ 73 & 0.0201 & 0.0003 & 0.9394 & & & \\ 75 & 0.0214 & & & & & \end{array}$




\section{Appendix 7}

\section{Customised R functions}

Below are three customised $\mathrm{R}$ functions that I used to retrieve the regression scores (see Main Text) of my D-PGLS analyses. The functions require geomorph and RRPP packages to be loaded in the environment before their use.

is.procD Test fitted model object class

\section{Description}

Check if an object is an instance of the 'procD.lm' or 'lm.rrpp' class.

\section{Usage}

is.procD ( $\mathrm{X})$

\section{Arguments}

$$
\mathrm{x} \quad \text { an object }
$$

\section{Details}

This is an internal function created for the use of the two subsequent functions. It is simply used to confirm the object I am extracting the scores from corresponds to a D-PGLSfitted object. These sorts of objects are created by geomorph and RRPP packages (Adams et al. 2020; Collyer \& Adams 2018; 2020).

\section{Value}

TRUE or FALSE.

\section{Example}

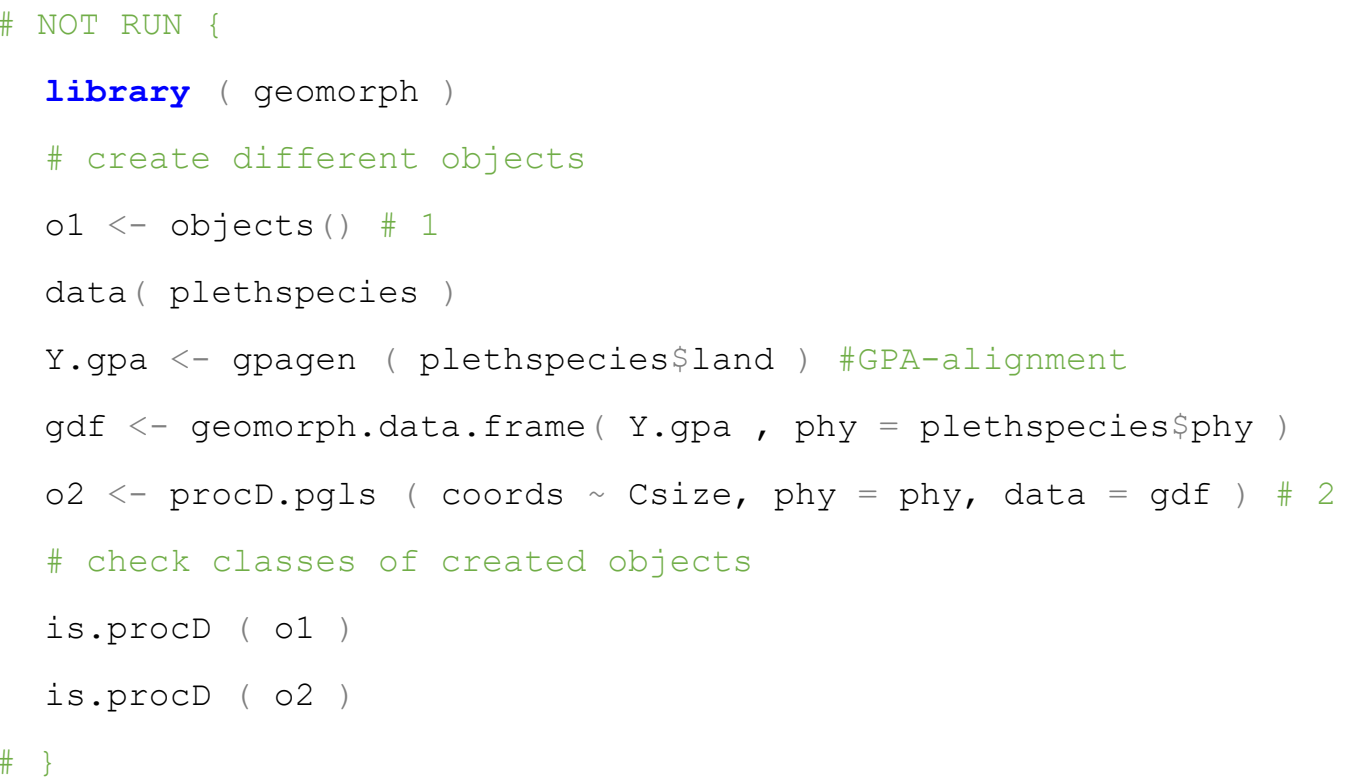




\section{Source code of function}

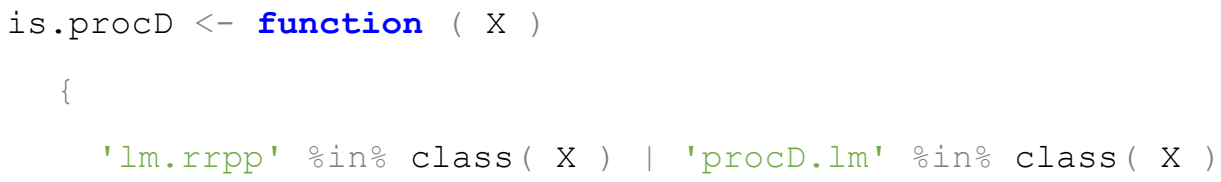

\section{Description}

Function used to extract the regression scores from a D-PGLS-fitted model.

\section{Usage}

procD.scores ( model)

\section{Arguments}

model

a model object fitted using procD.lm or lm.rrpp. Note that procD.pgls-fitted models are just a modification of procD. $1 \mathrm{~m}$.

\section{Details}

This function was used to extract the regression scores (as defined in Drake \& Klingenberg 2008) from a D-PGLS-fitted model. This is a wrapper function of

RRPP::plot.lm.rrpp ( model, type = 'regression', reg.type = 'RegScore')

from RRPP package (Collyer \& Adams 2018; 2020). However, it does not allow the user to store such regression scores, and hence not allowing the calculation of such scores for specimens not included in the model in the first place. This is the main difference to ours. I chose to retain these values for subsequent result interpretations (see Main Text).

\section{Value}

A list containing the following:

model

scores the D-PGLS model input to retrieve the regression scores.

an $n \times B$ matrix, in which $n$ is the number of rows corresponding to the specimens/taxa in the dataset; and $B$ is the number of columns corresponding to the names of the predictors in the model, for which the scores were calculated separately. 


\section{Example}

\# NOT RUN \{

\# This is an example adapted from geomorph package manual

\# load geomorph

library ( geomorph )

data( plethspecies )

Y.gpa <- gpagen ( plethspecies\$land ) \#GPA-alignment

gdf <- geomorph.data.frame ( Y.gpa , phy = plethspecies\$phy )

\# Model-fitting

pleth.pgls <- procD.pgls ( coords Csize, phy = phy, data = gdf, iter $=999$ )

\# get regression scores from fitted model

procD.scores ( pleth.pgls )

\# $\}$

\section{Source code of function}

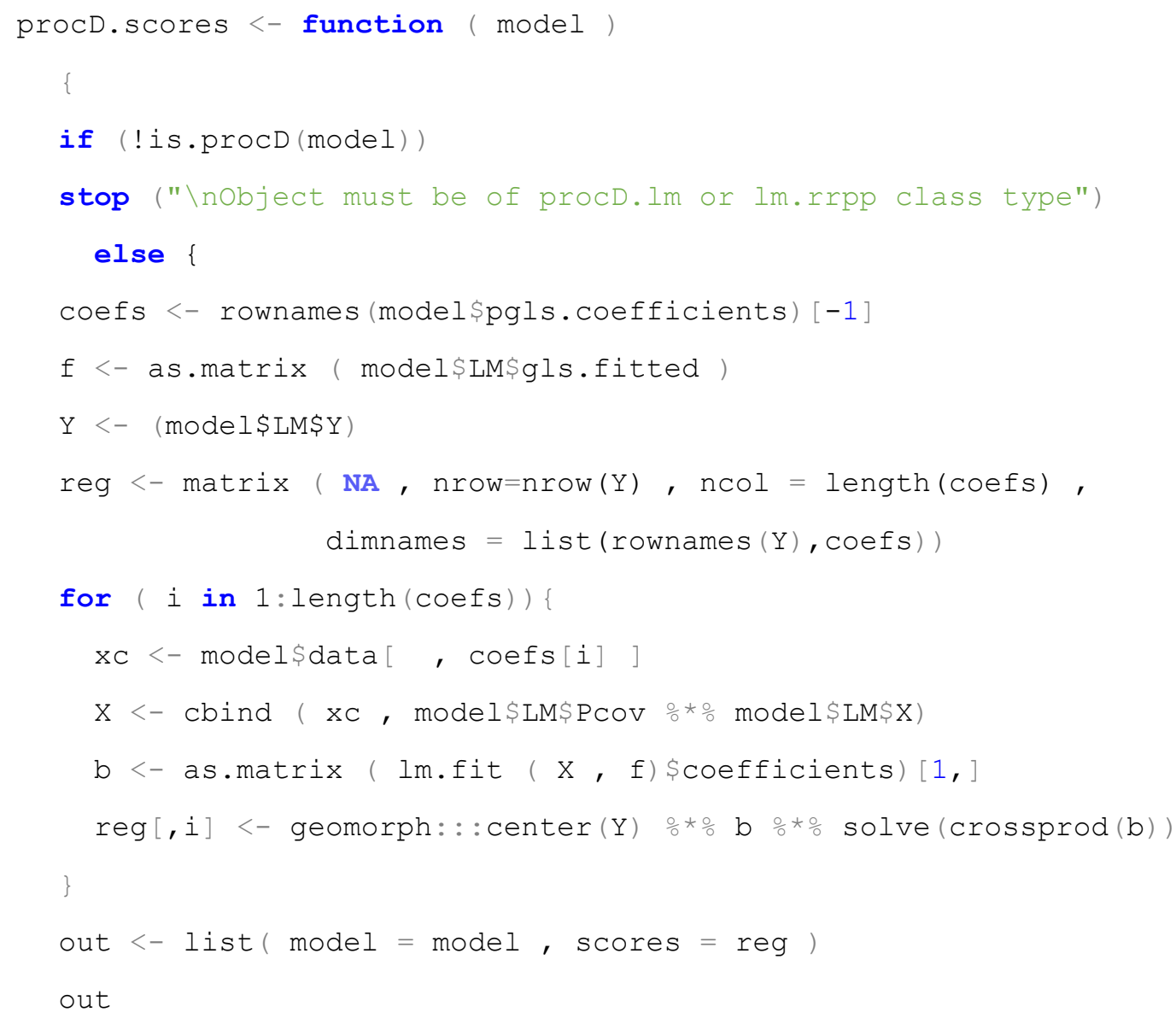




\section{Description}

Function used to calculate regression scores of a D-PGLS-fiited model for a given set of specimens/taxa not present in the model.

\section{Usage}

predict.procD.scores ( model, newdata )

\section{Arguments}

model

newdata a model object fitted using procD. $1 \mathrm{~m}$ or $1 \mathrm{~m} . \mathrm{rrpp}$. Note that procD.pgls-fitted models are just a modification of procD. $1 \mathrm{~m}$.

either a 3D array of $p \times k \times n$ dimensions in which $p$ is the number of landmarks, $k$ is the number of dimensions and $n$ the number of specimens/taxa in the sample; or a 2D array of the same dataset of dimensions $n \times p$, in which $n$ is the number of specimens/taxa, and $p$ is the number of landmarks multiplied by the dimensionality of the data $(2$, if $2 \mathrm{D}$ or 3 , if $3 \mathrm{D})$. This should contain the data for which the scores will be calculated. See 'Details'.

\section{Details}

This function calculates the same regression scores (as defined in Drake \& Klingenberg 2008; see previous procD.scores function) for those specimens not present in the original D-PGLS-fitted model, provided their coordinates are superimposed in the consensus shape of the original D-PGLS model. If a 3D array is provided, e.g. 3D coordinates aligned using geomorph : : gpagen, this function transforms it into a 2D array using geomorph: : two.d.array. So, there is no need to convert it in a previous step.

This was created to compute regression values for taxa of which there is not enough information to include in the model-fitting step. It applies, for instance, to fossil taxa, for which it is very difficult (if possible) to attribute an ecological category based on simple analogy to extant species. I imagine it could also be useful to get the scores for extant taxa that have little or no information about its natural history in present literature (e.g. cryptic or very endangered species).

\section{Value}

An $n \times B$ matrix, in which $n$ is the number of rows corresponding to the specimens/taxa for which the scores were calculated; and $B$ is the number of columns corresponding to the names of the predictors in the model, for which the scores were calculated separately. 


\section{Example}

\# NOT RUN \{

\# This is an example adapted from geomorph package manual

\# load geomorph

library ( geomorph )

data( plethspecies)

\# Reduce dataset to trim taxa for which scores will be predicted

plethspecies\$land_reduced $<-$ plethspecies\$land $\left[,,^{-c}(1,5,6)\right]$

\# also make sure your tree matches the new reduced landmark dataset

using ape: :keep.tip()

plethspecies\$phy reduced $<-$ ape: :keep.tip (plethspecies\$phy, tip = dimnames (plethspecies\$land_reduced) [ [3] ])

Y.gpa2 <- gpagen ( plethspecies\$land_reduced ) \#GPA-alignment

gdf2 <- geomorph.data.frame ( Y.gpa2 , phy = plethspecies\$phy_reduced )

\# Model-fitting

pleth.pgls2 <- procD.pgls ( coords $~$ Csize, phy = phy, data = gdf2, iter $=999$ )

\# get regression scores for the taxa you removed in previous steps

to_predict $<-$ plethspecies\$land $[$, , c $(1,5,6)]$

predict.procD.scores ( pleth.pgls, to_predict )

$\# \quad\}$

\section{Source code of function}

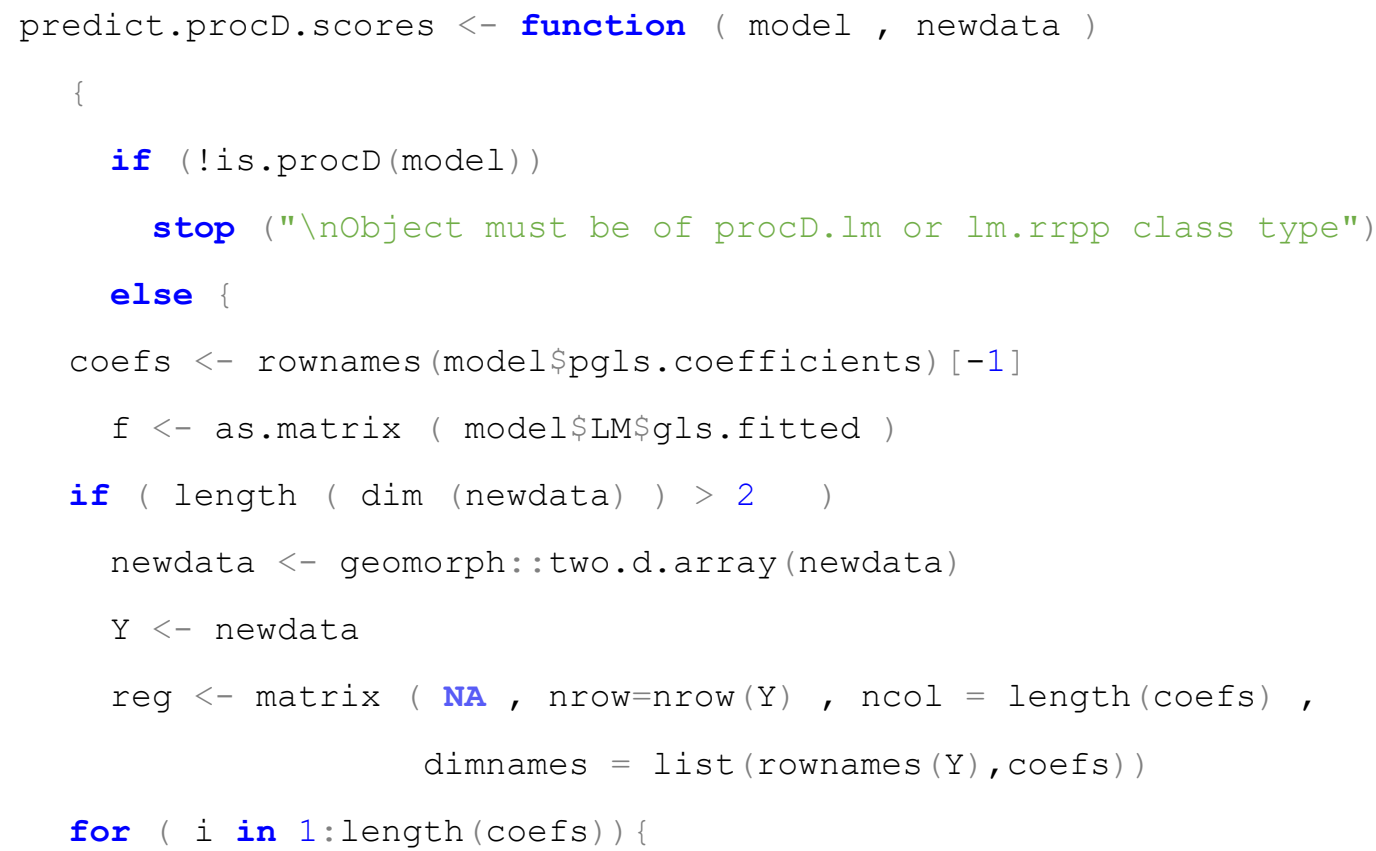




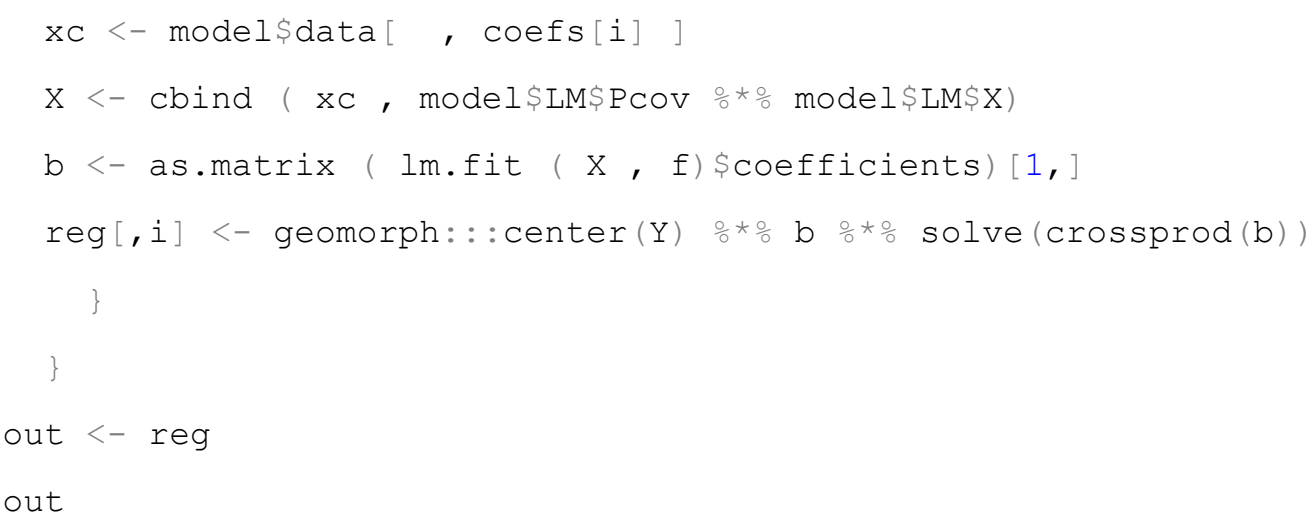

\section{References}

Adams, D.C., Collyer, M.L. \& Kaliontzopoulou, A. (2020) Geomorph: Software for geometric morphometric analyses. $\mathrm{R}$ package version 3.2.1. https://cran.rproject.org/package $=$ geomorph .

Collyer, M.L. \& Adams, D.C. (2018) RRPP: An R package for fitting linear models to highdimensional data using residual randomization. Methods in Ecology and Evolution, 9(2), 1772-1779.

Collyer, M.L. \& Adams, D.C. (2020) RRPP: Linear Model Evaluation with Randomized Residuals in a Permutation Procedure. https://CRAN.R-project.org/package=RRPP.

Drake, A.G., \& Klingenberg, C.P. (2008) The pace of morphological change: historical transformation of skull shape in St Bernard dogs. Proceedings of the Royal Society B: Biological Sciences, 275(1630), 71-76. 